
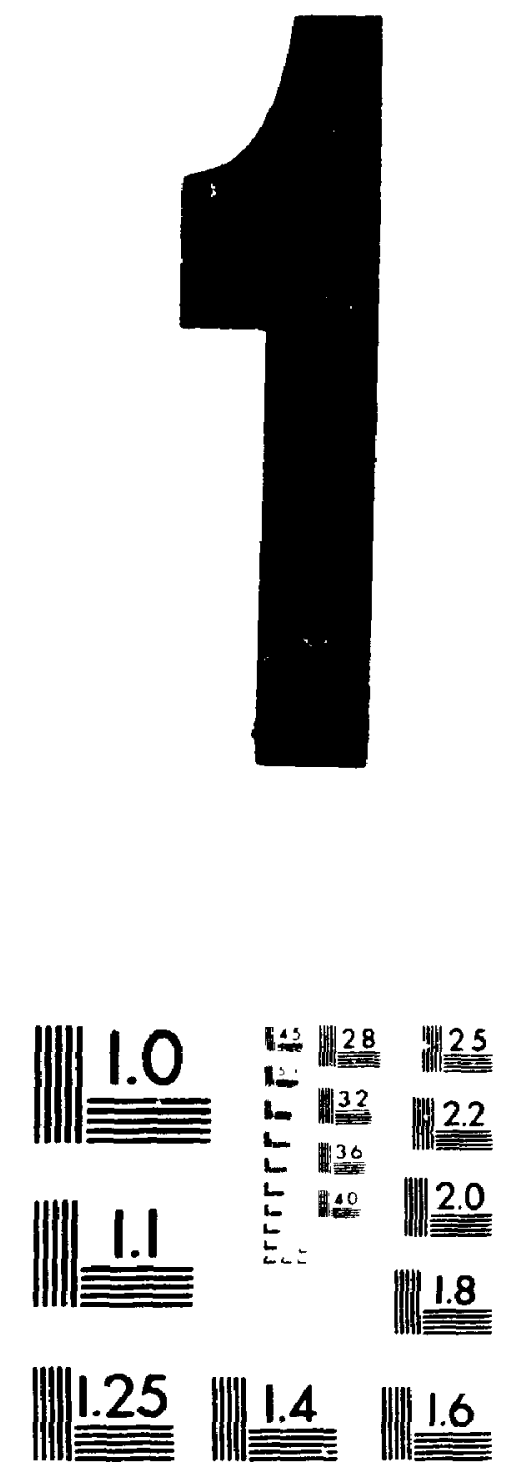

MICPOCOPY RESOIUTION TEST CHART NATIONAL BUIREAU OH STANLARDS

STANDARD REFERENCE MATERIAL 1U10d

IANSI and ISOT TEST CHART NO 2 
The quality of this microform is heavily deperident upon the quality of the original thesis submitted for microfilming. Every effort has been made to ensure the highest quality of reproduction possible.

If pages are missing, contact the university which granted the degree.

Some pages may have indistinct print especially if the original pages were typed with a poor typewriter ribbon or if the university sent us an inferior photocopy.

Reproduction in full or in part of this microform is governed by the Canadian Copyright Act, R.S.C. 1970, c. C-30, and subsequent amendments.
La qualité de cette microforme dépend grandement de la qualité de la thèse soumise au microfilmage. Nous avons tout fait pour assurer une qualité supérieure de reproduction.

S'il manque des pages, veuillez communiquer avec l'université qui a conféré le grade.

La qualité d'impression de certaines pages peut laisser à désirer, surtout si les pages originales ont été dactylographiées à l'aide d'un ruban usé ou si l'université nous a fait parvenir une photocop e de qualité inférizure.

La reproduction, même partielle, de cette microforme est soumise à la Loi canadienne sur le droit d'auteur, SRC 1970, c. C-30, et ses amendements subséquents. 


\title{
DESIGN OF A CRUMB RUBBER MODIFIED ASPHALT PAVEMENT USING THE STONE MASTIC ASPHALT CONCEPT
}

by

\section{Robert Veizer}

\author{
A thesis submitted to \\ the Faculty of Graduate Studies and Research \\ in partial fulfillment of the requirements \\ for the degree of \\ Master of Engineering*
}

\author{
Department of Civil and Environmental Engineering \\ Carleton University \\ Ottawa, Canada \\ - Robert Veizer, November, 1993
}

- The Master of Engineering in the Civil and Environmental Engineering Program is a joint program with the University of Ottawa, administered by the OttawaCarleton Institute for Civil Engineering. 
The author has granted an irrevocable non-exclusive licence sllowing the National Library of Canada to reproduce, loan, distribute or sell copies of his/her thesis by any means and iii any form or format, making this thesis available to interested persons.
L'auteur a accordé une licence irrévocable et non exclusive permettant à la Bibliothèque nationale du Canada de reproduire, prêter, distribuer ou vendre des copies de sa thèse de quelque manière et sous quelque forme que ce soit pour mettre des exemplaires de cette thèse à la disposition des personnes intéressées.
L'auteur conserve la propriété du droit d'auteur qui protège sa thèse. Ni la thèse ni des extraits substantiels de celle-ci ne doivent être imprimés ou autrement reproduits sans son autorisation.
The author retains ownership of the copyriglit in his/her thesis. Neither the thesis nor substantial extracts from it may be printed or otherwise reproduced without his/her permission. 


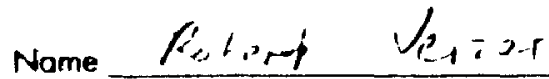

Dissertation $A^{\prime}$ stracts International is arranged by broad, general subject categories Please select the one subject which most nearly describes the content of your dissertation Enter the corresponding four-digit code in the spaces provided.

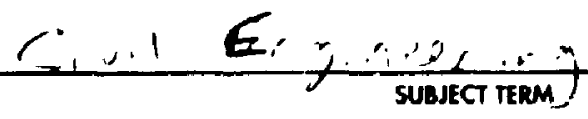

\section{Subjoct Categories}

\section{THE HUMANITIES AND SOCIAL SCIENCES}

\section{COMmumiratrons anD THE ARTS}

Archilechurn

Cinerngs

Durnet

Fine Arts

information Scrence

Journolism

Librury Srience

Mass Communicralions

Musie

Syeoch Communication

Thenter

\section{EDUCATION}

Administration

Adult and Continume

Agricultural

Bilingual and Multiculiur al

Businguas

Conimunity College

Curriculum and Instruction

Forly Chitdhood

Elemenicury

Guidonce and Counseling

Hoolits

Higher

History of

Home Economics

Industrici

lanyuoge and liter oturs.

Mathernatics

Music

Philosophy of

Physical
0729

0377

0378

0357

0723

0391

0399

0708

0413

0465

0515

0514

0516

0517

0282

0688

0275

0275
0727

0518

0524

.0277

0519

0680

0745

0520
0278

0278
0521

0219

0280

0522

0998
Psychology

Reoding

Sciences

Seccndary

Sociol Sciences

Sociology of

Special

Teacher Training

Technology

Tesis and Meosurements

Vocationol

\section{UMGUAGE, LTERATURE AND} LINGUISTICS

Language

Ceneral

Linguistics

Modern

Literciture

General

Comporative

Medieval

Modern

Atricon

American

Asion

Canodion (Engilsh)

$r$ modian (French)

iglish

Sermanic

Latin American

Middle Eastern

Romance

Slavic and East European

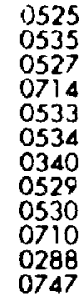

0525
0535

0527

Business Administration
533

053.4

340

529

0710

0288

\section{Americon Studies}

Americon Stud

Archoeology

Cultural

Generol

Accounting

Bonking

Manogisment

Morket ng

Canadion SHudies

Economics.

Teneral

Agricultural

Commerce-ôusiness

Finance

History

Labor

Theory

Geogrophy

Gerontology

History

Gerierai

0422

0318

0321
0319

0320

0322

0469

0323

0.324

0326

0310

0310
0272

0770

045

0338

0385

0501

0.503

0505

0508
0509

0510

0511

0358

0366

0351

0313
0314

0578

THE SCIENCES AND ENGINEERING

\section{mologkal saences}

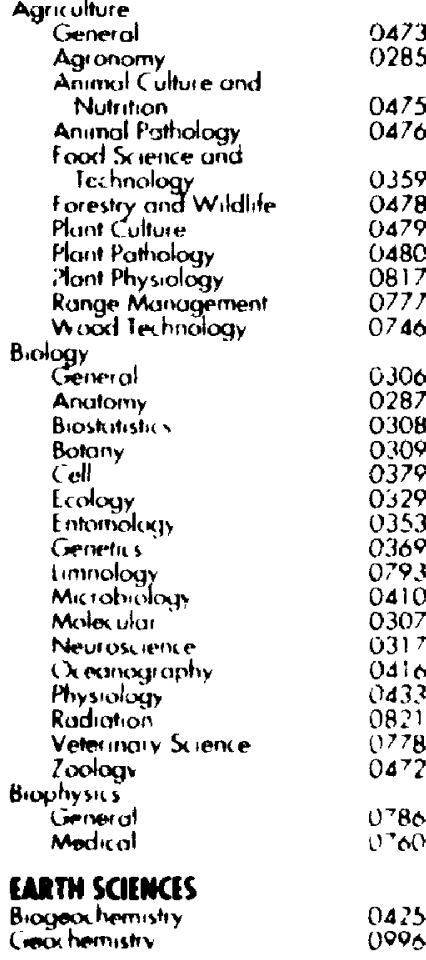

$\begin{array}{ll}\text { Geodesy } & 0370 \\ \text { Geology } & 0372 \\ \text { Geophysics } & 0373 \\ \text { Hydrology } & 0388 \\ \text { Minetalogy } & 0411 \\ \text { Paleobolony } & 0345 \\ \text { Poleoccology } & 0426 \\ \text { Poleontology } & 0418 \\ \text { Paleozoology } & 0985 \\ \text { Poiynology } & 0427 \\ \text { Thysical Geography } & 0368 \\ \text { Physical Oceonography } & 0415\end{array}$

\section{MEALTM AND ENVIRONWENTA}

\section{SCIENCES}

Environmental Sciences $\quad 0768$

Health Sciences

General

Audiology

Chemotherapy

Dentistry

Hospital Manogement

Human Development

Human Develo

Medicine and Surgery

Mental Heolth

Nuising

Otistetrics and Gynecology

Oxcupational Heoltit and

Therapy

Opheropy

Pothology

Pharmocology

Phormoor

Phystcal therapy

Pubils Heolith

Rodiotogy
Speech Pathology

Home Economics

\section{PHYSICAL SCIENCES}

Pure Sciences

Chemistry

Agriculfural

Analytical

Bucchemistry

Inorganic

Organic

Pharmaceutical

Physical

Polymor

Mathemaics

Physics

General

Acoustics

Astronomy and

Astrophysics

Atmospheric Science

Atomic

Electronics and Electricity

Elementary Particles and

High Energy

Fluid and Plasmo

Moteculor

Nucleor

Optics

Rudiation

Statistics

Applied Sciences

Applied Mechanics

Computer Science
0460
0383

0

0749

0486

0487

0488

0738

0490

0491

0494

0495

0754
0405

0405

0605
0986

0606

0606
0608

0748

0607

0798

0759

0759

0610

0752

0756

0611

0463

0346

0984

Ancient

Medieva

Modern

Block

Africon

033

Asia, Australia and Oceanio 0332

Canadian

Latin Amer zan

Middle Eastern

United Siares

History of Science

Low

Polifical Science

General

International Law and 


\section{Carleton University}

Thesis contains black \& white illustrations which when microfilmed may lose their significance. The hardcopy of the thesis is available upon request from Carleton University Library. 
The Undersigned recommend to the Faculty of Graduate Studies and Research acceptance of the thesis

'Design of a Crumb Rubber Modified Asphalt Pavement using the Stone Mastic Asphalt Concept"

Submitted by ROBERT VEIZER, B.A.Sc.

in partial fulfilment of the requirements for the degree of Master of Engineering

CD Ehandayge-

Dr. A.G. Razaqpur, Departunent of Civil and Environmental Engineering Qty 1 - thec. Dr. O.J. Svec, Thesis Supervisor

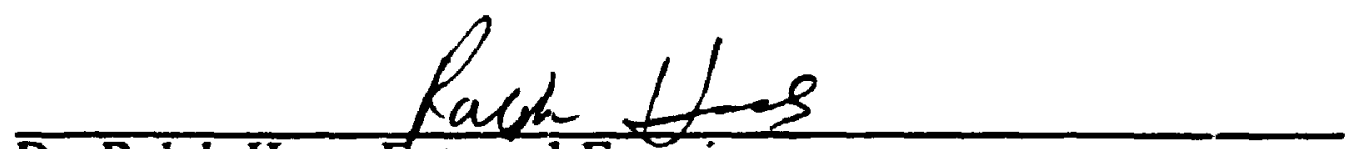

Dr. Ralph Haas, External Examiner

Carleton University

Ottawa, Ontario, Canada

November 30, 1993 


\section{Abstract}

One serious environmental problem related to the transportation field is the stockpiling of old rubber tires. Several huge old tire fires have already occurred in Canada and the USA and have caused considerable air and possibly soil pollution. Therefore, it is of great importance to develop techniques to recycle this potentially valuable material, such as by incorporating it into asphalt concrete.

A detailed program of literature review, Marshall mix design, and performance testing was carried out in order to investigate the effectiveness of adding crumb tire rubber into asphalt pavements. The objective of this research was to develop an asphalt rubber pavement using the stone matrix asphalt concept.

The results of the literature review suggested that adding crumb tire rubber to asphalt cement is a very promising endeavour and that the resulting material may provide improved capability of resisting rutting and cracking failure.

A Marshall mix design program effectively selected the optimum mix of each SMr mix design. The experimental results of the performance testing clearly showed that the rubber modified SMA mixes are superior to the conventional SMA mixes. The large aggregate mix results were not as promising but can be improved with slight modifications. 


\section{Acknowledgements}

I would like to express my gratitude to my thesis co-supervisors, Dr. Otto J. Svec and Professor A.O. Abd El Halim for their invaluable advice, guidance, and generous suggestions throughout the course of this work. Without their help this research would not have been possible.

Financial assistance from the Natural Sciences and Engineering Research Council is gratefully acknowledged. The author also gratefully acknowledges IRC and NRC for their support and assistance.

Special thanks go to the following persons at the Centre for Surface Transportation Technology at the National Research Council (CSTT/NRCC) who contributed to the experimental work of this thesis: Dave Eldred, Mario Gervais, and Bill Bekking who provided technical support for the compaction and testing programs, El Hussein Mohamed and Zhongqi Yue for their professional opinion and advice on many tochnical matters, and LaVerne Palmer for his encouragement and support.

The author also gratefully acknowledges McFarland H J Construction Co., Husky Oil, and Bitumar for their supplies of aggregate, asphalt, and asphalt rubber respectively.

Finally, I wish to take this opportunity to express my deepest appreciation to my parents for their encouragement and understanding throughout my studies. This thesis is dedicated to them. 


\section{Table of Contents}

Acceptance Sheet $\ldots \ldots \ldots \ldots \ldots \ldots \ldots \ldots \ldots \ldots \ldots \ldots \ldots$ ii

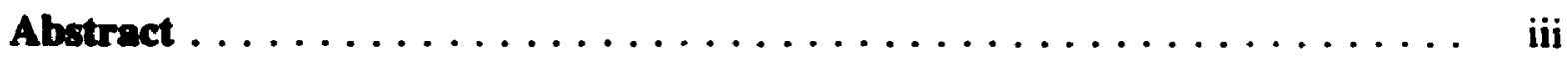

Acknowledgements $\ldots \ldots \ldots \ldots \ldots \ldots \ldots \ldots \ldots \ldots \ldots \ldots \ldots$ iv

Table of Contents $\ldots \ldots \ldots \ldots \ldots \ldots \ldots \ldots \ldots \ldots \ldots$

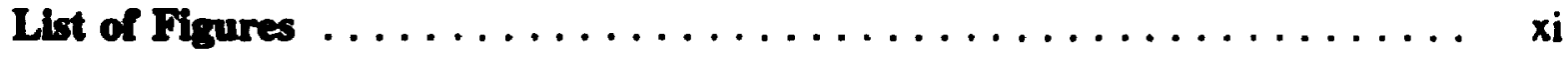

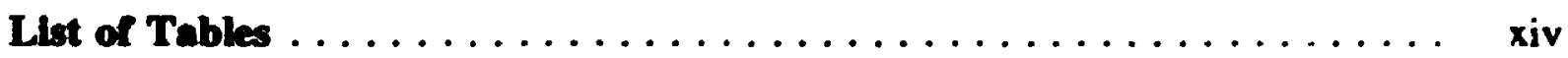

Llst of Symbols and Abbreviations $\ldots \ldots \ldots \ldots \ldots \ldots \ldots$

Chapter 1: Introduction ................... 1

1.1 The Scrap Tire Disposal Crisis $\ldots \ldots \ldots \ldots \ldots \ldots \ldots \ldots \ldots$

1.2 Utilization Technologies for Scrap Tires . . . . . . . . . . . . . . 2

1.2.1 Tire Derived Fuel (TDF) . . . . . . . . . . . . . . 2

1.2.2 Civil Engineering Usage of Scrap Tires $\ldots \ldots \ldots \ldots$

1.2.3 Crumb Rubber Modifier (CRM) Technology . . . . . . . . . . 6

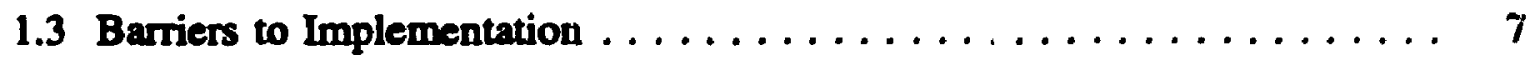

1.4 Objectives of the Research $\ldots \ldots \ldots \ldots \ldots \ldots$

1.5 Scope - Organization of the Thesis $\ldots \ldots \ldots \ldots \ldots$ 


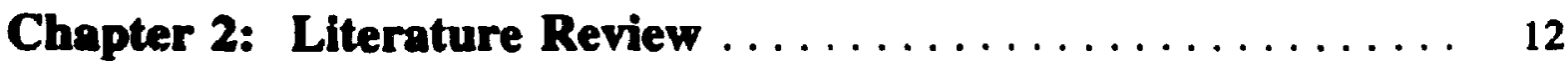

2.1 Modified Asphalts $\ldots \ldots \ldots \ldots \ldots \ldots \ldots \ldots \ldots \ldots \ldots \ldots$

2.2 Laboratory Studies of Crumb Rubber Modified Asphalt Pavements . . . . 14

2.2.1 Historical Development $\ldots \ldots \ldots \ldots \ldots \ldots \ldots \ldots \ldots \ldots .14$

2.2.2 Use of Rubber in CRM Pavencents . . . . . . . . . . 17

2.2.3 Use of Additives in CRM Pavements . . . . . . . . 18

2.2.4 Dry Process CRM Asphalt Concrete $\ldots \ldots \ldots \ldots \ldots \ldots \ldots \ldots 20$

2.2.5 Wet Process CRM Asphalt Concrete $\ldots \ldots \ldots \ldots \ldots \ldots \ldots 22$

2.2.6 Additional Types of CRM Asphalt Concrete $\ldots \ldots \ldots \ldots \ldots 27$

2.3 Field Trials of CRM Asphalt Pavements $\ldots \ldots \ldots \ldots \ldots \ldots$. . . . 29

2.3.1 Dry Process CRM Asphalt Concrete $\ldots \ldots \ldots \ldots \ldots \ldots \ldots 29$

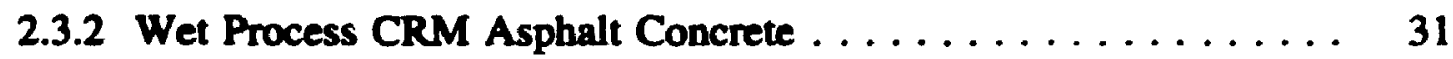

2.4 Potential Advantages of CRM Asphalt Concrete $\ldots \ldots \ldots \ldots \ldots \ldots$

2.5 Potential Disadvantages of CRM Asphalt Concrete .......... 35

2.6 Economic Analysis of CRM Asphalt Concrete $\ldots \ldots \ldots \ldots \ldots \ldots$

2.7 Conclusions of the Literature Review $\ldots \ldots \ldots \ldots \ldots \ldots \ldots \ldots .40$

Chapter 3: Testing Program Overview ............ 42

3.1 Testing Philosophy $\ldots \ldots \ldots \ldots \ldots \ldots \ldots \ldots \ldots \ldots \ldots \ldots, \ldots \ldots$

3.2 Aggregate Gradation Selection for use with CRM Asphalt Cement .... 45

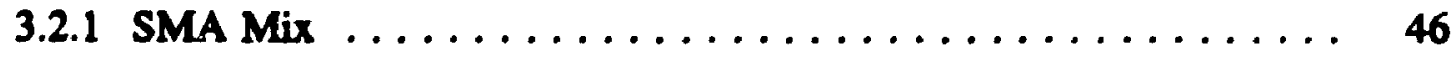

3.2.2 Large Aggregate Mlix $\ldots \ldots \ldots \ldots \ldots \ldots \ldots \ldots \ldots \ldots, 47$ 
Chapter 4: Marshall Mix Design Program for SMA Mix . . . si

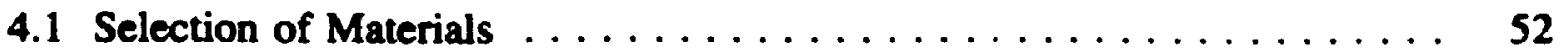

4.1.1 Aggregates $\ldots \ldots \ldots \ldots \ldots \ldots \ldots \ldots \ldots \ldots \ldots \ldots \ldots$

4.1.2 Binder $\ldots \ldots \ldots \ldots \ldots \ldots \ldots \ldots \ldots \ldots \ldots \ldots \ldots \ldots$

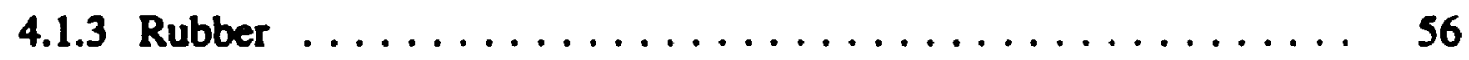

4.1 .4 Fibre $\ldots \ldots \ldots \ldots \ldots \ldots \ldots \ldots \ldots \ldots \ldots \ldots \ldots \ldots$

4.2 Manufacture of Mixes $\ldots \ldots \ldots \ldots \ldots \ldots \ldots \ldots \ldots \ldots \ldots$

4.2.1 Aggregate Gradation $\ldots \ldots \ldots \ldots \ldots \ldots \ldots \ldots \ldots \ldots$

4.2.2 Asphalt-Rubber Binder Preparation $\ldots \ldots \ldots \ldots \ldots \ldots \ldots \ldots$

4.2.3 Mixing Conditions $\ldots \ldots \ldots \ldots \ldots \ldots \ldots \ldots \ldots \ldots \ldots 62$

4.2.4 Compaction Conditions $\ldots \ldots \ldots \ldots \ldots \ldots \ldots \ldots \ldots \ldots \ldots$

4.3 Marshall Testing Procedure $\ldots \ldots \ldots \ldots \ldots \ldots \ldots \ldots \ldots . \ldots 64$

4.3.1 Bulk Relative Density . . . . . . . . . . . . . 64

4.3.2 Maximum Relative Density . . . . . . . . . . . . 64

4.3.3 Stability and Flow $\ldots \ldots \ldots \ldots \ldots \ldots \ldots \ldots \ldots \ldots, 64$

4.3.4 Air Voids (AV) and Voids in Mineral Aggregate (VMA) . . . 66

Chapter 5: Marshall Mix Design Results for SMA Mixes . . . . 67

5.1 Optimum Mix Determination for Control and Rubber Samples . . . . . . 69

5.2 Summary of Results $\ldots \ldots \ldots \ldots \ldots \ldots \ldots \ldots \ldots \ldots \ldots \ldots$

5.2.1 Bulk Relative Density . . . . . . . . . . . . . 72

5.2.2 Stability and Flow $\ldots \ldots \ldots \ldots \ldots \ldots \ldots \ldots \ldots \ldots, 72$ 
5.2 .3 Air Voids $\ldots \ldots \ldots \ldots \ldots \ldots \ldots \ldots \ldots \ldots \ldots \ldots \ldots$

5.2.4 Voids in Mineral Aggregate $\ldots \ldots \ldots \ldots \ldots \ldots \ldots \ldots .73$

5.2.5 General Results $\ldots \ldots \ldots \ldots \ldots \ldots \ldots \ldots \ldots \ldots \ldots$ 7ó

Chapter 6: LAM Specifications $\ldots \ldots \ldots \ldots \ldots \ldots \ldots \ldots$

6.1 Selection of Materials $\ldots \ldots \ldots \ldots \ldots \ldots \ldots \ldots \ldots \ldots \ldots$

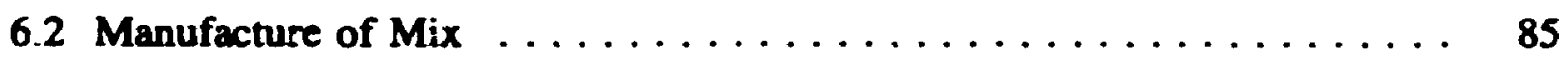

6.2.1 Aggregate Gradation $\ldots \ldots \ldots \ldots \ldots \ldots \ldots \ldots \ldots \ldots$

6.2.2 CRM Asphalt Cement Binder Preparation and Mixing conditions . $\quad 88$

6.2.3 Compaction Conditions $\ldots \ldots \ldots \ldots \ldots \ldots \ldots \ldots \ldots$

6.3 Selection Criteria for Performance Based Testing . . . . . . . . . 93

Chapter 7: Performance Based Testing Program ......... . 94

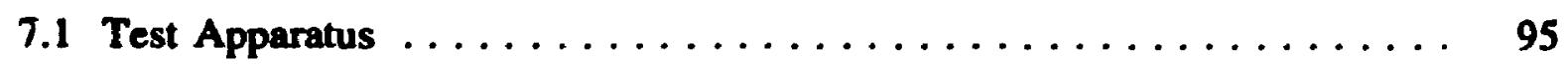

7.1.1 Hydraulic Actuator and Controller $\ldots \ldots \ldots \ldots \ldots \ldots . \ldots 9$

7.1.2 Instrumentatiion and Data Acquisition System $\ldots \ldots \ldots \ldots 95$

7.1.3 Temperature Controlled Chamber . . . . . . . . . . 97

7.2 Description of Testing Methods $\ldots \ldots \ldots \ldots \ldots \ldots \ldots \ldots \ldots$

7.2.1 Indirect Tensile Strength Test $\ldots \ldots \ldots \ldots \ldots \ldots \ldots \ldots$

7.2.2 Fatigue Testing $\ldots \ldots \ldots \ldots \ldots \ldots \ldots \ldots \ldots \ldots \ldots \ldots$

7.2.3 Repetitive Uniaxial Compressiou Test .............. 104

7.3 Test Procedure Summary $\ldots \ldots \ldots \ldots \ldots \ldots \ldots \ldots \ldots \ldots \ldots . \ldots . \ldots$ 


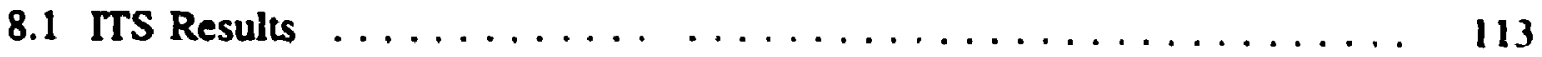

8.2 Fatigue Testing Results $\ldots \ldots \ldots \ldots \ldots \ldots \ldots \ldots \ldots \ldots \ldots \ldots$

8.3 Repetitive Uniaxial Compression Test Results $\ldots \ldots \ldots \ldots \ldots \ldots$

8.3.1 RUCT Test at $25^{\circ} \mathrm{C} \ldots \ldots \ldots \ldots \ldots \ldots \ldots \ldots \ldots \ldots$

8.3.2 RUCT Test at $40^{\circ} \mathrm{C} \ldots \ldots \ldots \ldots \ldots \ldots \ldots \ldots \ldots \ldots$

8.3.3 K-Value Comparisons $\ldots \ldots \ldots \ldots \ldots \ldots \ldots \ldots \ldots \ldots, 126$

8.4 Summary of Results $\ldots \ldots \ldots \ldots \ldots \ldots \ldots \ldots \ldots \ldots \ldots$

Chapter 9: Analysis and Discussion $\ldots \ldots \ldots \ldots \ldots \ldots \ldots$ 131

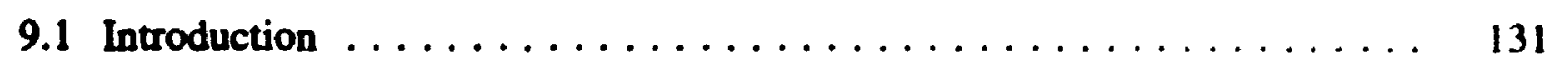

9.2 Discussion of Marshall Test Results for SMA $\ldots \ldots \ldots \ldots \ldots \ldots$

9.3 Discussion of Performance Related Testing Results . . . . . . . . . 136

9.3.1 Variability of Test Data . . . . . . . . . . . . 140

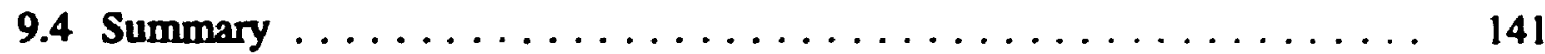

Chapter 10: Summary, Conclusions and Recommendations . . 142

10.1 Summary $\ldots \ldots \ldots \ldots \ldots \ldots \ldots \ldots \ldots \ldots \ldots \ldots \ldots \ldots, 142$

10.2 Conclusions $\ldots \ldots \ldots \ldots \ldots \ldots \ldots \ldots \ldots \ldots \ldots \ldots \ldots \ldots$

10.3 Recommendations for Future Research $\ldots \ldots \ldots \ldots \ldots \ldots \ldots$ 
References $\ldots \ldots \ldots \ldots \ldots \ldots \ldots \ldots \ldots \ldots \ldots \ldots \ldots \ldots \ldots$

Appendix $\ldots \ldots \ldots \ldots \ldots \ldots \ldots \ldots \ldots \ldots \ldots \ldots \ldots \ldots \ldots \ldots$ 


\section{List of Figures}

Figure Page

1.1 Relationship of Crumb Rubber Modifier $\ldots \ldots \ldots \ldots \ldots \ldots \ldots$

2.1 Comparative Aggregate Gri Jation Curves for conventional and Rubber Modified Asphalt Pavements $\ldots \ldots \ldots \ldots \ldots \ldots \ldots \ldots, 21$

2.2 Effect of Digestion Time and Temperature on Elastic Recovery for Asphalt-Rubber trom National Rubbei Tire Buffings . . . . 25

3.1 Testing Philosophy for SMA Mixes $\ldots \ldots \ldots \ldots \ldots \ldots \ldots \ldots, 44$

3.2 Comparison of Floating Coarse Aggregate in HMA with Stone-to-Stone Contact of SMA $\ldots \ldots \ldots \ldots \ldots \ldots \ldots \ldots \ldots \ldots \ldots$

3.3 Stone-to-Stone Contact of the LAM . . . . . . . . . . . 49

4.1 Grain Size Analysis of Filler Material $\ldots \ldots \ldots \ldots \ldots \ldots \ldots \ldots$ 55

4.2 Gradation Specification for Splittmastixasphalt (SMA) Mix Design .... 61

4.3 MTO Marshall Mix Design Form $\ldots \ldots \ldots \ldots \ldots \ldots \ldots \ldots$

5.2 Comparison of 5 Different SMA Mixes $\ldots \ldots \ldots \ldots \ldots \ldots \ldots 74$

5.2 Marshall Mix Design for SMA $\operatorname{mix}($ Control) $\ldots \ldots \ldots \ldots \ldots 77$

5.3 Marshall Mix Design for SMA mix (Ecoflex) $\ldots \ldots \ldots \ldots \ldots \ldots$

5.4 Marshall Mix Design for SMA $\operatorname{mix}(5 \%$ Rubber) $\ldots \ldots \ldots \ldots 79$ 
5.5 Marshall Mix Design for SMA mix (10\% Rubber) $\ldots \ldots \ldots \ldots . .80$

5.6 Marshall Mix Design for SMA mix (15\% Rut ber) $\ldots \ldots \ldots \ldots .81$

5.7 Marshall Mix Design for SMA mix (20\% Rubber) $\ldots \ldots \ldots \ldots . \ldots 2$

6.1 Gradation of Gap-Graded LAM . . . . . . . . . . . . 89

6.2 Rainhart Series 142 Gyratory Shear Compactor . . . . . . . . . 92

7.1 Schematic of Performance Tests Setup . . . . . . . . . 96

7.2 Loading Setup for $\mathrm{ITS}$ and Fatigue Tests $\ldots \ldots \ldots \ldots \ldots$

7.3 Indirect Tensile Strength Test $\ldots \ldots \ldots \ldots \ldots \ldots \ldots \ldots \ldots$

7.4 Fatigue Test Loading Function $\ldots \ldots \ldots \ldots \ldots \ldots \ldots \ldots \ldots$

7.5 Sample Fatione Data $\ldots \ldots \ldots \ldots \ldots \ldots \ldots \ldots \ldots \ldots \ldots$

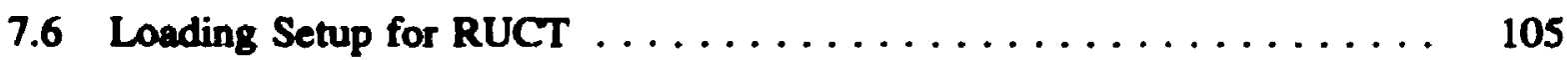

7.7 RUCT Loøding Function $\ldots \ldots \ldots \ldots \ldots \ldots \ldots \ldots \ldots \ldots \ldots$

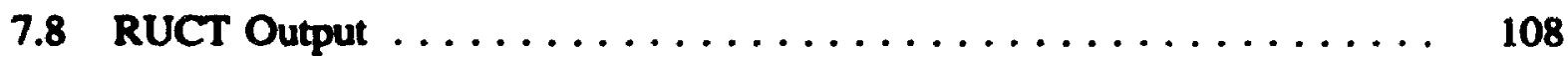

7.9 Stages of Axial Strain $\ldots \ldots \ldots \ldots \ldots \ldots \ldots \ldots \ldots \ldots \ldots . \ldots \ldots$

8.1 Indirect Tensile Strength of Optimum SMA Mixes $\ldots \ldots \ldots \ldots \ldots 114$

8.2 Indirect Tensile Strength of Optimum LAM Mixes $\ldots \ldots \ldots \ldots \ldots 114$

8.3 Fatigue Test Results for Control and Rubber SMA Mixes $\ldots \ldots \ldots, 117$

8.4 Fatigue Test Results for Control and Ecoflex SMA Mixes ....... 117

8.5 Fatigue Test Results for $\operatorname{LAM} \ldots \ldots \ldots \ldots \ldots \ldots \ldots \ldots \ldots \ldots$

8.6 Effect of Mix Type on Accumulated Permanent Axial Strain Tested at $25^{\circ} \mathrm{C}$ (SMA Mixes) $\ldots \ldots \ldots \ldots \ldots \ldots \ldots \ldots \ldots$ 
8.7 Effect of Mix Type (continued) on Accumulated Permanent Axial Strain Tested at $25^{\circ} \mathrm{C}$ (SMA Mixes) $\ldots \ldots \ldots \ldots \ldots \ldots$

89 Effect of Mix Type on Accumulated Permanent Axial Strain Tested

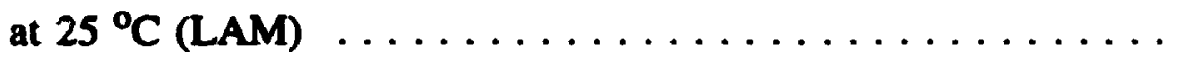

8.9 Effect of Mix Type on Accumulated Permanent Axial Strain Tested at $40^{\circ} \mathrm{C}$ (SMA Mixes) $\ldots \ldots \ldots \ldots \ldots \ldots \ldots \ldots \ldots \ldots$

8.10 Effect of Mix Type (continued) on Accumulated Permanent Axial Strain Tested at $40^{\circ} \mathrm{C}$ (SMA Mixes) $\ldots \ldots \ldots \ldots \ldots \ldots 124$

8.11 Effect of Mix Type on Accumulated Permanent Axial Strain Tested

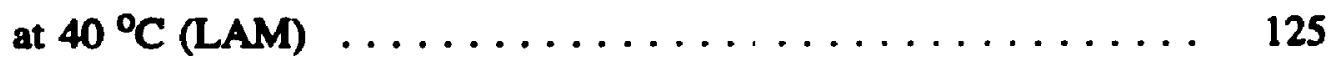

$8.12 \mathrm{~K}$-Values for SMA Mixes $\left(25^{\circ} \mathrm{C}\right) \ldots \ldots \ldots \ldots \ldots \ldots \ldots \ldots \ldots$

8.13 K-Values for SMA Mixes $\left(40^{\circ} \mathrm{C}\right) \ldots \ldots \ldots \ldots \ldots \ldots \ldots \ldots \ldots, \ldots \ldots$

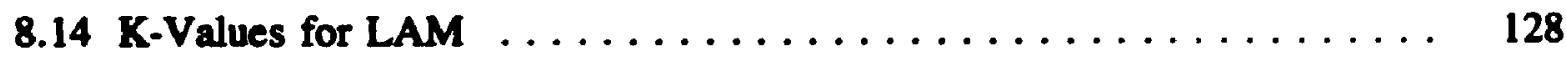

9.1 SMA Mix Containing $20 \%$ Crumb Tire Rubber $\ldots \ldots \ldots \ldots \ldots$ 


\section{List of Tables}

Table

1.1 Current and Potential 5 Year Usage of Scrap Tires . . . . . . . . . . 4

2.1 CRM Asphalt Concrete Specimen Preparation Conditions . . . . . . . . 23

2.2 Reported Advantages of CRM Asphalt Cement . . . . . . . . . . . 34

2.3 In-Place Costs for Asphalt Concrete and CRM Asphalt Concrete . . . 37

4.1 Aggregate Fractions Gradation $\ldots \ldots \ldots \ldots \ldots \ldots$

4.2 Rubber Gradation Specifications $\ldots \ldots \ldots \ldots \ldots \ldots$

4.3 Aggregate Blend $\ldots \ldots \ldots \ldots \ldots \ldots \ldots \ldots \ldots \ldots \ldots \ldots \ldots \ldots \ldots$

5.1 Marshall Design Criteria $\ldots \ldots \ldots \ldots \ldots \ldots \ldots \ldots$

5.2 Results from Marshall, BRD and MRD tests . . . . . . . . . . . 70

5.3 Asphalt Properties at Optimum Binder Content $\ldots \ldots \ldots \ldots \ldots \ldots$

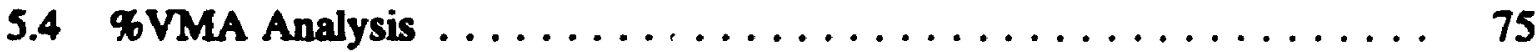

6.1 Aggregate Fractions Gradation (large aggregate) . . . . . . . . . . . 84

6.2 Rubber Gradation Specifications $(\operatorname{GTR}-4) \ldots \ldots \ldots$

6.3 Aggregate Blend for LAM ... . . . . . . . . . . . . 87

7.1 Performance Test Summary $\ldots \ldots \ldots \ldots \ldots \ldots$

8.1 Summary of Asphalt Rubber Performance Compared to the Control Mix 130 


\section{List of Symbols and Abbreviations}

$\begin{array}{llll}\text { ARPG } & : & \text { Asphalt Rubber Producers Group } \\ \text { BRD } & : & \text { Bulk Relative Density } \\ \text { CRAC } & : & \text { Chunk Rubber Asphalt Concrete } \\ \text { CRREL } & : & \text { Cold Regions Research and Engineering Laboratory } \\ \text { CRM } & : & \text { Crumb Rubber Modified } \\ \text { CSTT/NRC } & : & \text { Centre for Surface Transportation Technology / National } \\ & & \text { Research Council of Canada } \\ \text { EPA } & : & \text { Environmental Protection Agency } \\ \text { GTR } & : & \text { Ground Tire Rubber } \\ \text { ISTEA } & : & \text { Intermodal Surface Transportation Efficiency Act } \\ \text { ITS } & : & \text { Indirect Tensile Strength } \\ \text { K } & : & \text { Rate of Permanent Deformation for RUCT } \\ \text { LA } & : & \text { Large Aggregate } \\ \text { LAM } & : & \text { Large Aggregate Mix } \\ \text { LVDT } & : & \text { Linear Variable Displacement Transducer } \\ \text { HMA } & : & \text { Hot Mix Asphalt } \\ \text { MR } & : & \text { Resilient Modulus }\end{array}$




$\begin{array}{lll}\text { MOO } & : & \text { Ministry of Transportation of Ontario } \\ \text { MRS } & : & \text { Material Test System } \\ \text { NAPA } & : & \text { National Asphalt Pavement Association } \\ \text { N }_{f} & : & \text { Number of Cycles at Fatigue Failure } \\ \text { PARC } & : & \text { Porous Asphalt Rubber Concrete } \\ \text { PMA } & : & \text { Polymer Modified Asphalt } \\ \text { RUCK } & : & \text { Repetitive Uniaxial Compression Test } \\ \text { SAM } & : & \text { Stress Absorbing Membrane } \\ \text { SAM } & : & \text { Stress Absorbing Membrane Interlayer } \\ \text { SHR } & : & \text { Strategic Highway Research Program } \\ \text { SHA } & : & \text { Stone Matrix Asphalt, Spiittmastixasphalt } \\ \text { TDF } & : & \text { Tire Derived Fuel } \\ \text { VIA } & : & \text { Voids in Mineral Aggregate }\end{array}$

xvi 


\section{Chapter 1}

\section{INTRODUCTION}

\subsection{The Scrap $M$ Disposal Crisis}

Every year the industrialized nations generate more than nine million tons of scrap tires. More than $\mathbf{2 0 0}$ million waste tires are currently found in stockpiles across Canada with this number increasing by more than 20 million tires per year. In Ontario, six million passenger tires plus one million truck tires are scrapped each year. In the United States, approximately 285 million tires are discarded. Of this figure, 33 million are retreaded and 22 million are reused. Forty two million additional tires are used in various alternative manners. The remaining 188 million scrap tires are discarded in stockpiles, landills, or illegal dumps (Heitzman 1993). This procedure produces enormous strains on already overloaded lardfills and threatens the environment with fire and health hazards. Used tire stockpiles are an excellent breeding ground for mosquitos and an ideal habitat for vermin. Rubber from old automobile tires, however, can become valuable material for other uses. Every effort should be made to explore possibilities in civil engineering and other fields. Numerous other projects are being carried out, seeking ways to reduce 
this solid waste problem. Promising research into areas such as tire-derived fuel (TDF), lightweight embankisıents, slope stability and retaining walls, and ubber modified asphalt give hope to reducing discarded tires as a solid waste problem. The remoulding of crumb tire rubber into mud guards, floor mats, carpet padding, or other rubber products also helps in reducing tire stockpiles. Of the available disposal methods, only fuel for combustion ani cruinb rubber modifier (CRM) for asphalt paving, have shown the potential to use a significant number of scrap tires. This thesis addresses the solid waste problem by developing a new crumb rubber asphalt material.

\subsection{Utilization Technologles for Scrap Tires}

Most discarded truck and automobile tires go into landfills and since they do not disintegrate with time, they remain a continual problem. A report sponsored by the National Asphalt Pavement Association (Hughes 1993) outlines interesting new technologies for scrap tire usage as an energy resource in civil engineering applications, and as crumb rubber modified (CRM) usphalt pavement.

\subsubsection{Tre-Derived Fuel (TDF)}

Tire derived fuel has a heating value of $9.68 \mathrm{Kw}$-hrs per $\mathrm{kg}$ (15000 Btu per pound), which is higher than most types of coal. In a report prepared for the Environmental Protection Agency (EPA), the potential energy source of $2.05^{*} 10^{7} \mathrm{Mw}$-hrs per year ( 0.07 quadrillion Btu per year) that would be furnished by the roughly 242 million waste tires per year "...is equivalent to 12 m.llion barrels of crude oil..." (EPA, 
1991). With proper emission controls, burning tires for fuel can be a clean and environmentally sound method of disposing of a difficult waste. Current uses of TDF are in cement kilns, electric utilities, tire-to-energy facilities, and pulp/paper mills. The report has assessed the current and five-year potential usage by industry as shown in Table 1.1. (Hughes 1993).

From an environmental standpoint, the burning of tires in cement kilns, boilers at electric power plants, dedicated tires-to-energy fucilities, or pulp and paper mills, has litule adverse affect on pollution and at worst is better than coal emissions.

Creating tire derived fuel has been shown to be economical with great potential cost savings. For example, in electric utilities the cost of the TDF ranges from zero to $\$ 1.13 / \mathrm{Mw}-\mathrm{b}=, \$ 0.33 / \mathrm{million}$ Btu's). The cost of coal is between $\$ 6.16$ and $\$ 6.85 / \mathrm{Mw}-\mathrm{hr}$ ( $\$ 1.80$ and $\$ 2.00 /$ million Btu's).

\subsubsection{Civil Engineering Usage of Sernp Tires}

Civil engineering usages of scrap tires include lightweight embankments, drainage layers, slope stability and retaining walls. Hughes lists some advantages attributed to shredded and whole tires. He states that they:

1. are a lightweight material,

2. are replacements for more expensive or scarce aggregate,

3. provide a material with high permeability characteristics,

4. are resistant to ultraviolet radiation,

5. are non-bi degradable (important as a stable fill), 
Table 1.1: Current and Patential 5 Year Usage of Scrap Tires

\begin{tabular}{|c|c|c|}
\hline Industry & 1992 Usage & Potential 1997 \\
\hline Cement Kilns & $7^{*}$ & 60 \\
\hline Pulp and Paper & 14 & 55 \\
\hline Electricity & 21 & 75 \\
\hline Tires-to-Energy & 15 & 40 \\
\hline
\end{tabular}

Note: numbers are in millions of scrap tires

* Permitted Capacity is 14 million tires

(from Hughes 1993) 
6. provide a material with improved thermal characteristics relative to frost penetration,

7. are cost effective, and

8. are technically superior to land filling.

Though these methods have proven to be sound in an engineering sense they still do not eliminate the scrap tires as solid waste.

The use of scrap tire rubber as a lightweight fill has been used by Oregon, Vermont, Minnesota, and Washington. Hughes states that shredded scrap tire rubber proved to be the safest, quickest, and most cost-effective solution availa sle for lightweight fill design in Minnesota. The report also shows other interesting uses of this potentially valuable material.

The use of shredded scrap tires for subbase drainage layers in highways is attractive due to the substantial quantity of scrap tires which can be dispssed of in a mile of highway. Coarsely shredded or chopped tires has permeability values comparable to the permeability values of $38.1 \mathrm{~mm} \times 19.1 \mathrm{~mm}\left(11 / 2^{\prime \prime} \times 3 / 4^{\prime \prime}\right)$ coarse a.ggregate. The low unit weight of the material allows the chips to be placed over marshy land where heavier materials tend to sink.

Whole tires are used for retaining walls to improve slope stability. The scrap tires are piled in such a way as to not alter their original shape when stacked. The tires should be used on lower slopes and in locations not visibie to motorists. Engineering fabric is often used behind, under and over the tires to prevent soil erosion. The cost of such retaining walls is about half the cost of a gabion and a third the cost of a concrete crib wall. 


\subsubsection{Crumb Rubber Modiner (CRM) Technology}

Crumb rubber modified asphalt has a potential to eliminate a large number of scrap tires as waste if it becomes widely accepted and used. CRM asphalt cement presently consumes 1 to 2 million tires/yr in the United States. The CRM technology incoryorates from 2 to 6 tires per metric ton of hot-mix asphalt (HMA) paving material.

The use of rubber modified asphalt has been given much attention through many investigations as a means of utilizing waste tures, while at the same time attempting to improve pavernent performance. Many cases are cited in literature where rubber modified asphalt has shown superior performance to conventional asphalt cement. Some examples are described by Charania et al. (1991), Larsen (1989), and Renshaw et al. (1989). Superior performance has been doctimented in many field tests of CRM pavements, while equal and sometimes inferior performance $h r$ been shown in others. Uncertainty over performance and recyclability as well as increased costs has persuaded some people to dismiss CRM asphalt as a viable paving material. Robert $\mathbf{M}$. Thompson, immediate past chairman of the National Asphalt Pavement Association (NAPA), is trying to prevent the implementation of Section 1038 (b) of the Intermodal Surface Transportation Efficiency Act (ISTEA) until further definitive research is carried out on CRM Asphalt pavements (NAPA 1993). Section 1038 requires that a certain percentage of Hot Mix Asphalt (HMA) tonnage constructed with Federal-aid funds contain crumb rubber from scrap tires. These minimum utilization requirements are 5 percent of the Federal-aided HMA tonnage in 1994, 10 percent in 1995, 15 percent in 1996, and 20 percent in 1997, must contain crumb rubber modifier (CRM). Failure to comply with these minimum requirements will 
result in the loss of Federal-aided highway funds. The cost of HMA increases with the addition of CRM anywhere from 20 to 100 percent. It is inconclusive whether improved performance (if any) offsets the additional cost of CRM asphalt cement pavements.

In general the application of crumb rubber modifier (CRM) technology can be divided into two categories: the wet process and the dry process. These categories are derived from the basic process used to add the crumb rubber to an asphalt paving mixture. The term wet process defines any method that blends the crumb tire rubber with the asphalt cement before introduction to the aggregate. The dry process mixes the crumb tire rubber, usually in larger chunks, with the aggregate before this mixture encounters the asphalt binder. When CRM is incorporated into an asphalt paving material, the CRM will modify the properties of the binder and is called CRM asphalt concrete. When CRM is used as a rubber aggregate, the HMA is called rubber-modified hot-riis asphalt (Heitzman 1993). Figure 1.1 presents a summary of CRM asphalt processes. The individual processes shown in this figure are describe in Chapter 2 - Literature Review.

\subsection{Barriers to Implementation}

There are several barriers to the increased use of scrap tires in ar:y of the previous applications. General problems stated in the report prepared by Hughes are:

1. source of supply,

2. consistency of supply,

3. high capital or initial costs,

4. conservative nature of user industries, 


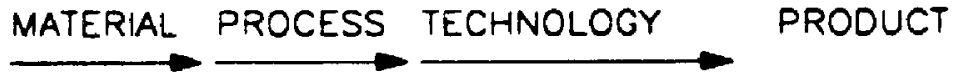

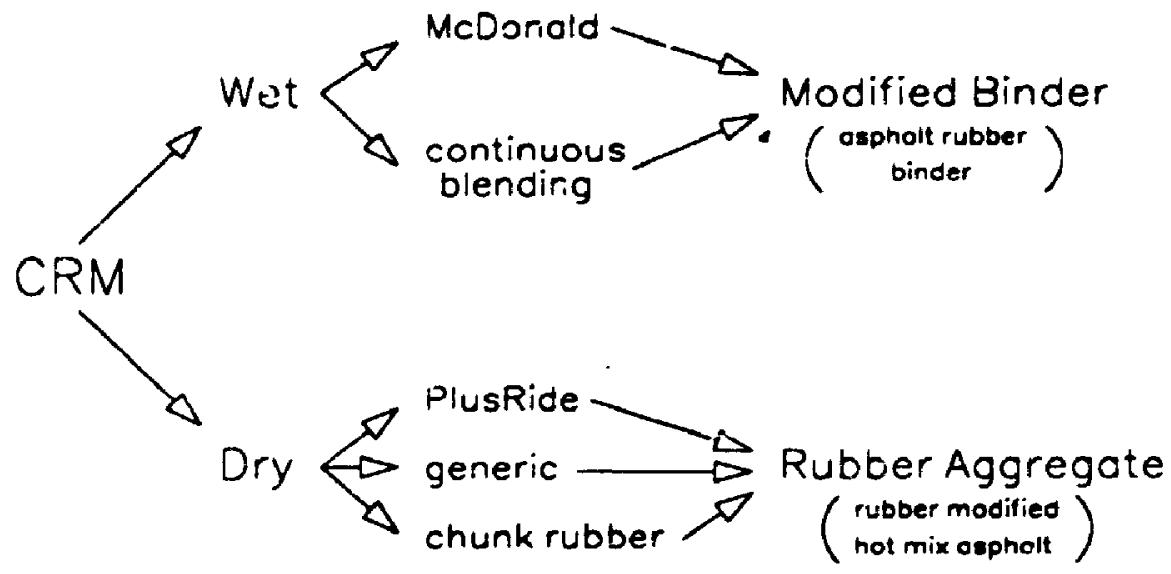

Figure 1.1: Relationship of Crumb Rubber Modifier (after Heitzman 1993) 
5. nonstandardization of air permit modifications,

6. lack of education of the public.

While these problems pertain to all the utilization technologies of scrap tire rubber specific problems which relate to CRM asphalt are as follows:

1. only 50 to 60 percent of the scrap tire is used,

2. production requires increased energy consumption,

3. the cost of an asphalt pavement is increased by more than $\mathbf{5 0}$ percent with as yet. unproven equivalent life performance benefits,

4. there is uncertainty over recyclability of the material,

5. the effect of fumes on workers is not known,

6. national standards on $\mathrm{mix}$ design procedures and performance criteria are lacking.

These problems are serious and must be addressed before widespread implementation of CRM asphalt pavements is possible.

\subsection{Objectives of the Research}

In this chapter, it has been indicated that there is a serious disposal problem involving discarded tires. One of the methods used in recycling scrap tires is to incorporate ground tire rubber crumbs with asphalt cement to produce CRM asphalt concrete. While there has been documented evidence of superior performance of CRM asphalt concrete, some researchers still remain unconvinced of it's effectiveness under varying climatic conditions.

The major objective of this thesis is to develop a new CRM pavement system 
based on the stone matrix asphalt (SMA) concept. The SMA concept has been selected due to unique gradation specifications which, in the authors opinion, are favourable for use with CRM pavement systems. A full depth pavement system will be designed using CRM pavement technology.

\subsection{Scope - Organization of the Thesis}

This section briefly outlines the scope of the investigation along with the remaining chapters of the thesis and their purpose.

Chapter 2 presents the major results of a literature review. Initially, only applications of CRM asphalt concrete that have been described in literature during the past five years are examined. Older reports that are referenced and of interest are also reviewed. A brief study of laboratory and full-scale field tests of both wet process and dry process pavements, and the economics of $\mathrm{CRM}$ asphalt are also presented. The literature review shows the promise of CRM asphalt corserete and demonstrates that further investigation is needed.

Chapter 3 contains the testing philosophy adopted for this research along wih gradation selections for use with the CRM asphalt cement binder.

In Chapter 4, the concept of SMA is described and the design of the SMA mix selected for this project is documented. The details of the experimental program and the procedures used are described. The Marshall mix design was chosen to select the optimum asphalt content for the SMA mixes used for this study. The method of selection of materials, the manufacture of the mixes, as well as the testing procedures are outlined 
in detail.

Chapter 5 contains the results of the mix design procedure describe in Chapter 4 . The optimum contents are selected and presented along with mix comparisons. Preliminary results are drawn from the Marshall mix design study.

The specifications for the large aggregate mix are presented in Chapter 6 . Aggregate gradation and the $\mathrm{mix}$ preparation conditions are detailed.

Chapter 7 describes the performance based testing program. A description of the equipment and testing methods used to evaluate and compare the various mixes, is presented.

Chapter 8 describes the results of the performance based testing program. A full evaluation of the effects of rubber on the stone mastic asphalt and large aggregate mixes is also documented.

Chapter 9 gives a complete analysis and discussion of the testing results. Both the Marshall program and performance test results will be discussed.

Finally, Chapter 10 presents the summary and the conclusions of this study and recommendations for future research. 


\section{Chapter 2 \\ LITERATURE REVIEW}

This chapter reviews the laboratory research, available in the literature, which was performed on crumb rubber modified (CRM) asphalt concrete and CRM applications on roadways.

All documents dealing with CRM asphalt concrete in the last five years and found on the Transportation Research Information Service (TRIS) database were reviewed. Among the other services contributing to TRIS are the Highway Research Information Service (HRIS), the Maritime Research Information Service (MRIS), the Railroad Information Service (RRIS), the Air Transportation Research Information Service (ATRIS), the Urban Mass Transportation Research Information Service (UMTRIS), the International Road Research Documentation (IRRD). Transportation Libraries (TLIB), and Highway Safety Literature (HSL). As well any references of interest found in the reports obtained from TRIS were also examined. The author's information was kept current by reviewing a bi-monthly update on any new CRM asphalt concrete publications.

Sections on modified asphalts, advantages and disadvantages of CRM asphalt concrete, and economics are also included. 
Finally, the major conclusions of the literature review as they apply to the use of CRM asphalt concrete are presented.

\subsection{Modified Asphalts}

In an attempt to utilize waste and by-products to save the environment from further contamination, research into the recycling of materials has greatly increased. A potentially huge opportunity for utilizing various wastes and by-products is in highway construction. Studies on fly ash, bottom ash, incinerator residue, sulfate wastes, digested sewage sludge, ceal mine refuse, glass, plastics, waste rubber, and cement manufacturing wastes have been completed.

A large-scale industrial waste utilization project was constructed in connection with Transpo 72, an International Transportation Exposition held at Dulles International Airport. The basic waste composition used consisted of fly ash, dolomitic lime, sulfate wastes, flue gas desulphurization sludge (FG) and fluorogyp (FLG). Brink (1973) indicates that satisfactory mixtures of the waste materials could be produced in a portable

plant and that a suitable pavement could be constructed. However, localized failures indicated that further study was needed to develop optimum compaction conditions in the field.

Other wastes used in asphalt concrete have been summarized by Ormsby and Fohs (1990). The wastes reviewed in the report include:

- lime and cement kiln dusts

- cellulosic wastes 
- wood lignins

- bottom ash

- incineratur residue

- $\quad$ sewage sludge

- mining wastes

- scrap rubber

Although many wastes have been investigated for use with asphalt navements, only scrap tire rubber is of interest in this thesis.

\subsection{Loboratory Studies of Crumb Rubber Modified Asphalt Pavements}

\section{2 .1 Alitorieal Development}

The first patents issued for modification of bitumen with rubbery materials was in 1843 by a British patent. The following year a British patent was obtained by Cassell concerning the application of bitumen-rubber mixtures to road surfacing. In 1935 Russian literature carried a first reference on the work of D. Pospkhov and A. Fokin titled "Mixtures of Asphalt and Synthetic Rubber" (Allison 1967). However, it wasn't until the mid 1960's that CRM modified asphalt cement, which was pioneered by Charles H. McDonald of the City of Phoenix, has been more readily accepted (Charania et al.undated). Earlier experiments of CRM asphait concrete used a relatively small percentage of rubber to asphalt, usually as a dry additive. Virtually none of this work showed significant benefits to justify the additional costs of construction. Charles McDonald 
discovered that a time-temperature related gel-like material resulted from the pre-reaction of mixing vulcanized crumb rubber with hot paving grade asphalt. This new material is considerably more viscous than regular asphalt. This type of CRM asphalt concrete is produced by the "wet process". The first uses of a CRM asphalt concrete chip seal showed good engineering characteristics; however chip loss, which caused damage to cars, drew public opposition to the project. A special CRM asphalt concrete hot mix was developed to solve this problem. There are two primary applications of "wet-process" CRM asphalt concrete today. The first is a Stress Absorbing Membrane (SAM) where a hot asphalt rubber chip seal is applied to the damaged surface. A stress Absorbing Membrane Interlayer (SAMI) differs in that a 1.5 to 2 inch asphalt concrete layer is overlayed on the CRM asphalt concrete. A study by the Asphalt Rubber Producers Group has shown that CRM asphalt concrete used on damaged streets in Phoenix needed no subsequent maintenance for 20 years (Charania et al.-undated)

Another method of producing CRM asphalt concrete is by the dry process. This is a process that uses relatively large rubber particles to replace some of the aggregate in the mixture. The amount of crumb tire nubber typically used is between 3 to $4 \%$ by weight of the aggregate. This product was also developed in the late 1960's by Sweden and patented under the trade names of "Rubit" in Sweden and as "PlusRide" in the United States (Takallou and Hicks 1988). This process uses much more scrap nuber per mile of road, but it doesn't seem to perform as well as mixes produced by the wet process.

Other types of CRM asphalt concrete in use are Porous Asphalt Rubber Concrete (PARC) and Chunk Rubber Asphalt Concrete (CRAC) of which the former is 
manufactured by the wet process and the latter by the dry process. Both mixes bear modifications to standard wet and dry process mixes. PARC was developed in France to maintain superior drainage, high skid resistance and reduce tire rolling noise while maintaining excellent durability (Sainton 1990). CRAC was created by the U.S. Army Cold Regions Research and Engineering Laboratory (CRREL) to improve ice disbonding on roads (Eaton et al. 1991).

Though some people might debate the use of rubber in asphalt as imparting any advantages, the United States Congress seems intent on implementing this technology. Former President Bush signed a bill mandating the use of CRM asphalt concrete beginning on January 1, 1994 for any State requiring federal funds. The U.S. Congress passed The Intermodal Surface Transportation Efficiency Act (ISTEA) in 1992, which requires all states to use increasing percentage of rubber in the construction of asphalt concrete pavements $(5,10,15$, and $20 \%$ by weight) over the next five years (starting in 1994). Section 1038 of H.R. 2950 states "Beginning on January 1, 1994 each State must use asphalt pavement containing recycled rubber in 5 percent of the total tons of asphalt pavement laid in the state and financed in whole or in part by federal funds. The required percentage of asphalt pavement containing recycled rubber, in relationship to total tons of asphalt pavement laid in each State, increases by 5 percent each year until reaching 20 percent in 1997, where it remains for each year thereafter. If a State fails to meet this requirement, the amount of federal funds the asphalt pavement containing recycled rubber would have required will be withheld." (Manhole Messenger 1992). 


\subsubsection{Use of Rubber in CRM Pavements}

Rubber used to mix with asphalt cement should be used from recycled tires because it is a waste product. There are two types of crumb rubber current:y being used. The first is obtained from tire buffings or peelings and the second is from whole-tire processing. The former creates a much more uniform product, while the latter is more desirable since it uses the entire tire. Chehovits (1989) states that there are several characteristics of the rubber that influence properties of the CRM asphalt cement blend. Physical properties including particle size (gradation), shape (angular or elongated), surface texture (depending on grinding method), and contaminant presence (fib- s, etc.) all influence properties of the CRM asphalt cement. He also states that chemical compositional characteristics influence blend properties. Rubber hydrocarbon content. specific type of rubber polymer of blends, plasticizer content, and reinforcement type and content (carbon black, etc.) must all be considered.

Salter and Mat (1990) studied the effects of three types of rubber on the behaviour of asphaltic concrete mixes. The types of rubber used were natural (not tire rubber) and are as follows:

- Pulvatex, an unvulcanized rubber powder manufactured from concentrated natural latex. It is composed of 60 percent natural rubber powder and 40 percent separator.

- Crusce Standard, an unvulcanized spray-dried rubber powder containing approximately 6 percent silica filler and 1 percent calcium stearate as a partitioning agent. 
- LCS Revertex, an unvulcanized latex concentrated by evaporation to 68 percent solids and stabilized with potassium hydroxide and soap.

The addition of all three types of rubber additives in the binder caused a decrease in penetration, and an increase in softening point in comparison with the unmodified binder. The Marshall testing program showed a small increase in optimum binder content for the modified mixes, however, stability values depended on the type of rubber used. The addition of rubber increased stability values for Pulvatex and LCS Revertex but not for Crusoe Standard. Similar results were obtained by the force ductility test. Fatigue testing showed improvements of up to 88 percent by CRM asphalt cement blends.

Salter and Mat (1990) have indicated that the addition of rubber to asphalt has, in general, produced desirable properties but also that the type of rubber used is an important factor to be considered.

LaGrone (1981) defined the terms related to processing of scrap rubber and provided the typical composition of scrap rubbers available for the production of CRM asphalt cement binders. The type of rubber selected affects the elasticity of the resulting binder and the stability of the reacted product.

\subsubsection{Use of Addittres in CRM Pavements}

In a report by Jimenez et al. (1979), temperature-viscosity relationships were developed for a regular asphalt and a CRM asphalt cement blend. The CRM asphalt cement blend has a ratio of vulcanized rubber to regular asphalt of 2575 . The viscosity equations are: 


$$
\begin{array}{ll}
\text { regular asphalt cement } & \eta=6.767 \times 10^{25} \circ F^{-10.69} \\
\text { CRM asphalt cement blend } & \eta=5.768 \times 10^{14} \circ F^{-4.494}
\end{array}
$$

where $\eta$ is the viscosity in poises at a shear rate of $0.05 \mathrm{sec}^{-1}$. Test method 7245-78 of the American Association of State Highway and Transportation Officials (AASHTO) specifies that the asphalt should be at a temperature that corresponds to a viscosity of 170 cSt for compaction. This requirement would correspond to a temperature of $938^{\circ} \mathrm{C}$ $\left(1721^{\circ} \mathrm{F}\right)$ for the $\mathrm{CRM}$ asphalt cement. This temperature is surely unreasonable and if the CRM asphalt cement is too viscous and becomes a problem, extending oils can be used to soften the material for improving the degree of interaction between the asphalt and rubber and improving workability. It should be noted that a much higher shear rate will be required to properly coat aggregates with CRM asphalt cement. Other additives such as adhesion agents can be used to improve film stripping resistance.

Takallou and Sainton (1993) examined the effects of four different content levels of oil extenders on the penetration and softening point of CRM asphalt cement. Test results indicate that an increase in the percentage of oil extender will decrease the softening point, increase penetration, increase the capacity for stretching and tension. and reduce resistance to shear flow. The authors concluded that a maximum of 6 percent of extender oil provides optimal binder properties. 


\section{2 .4 Dry Process CRM Asphalt Concrete}

The method of adding rubber to asphalt mixes in a dry process was originally developed in late 196n's in Sweden and patented under the trade names of "PlusRide" in the U.S. and "Rubit" in Sweden. In this system, rubber-asphalt mixtures are prepared by a process that uses 3 to 4 percent by weight of relatively large $1.6 \mathrm{~mm}$ to $6.4 \mathrm{~mm}(1 / 16 "$ to $\left.1 / 4^{\prime \prime}\right)$ rubber particles to replace some of the aggregate in the mixture.

The aggregate gradation for this type of system must be modified to accommodate the extra rubber particles. A rubber-modified pavement is gap-graded for this purpose (see Figure 2.1). The gap in the gradation is typically in the $3.2 \mathrm{~mm}$ to $6.4 \mathrm{~mm}$ (1/ to $1 / 4$ in.) size range. The rubber particles replace the stone aggregate that normally would occupy this space. One of the problems in producing this type of mix has been achieving the proper gap in the grading curve and obtaining sufficient fines (passing No. 200) to serve as a void filler. The lack of mineral filler causes high air voids which is not desirable in the Marshall mix design.

Takallou and Hicks (1988) performed a laboratory study on the dry process CRM asphalt concrete. The Marshall mix design was used to determine the optimum asphalt contents of the different mix combinations. Once this was accomplished, the resilient modulus and fatigue life tests were used to evaluate the mixes. It was discovered that the mixture with gap-graded aggregate and 3 percent coarse rubber required the highest design asphalt content (9.3\%). The conventional dense graded asphalt mix required 5.5\% asphalt at optinum content.

The fatigue results revealed that the rubber-modified mixes had a much greater 


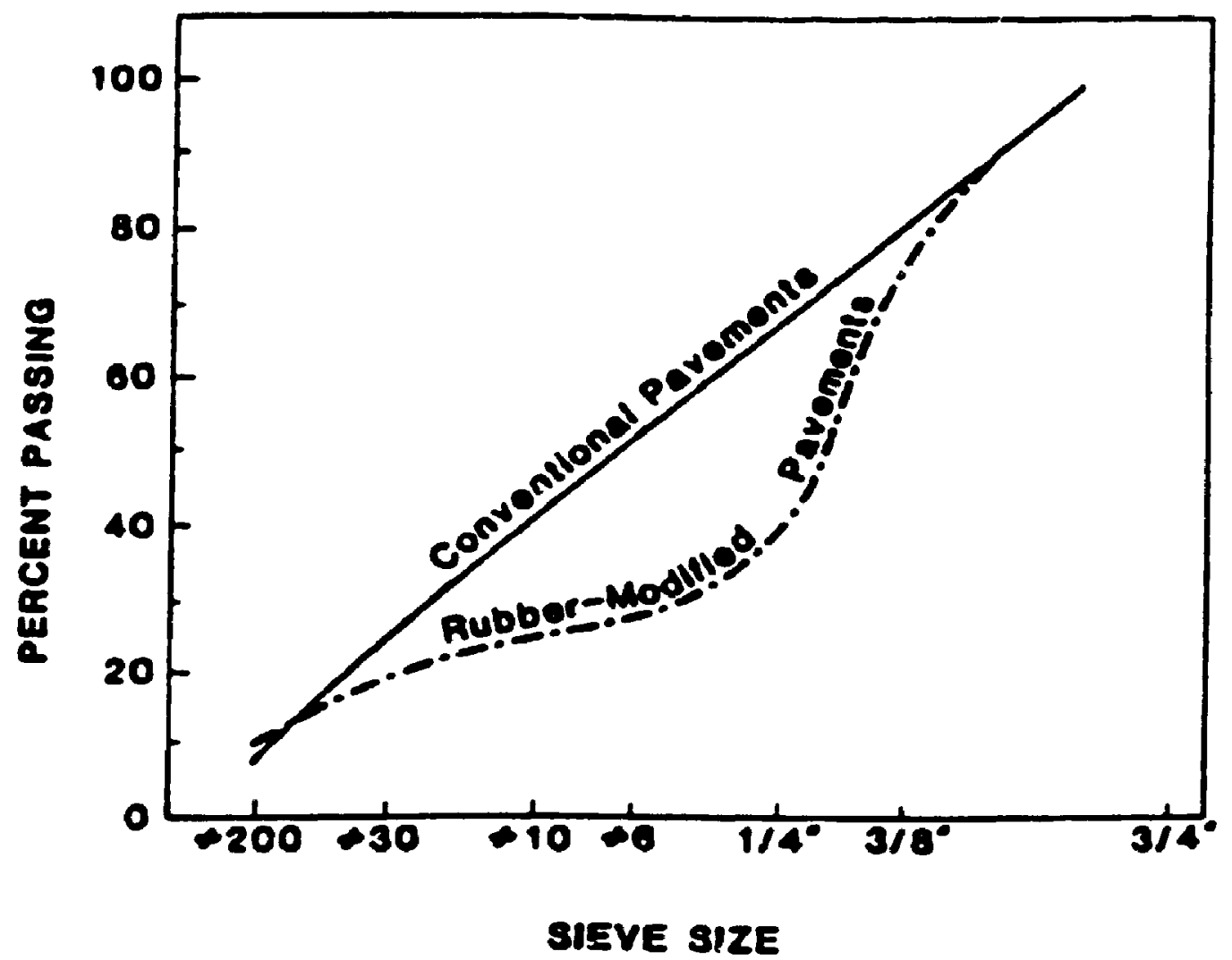

Figure 2.1: Comparative aggregate gradation curves for conventional and rubbermodiffed asphalt pavements (after Takallou and Hicks 1988) 
fatigue life than a conventional asphait concrete mix.

Lawrence et al., 1991, reported on Marshall tests performed on . CRM asphalt concrete mix placed in Thamesville, Ontario in 1990. They noted that the addition of coarse scrap rubber to dense graded hot mix has the effect of raising the flow value and lowering the stability values, with the flow value increased by almost $80 \%$ and the stability value lowered by over $50 \%$. The stability value for the CRIיA asphalt concrete mix used at Thamesville was below the minimum specified value for standard mixes.

\subsection{Wet Process CRM Asphalt Concrete}

Asphalt SAM's and SAMI's are produced by the wet process. In this process anywhere from 5\% to $30 \%$ ground rubber is introduced to the asphalt cement at temperatures from $325-450^{\circ} \mathrm{F}$. The mix of asphalt and rubber is then continuously stirred anywhere from $1 / 2$ to 2 hours at the elevated remperature. Extender oils may be used to reduce the viscosity and increase the workability if required. The CRM asphalt cement mixture is then allowed to cool and stored for future use.

Roberts and Lytton (1987) have compiled a list of preparation conditions of CRM asphalt cement (Table 2.1.).

The mixing and coinpaztion temperatures used for CRM asphalt concrete are considerably higher than those used for regular asphalt concrete. The primary reasons for such high temperatures are due to the very high viscosity of the CRM asphalt cement binder at temperatures defined for the Marshall method, and due to the difficulty of wetting the aggregate surface rvith CRM asphalt cement at normal temperatures. 
Table 2.1:

CRM Asphalt Concrete Specimen Preparation Conditions (After Roberts and Lytton, 1987).

\begin{tabular}{|c|c|c|c|c|c|}
\hline \multirow[b]{3}{*}{ Author } & \multirow{3}{*}{$\begin{array}{c}\text { Compaction } \\
\text { type }\end{array}$} & \multirow{3}{*}{$\begin{array}{c}\text { Mixing } \\
\text { Time } \\
\text { (min.) }\end{array}$} & \multicolumn{3}{|c|}{ Temperature Conditions ( $\left.{ }^{\circ} \mathrm{F}\right)$} \\
\hline & & & \multicolumn{3}{|c|}{ Mixing } \\
\hline & & & $\begin{array}{l}\text { Asphatt } \\
\text { Rubber }\end{array}$ & Aggregate & Compaction \\
\hline $\begin{array}{c}\text { Jimenez } \\
\text { (1979) }\end{array}$ & $\begin{array}{l}\text { California } \\
\text { Kneading } \\
\text { Compactor }\end{array}$ & 2 & 375 & 300 & 250 \\
\hline $\begin{array}{l}\text { Lalwani } \\
\text { (1982) }\end{array}$ & $\begin{array}{l}\text { Marshall } \\
\text { Hammer }\end{array}$ & $\mathbf{N} / \mathbf{I}$ & $\mathbf{N} / 1$ & N/I & $\mathbf{N} / \mathbf{I}$ \\
\hline $\begin{array}{c}\text { Dickson } \\
\text { (1981) }\end{array}$ & $\begin{array}{l}\text { Marshall } \\
\text { Hammer }\end{array}$ & $\begin{array}{l}\text { Until } \\
\text { coated }\end{array}$ & 375 & 375 & 375 \\
\hline $\begin{array}{c}\text { Vallerga } \\
\text { (1981) }\end{array}$ & N/ & $\mathbf{N} / \mathbf{I}$ & 350 & 350 & 325 \\
\hline
\end{tabular}

N/I: Not Included 
In a report by Jimenez (1989) the viscosity effects of adding rubber to hot asphalt cement were studied. The viscometers were of the falling coaxial cylinder type and the forced flow Schweyer Rheometer. The variables studied were:

- diameter of flow-tube

- amount of rubber in the blend

- gradation of rubber particles

- type of rubber

- test temperature

Jimenez determined that the viscosity of the CRM asphalt cement increased as the amount of rubber increased and also as the range of particle sizes increased. The viscosity of one blend of rubber showed greater temperature susceptibility than other blends. It is due to the increase in viscosity that higher compaction temperatures are used for sample preparation.

Oliver (1981) reported the effect of reaction time and temperature (Figure 2.2). It is quite evident that the properties of the CRM asphalt cement binder degrade after too long a reaction time at high temperatures. Therefore, one must take precautions when selecting mixing conditions for asphalt and crumb tire rubber. Oliver also showed that synthetic rubber is much more stable than natural rubber under higher digestion temperatures.

A full Marshall mix design study on CRM asphalt concrete mixes was performed by Al-Abdul-Wahhab and Al-Amri (1991). Two aggregate gradations with hot asphaltic concrete mixes containing 10\%, 20\%, and $30 \%$ reclaimed rubber as part of the binder 


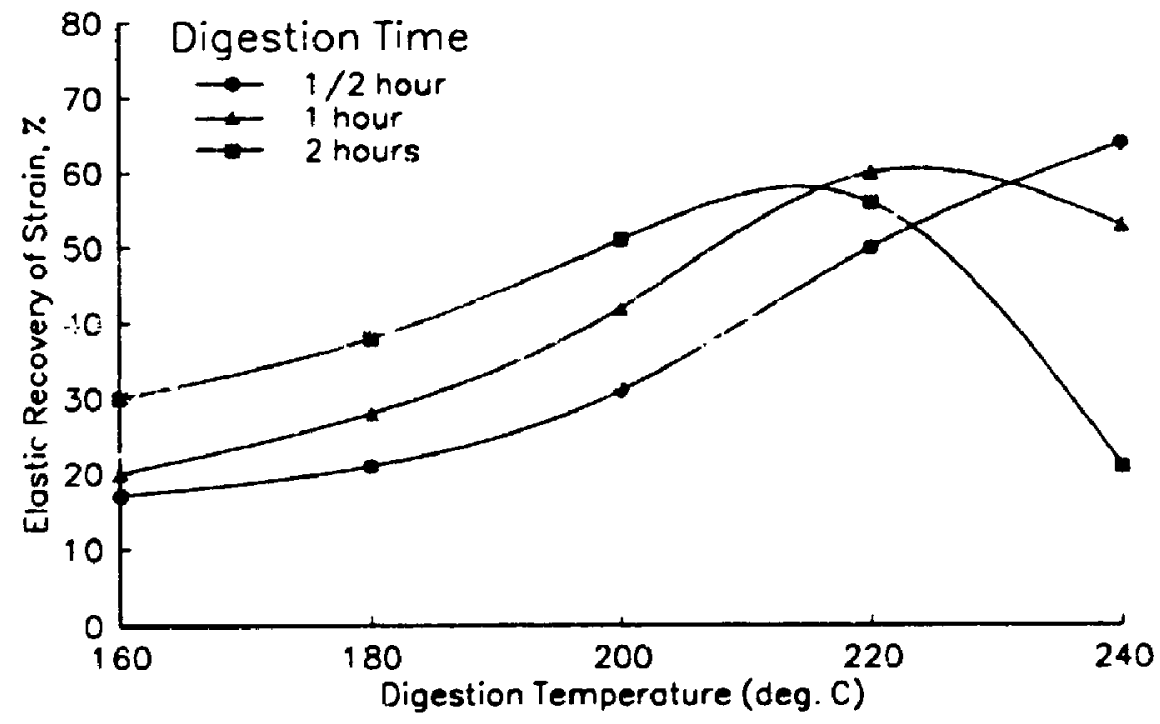

Figure 2.2:

Effect of Digestion Time and Temperature on Elastic Recovery for Asphalt-Rubber from National Rubber Tire Buffings (after Oliver 1981) 
were investigated. A mixing time of 2 hours at a temperature of $200^{\circ} \mathrm{C}$ has been shown to be superior for elastic properties of CRM asphalt cement. The Marshall method of mix design was employed in the preparation of test specimens for both gradations in order to obtain the optimum mix. Tests were then performed at the optimal asphalt content for mix comparisons. Wahhab and Amri performed the following iesis;

- $\quad$ softening point

- viscosity

- Marshall stability and flow

- Hreem stability

- split tensile test

- $\quad$ static creep test

- resilient modulus test

- fatigue test

Based on the experimentation it was determined that the addition of rubber improved the soltening point by $8^{\circ} \mathrm{C}, 10^{\circ} \mathrm{C}$, and $11^{\circ} \mathrm{C}$ for $10 \%, 20 \%$, and $30 \%$ rubber content, respectively. Such an improvement on softening point might improve the rutting resistance of these mixtures. The viscosity also increased with a higher rubber content. It was also found that the addition of $10 \%$ reclaimed rubber improved the resilient modulus, $M_{R}$, stiffness modulus, as well as the stability (Marshall and Hveem) and fatigue life. Salter and Mat (1990) achieved similar results for softening point, Marshall stability, and fatigue testing for CRM asphalt concrete mixes. Improvements of up to 88 pencent were noted in fatigue life. 


\subsubsection{Additional types of CRM Asphalt Concrete}

Different variations on the basic wet and dry process blends have been studied and tested by various groups. Two of these new brands of CRM asphalt concrete are Chunk Rubber Asphalt Concrete (CRAC) and Porous Asphalt Rubber Concrete (PARC).

CRAC which was developed by the U.S. Army Cold Regions Research and Engineering Laboratory (CRREL) differs from commercial CRM asphalt concrete products in that it contains four times as much rubber in larger pieces. CRAC is manufactured by the dry process and its goal is to enhance ice disbonding properties. Faton et al. (1991) used the Marshall method of mix design to determine the optimal asphalt content for the different CRAC samples. They prepared pavement samples containing $0 \%, 3 \%, 6 \%, 12 \%, 25 \%$, and $57 \%$ rubber by weight of sample. One mix was prepared with $93.5 \%$ rubber and $6.5 \%$ asphalt with no stone aggregate. Laboratory tests showed that the Marshall Stability values for CRAC doubled in strength for the 3, 6, and 12\% rubber contents. Also, cracks did not develop in the ice layer, nor, was there any deterioration in the ice-pavement bond during wheel tricking tests of the samples with no rubber. Cracking in the ice layer increased with increasing rubber content. Ice disbonding for samples with rubber contents less than or equal to $12 \%$ resulted from localized deformation, whereas samples with rubber contents greater than $12 \%$ experienced disbondment through area deflection. The authors conclude that CRAC does stimulate ice disbonding to a greater extent than "PlusRide" and certainly more than regular asphalt cement.

PARC, which is manufactured by the wet process, was developed in France in an 
effort to solve the problems of hydroplaning, water projection, noise reduction, and the mirror effect at night. Full-scale field experiments have been conducted on the A2 turnpike in the north of France. The French Road and Bridges Laboratory made rolling noise, roughness, and drainage tests after three years of traffic. Sainton (1990) describes the general advantages of PARC:

- high skid resistance at high speed and in rainfall

- no spray or splash

- no light reflection from wet pavement

- reduction of tire rolling noise

- low cost due to low density

CRM asphalt cement binder was chosen since pure asphalt cements have neither the cohesion nor the flexibility to give porous asphalt concrete resistance to heavy traffic. CRM asphalt cement has a high viscosity which allow: a high bino : $r$ content in porous asphait mixes which leads to binding strength, fatigue resistance, and aging resistance due to the thick film. Polymer modified asphalt (PMA) displayed good mechanical properties at first however after aging it became brittle at low temperature. From his work Sainton concluded that PARC displayed constant draining properties, good fatigue and rutting resistance, reduced tire noise and insensitivity to bad weather. 


\subsection{Field Trials of CRM Asphalt Pavements}

\subsubsection{Dry Process CRM Asphalt Concrete}

There are numerous cases documented of the use of this type of CRM asphalt concrete in full-scale field trials. The manufacturer of "PlusRide" claims that their product has the following benefits:

- higher friction resistance

- noise reduction from traffic

- deicing characteristics

- increased road life

The Minnesota Department of Transportation (Mr/DOT) conducted an evaluation of "PlusRide" at two selected sites. Both projects were constructed in September, 1984. The sume paving equipment was used to place the rubber modified mixture as was used for the conventional mixture. Placement of the rubber modified mixture was similar to the conventional mixture except that a considerably higher temperature was used. In a report by Allen and Turgeon (1990; they noted that there is no significant difference in tire noise level, friction resistance, deicilig: or ability to retard transverse reflective cracks. With these results and due to construction costs per ton being over twice the cost of the conventional mix, further test sections were not recommended.

An evaluation report for the Washington State Department of Transportation prepared by R.E. Allison (1990) produced similar results. A six year evaluation of a "PlusRide" asphalt concrete pavement laid in the city of Renton, Washington illustrated that there was no significant improvement corresponding to any of the claims made by 
"PlusRide" representatives.

A test section laid in Thamesville, Ontario is performing well to date apart from some concerns (Lawrence et al. 1991). Some large coarse aggregate particles are being dislodged from the surface wherever a particle of rubber is immediately under the aggregate. Secondly, the longitudinal construction joint at centreline is showing some joint opening and ravelling, and the mat is slower to dry out after rain. A Swedish study by Sandberg et al. (1990) on tire/road noise on rubberized asphalt concluded that Rubit surfaces do not give lower noise levels than converional asphalt surfaces. Though these cases may be disappointing, positive results with the dry process have been achieved.

Takallou H.B. et al. (1989) explain that extensive measurements by Alaska DOT\&PF showed an average reduction in stopping distance of $25 \%$ for the rubbermodified pavements in icy conditions. Deicing benefits have also been reported by Mn/DOT and Swedish road authorities.

A reduction in noise level of the traffic and reflective cracking has been reported on the Jan Smuts - Johannesburg freeway in a paper by Bergh et al. (1989). The mixture was composed of an open-graded bitumen rubber asphalt with a 2.25\% rubber content by weight of total mixture. Splash reduction in wet weather was also reported due to the open-graded property of the mixture and high laboratory voids achieved (20-27\%).

A review of the dry process in the literature gives the reader an uncertain outlook on the promise of this product. However, results obtained from the use of CRM asphalt concrete made by the wet process are not as ambiguous. 


\subsubsection{Wet Process CRM Asphalt Concrete}

There are numerous examples in the literature citing superior performance for CRM asphalt concrete in full scale test sections. The city of Phoenix, confident in the advantages of CRM asphalt concrete, has paved many streets with this product. One project, reported by Charania et al. (1991), placed CRM asphalt concrete on Indian School road, whose surface was in poor condition and badly cracked at the time. Application of an asphalt rubber chip seal was temporary and meant to prevent complete deterioration of the street. It was scheduled for reconstruction in two years. However, the street has performed satisfactorily with very little maintenance for over 20 years. Similar results were obtained by placing CRM asphalt concrete on the I-17 Frontage road and off ramp at Van Buren street. In a report by the Arizona Department of Transportation (ADOT 1988), it was concluded that performance data for the CRM asphalt concrete sections was promising and that ".the asphalt-rubber layers are effective in preventing reflection cracking".

A study by the Maine Department of Transportation (1990) concluded that "The initial costs of ARC are high compared to conventional asphalt pavements, estimates range from 45 to 114 percent. However, the results suggest a substantial extension in expected life of the pavement." This report summarized the CRM asphalt concrete experience of, various state transportation deparments. A California Department of Transportation (Caltrans) report by Doty (1988) observes "...that the service life of the (ARC overlays) under study may be considerably greater than those of equivalent thicknesses of conventional (pavement)...". Similar reports by Connecticut DOT (1989) 
and New York DOT show superior performance by CRM asphalt concrete test sections.

In October 1980, the Connecticut Department of Transportation (ConnDOT) placed an experimental $274 \mathrm{~m}$ (900-ft) section of CRM asphalt concrete on State Route 79 in Madison, CT (Larsen 1989). The pavement was placed as a $38.1 \mathrm{~mm}$ (1.5 in.) thick overlay in one lift using conventional paving techniques. A standard control section was placed at the same time. Larsen concluded in an eight-year evaluation that on the basis of transverse, longitudinal and alligator crackin r the asphalt-rubber mix performed better than the control mix. Skid resistance and roughness values remained acceptable and did not differ from the control section values.

South Africa constructed several bitumen-rubber test sections in 1982 . The basic composition of the modified mix consisted of the following by mass;

- $78 \%$ 80/100 penetration grade bitumen

- $2 \%$ high aromatic extender oil

- $20 \%$ ambiently ground crumb rubbet

Renshaw et al. (1989) claim that the performance of the bitumen rubber test sections in these projects has been very good and has "..amply demonstrated its ability to perform as originally claimed."

The Minustry of Transportation of Ontario (MTO) built trial sections in July 1990 on Highway 400, near Innisfil, to compare standard and modified HL1 mixes (Joseph and Kennepohl 1991). The modified mixes used in trial sections were: Premium asphalt, Novophalt, Neoprene, Vestoplast, and tire rubber ( $\$ 80$ mesh). Initial experience suggested that paving with CRM asphalt concrete was feasible using conventional equipment. The 
performance of the individual test sections have not been determined to date.

The Asphalt Rubber Producers Group (ARPG) based in Phoenix. Arizona make the following claims about wet process CRM asphalt concrete:

- increases pavement life

- resists rutting, aging and reflective cracking

- reduces pavement thickness

- $\quad$ provides optimum skid resistance

- traffic noise reduction of 65 to 85 percent

The first three claims seem to be backed up by numerous trial sections in use today. However, upon further study of the literature, claims of increased skid resistance are inconclusive. The ARPG cites examples of CRM asphait concrete used in Belgium, France, Germany, Austria, and Arizona where noise levels have been reduced from 50 to 90 percent. The type of CRM asphalt concrete mix commonly used for noise reduction is referred to as "Drainasphalt".

The use of wet process CRM asphalt concrete seems very promising from the results obtained to date. Further perfecting of construction procedures and the development of construction standards should increase the usage of this product.

\subsection{Potential Advantages of CRM Asphalt Concrete}

The advantages of CRM asphalt concrese have been formerly outlined in the chapter but are summarized in Table 2.2 .

These advantages make it attractive to consider using CRM asphalt cement as a 
Table 2.2: Reported Advantages of CRM Asphalt Cement

\begin{tabular}{|c|c|c|}
\hline $\begin{array}{l}\text { Method of } \\
\text { Manufecture }\end{array}$ & $\begin{array}{l}\text { Product } \\
\text { Name }\end{array}$ & Advantages over regular asphalt cement \\
\hline \multirow[t]{2}{*}{ dry process } & $\begin{array}{c}\text { Rubit } \\
\text { PlusRide }\end{array}$ & $\begin{array}{l}\text { - higher friction resistance } \\
\text { - traffic noise reduction } \\
\text { - deicing characteristics } \\
\text { - increased road life (debatable) }\end{array}$ \\
\hline & CRAC & - superior ice disbonding properties \\
\hline \multirow{2}{*}{ wet process } & $\begin{array}{l}\text { SAM } \\
\text { SAMI }\end{array}$ & $\begin{array}{l}\text { - retards reflection cracking } \\
\text { - resists rutting and aging } \\
\text { - improved skid resistance (debatable) } \\
\text { - increased road life } \\
\text { - improved fatigue properties }\end{array}$ \\
\hline & PARC & $\begin{array}{l}\text { - no spray or splash } \\
\text { - improved drainage } \\
\text { - reduced light reflection from wet pavement } \\
\text { - reduced tire rolling noise } \\
\text { - low cost }\end{array}$ \\
\hline both processes & & - removes a waste product (scrap tires) from landfills \\
\hline
\end{tabular}


binder for pavements. Although certain advantages are evident, the reasons outlined in section 2.5 discourage widespread use of CRM asphalt pavements.

\subsection{Potential Disadvantages of CRM Asphalt Concrete}

The main disadvantage of CRM asphalt cement is the increased cost of pavements using this binder (see next section). Other problems have been encountered in the construction of CRM asphalt concrete test sections which include:

- pick up while compacting with rubber tired rollers

- higher compaction tumperatures needed

- plugging of screens due to higher viscosity binder

- chip loss in low or non traffic areas

- uncertainty of emission effects on workers during construction of the pavement

- $\quad$ stripping

- uncertainty of improved performance

- rubberized asphalt binder must be used within bours of production due to temperature-time properties

- lack of design criteria and nonconventional testing methods

Another concern is whether CRM asphalt concrete pavements are recyclable. If CRM asphalt concrete turns out to be unrecyclable, a solid waste problem of several magnitudes larger will be realized and will effectively kill any intended use of this product. No attempts at addressing this problem could be found in the literature although it is known that MTO has tried recycling part of their test section near Thamesville, Ontario. 


\subsection{Economic Analysis of CRM Asphalt Concrete}

Although CRM asphalt concrete has higher initial costs it has the potential to be cost effective over the entire life cycle of the pavement. Hoyt et al., 1988 based cost estimates for CRM asphalt concrete on; (1) the cost of producing the CRM asphalt cement binder and (2) substitution of the cost of the CRM asphalt cement vinder for the cost of the asphalt cement in asphalt concrete unit prices. An additional $10 \%$ was added to the ccistruction costs due to a requirement for higher compaction te.nperatures and a possible greater compactive effort. The cost of CRM asphalt concrete compared to regular asphait concrete can be seen in Table 2.3.

For a breakdown on how these numbers were calculated refer to the report by Hoyt et al., 1988. Takpilou and Sainton (1993) attribute the increase in cost to the following factors.

\section{Wet System}

- Rubberized binder must be used within hours of its production; therefore the high cost of mobilizing the specialized equipment (blending unit, metering unit, storage tanks, etc.) at the production facility must be recovered in the cost per ton of rubberized binder used on that project.

- Licence foe for using the patented process. 
Table 2.3: In-Place Costs for Asphalt Concrete and CRM Asphalt Concrete (after Hoyt et al., 1988)

\begin{tabular}{|c|c|c|c|c|c|}
\hline & $\begin{array}{l}\text { Percent } \\
\text { Binder }\end{array}$ & $\begin{array}{c}\text { In-Place } \\
\text { Costs per } \\
\text { ton, } \\
\text { (\$rTon) }\end{array}$ & $\begin{array}{l}\text { Density } \\
\text { (lb/ti) }\end{array}$ & $\begin{array}{c}\text { Tons per } \\
\text { Square } \\
\text { Yard, } \\
\text { (TonS.Y.) }\end{array}$ & $\begin{array}{l}\text { In-Place } \\
\text { Costs per } \\
\text { Square Yd. } \\
\text { (\$S.Y.) }\end{array}$ \\
\hline $\begin{array}{l}\text { Asphalt } \\
\text { Concrete }\end{array}$ & 4.80 & 29.44 & 151.2 & 0.851 & 25.04 \\
\hline $\begin{array}{c}\text { CRM } \\
\text { AC }\end{array}$ & 5.23 & 47.25 & 144.y & 0.815 & 38.51 \\
\hline
\end{tabular}




\section{Dry System}

- Unique aggregate gradation.

- Introduction of crumb rubber to asphalt plants.

- Higher asphalt and filler content design requirements.

- Increase in mixing temperature

- Licence fee for using the patented process.

An equivalent uniform annual cost per square yand of each pavement over its life was calculated for four climate conditions. The projectid pavement life was determined by a computer program called ILLIPAVE. It was deiermined that CRM asphalt concrete was more cost effective in three of the four unique climatic zones (Hoyt et al. 1988).

Jacobson and Schnormeier (1989) determined that after 15 to 20 years, the CRM asphalt concrete pavement is $40 \%$ the cost of the standard. This value was based upon the difference between the cort of a standard chip seal and an asphalt rubber chip seal for pavement rehabilitation. Several field studies in the literature have shown that asphalt rubber chip seals have outlasted the standard chip seal by a factor of 2 to 3 times. Initial CRM asphalt concrete costs are twice as much as a conventional asphalt. However, all factors must be considered in pavement rehabilitation to determine the final cost numbers. Masters (1989) states that the additional costs of the CRM asphalt concrete versus the conventional methods ranges from $29 \%$ to $162 \%$ not taken life expectancy into account. He also reached the conclusion that in all cases, savings resulted using the CRM asphalt concrete rehabilitation systems compared to conventional systems. 
McQuillen et al. (1988) conducted an economic analysis of rubber-modified asphalt mixes manufactured by the dry process. The cost per ton of PlusRide at that time was $\$ 55.68$ compared to $\$ 39.00$ for conventional asphalt cement binder. Three different methods of comparing the costs were used. The first analysis used an assumed maintenance scenario and equal surfacing thicknesses to calculate the life required for equivalent annual costs. The second used equal surfacing thicknesses of rubber-modified and conventional aspialt pavements and only the capital cost to determine the required life for equivalent annual cost. The last method utilizet layer equivalency ratios to compare the capital costs of rubber-modified and conventional asphalt of unequal thicknesses (McQuillen et al.). It was concluded that the rubber modified asphalt mix was more cost effective than a conventional mix. This conclusion was based upon a computed life expectancy model by the Elastic Layer System Computer Program (ELSYM5). The conclusion that CRM asphalt concrete pavements is more cost effective is based on a pavement life for the rubber modified mixes of 20 to 23 years when compared with 15 years for a conventional mix. Also, the required thickness of a rubber modified mix can be reduced by 1.2 to 1.4 times compared with the conventional mix if the equivalency factors are used.

Although initial costs are higher, the use of CRM asphalt concrete appears to be economically feasible if the life expectancy predictions are reliable. 


\subsection{Conclusions of the Literature Review}

The preceding review of available literature has permitted conclusions to be drawn regarding the use of rubber in asphalt. The following major conclusions have been derived:

- scrap tires present a major solid waste disposal problem where CRM asphait concrete potentially offers a feasible solution to this dilemma,

- CRM asphalt concrete mixes tend to offer higher stability and fatigue resistance in laboratory testing,

- field performance of CRM asphalt concrete mixes have shown (in some cases) an improved service life over conventional mixes,

- CRM asphalt concrete overlays are effective in retarding reflective cracking in Arizona,

- CRM asphalt concrete can be placed with existing compaction equipment,

- the initial costs of CRM asphalt concrete are higher than conventional asphalt concrete, and

- gap graded aggregate mixes are employed to allow room for the rubber particles.

With these conclusions in mind the objective of this experiment-based study was to develop two CRM asphalt concrete mixes, that will perform better or at least as good as standard mixes. The Marshall method (SMA) and CSTT methods (LAM) of mix design were used. A performance based lesting plan was also devised on which to evaluate the CRM asphalt concrete mixes versus the control mix. Once the mixes have 
been fully evaluated, a dependable and feasible pavement system could be designed and made available for future full-scale field testing. 


\section{Chapter 3}

\section{TESTING PROGRAM OVERVIEW}

\subsection{Testing Philosophy}

Given the need for testing crumb rubber modified asphalt systems versus conventional flexible asphalt concrete systems a testing program was designed to obtain meaningful comparisons between the two pavement types. The following are mix designs and test methods available in engineering practice:

\section{Mix Desions}

- Marshall mix design. Once the aggregate gradation is selected, this method is used to determine optimum asphalt content in order to produce a mix for reliable field performance.

- Hveem mix design. Also used for construction design of hot-mix paving, but is not as popular.

\section{Test Methods}

- Laboratory performance related testing. This approach, though not yet standardized, 
is rapidly gaining acceptance by research organizations to better simulate field conditions and therefore predict performance. The Strategic Highway Research Program (SIRP) project A-003A was formulated to develop test methods suitable for standardization (Monismith et al. 1991). Similar efforts are under way in Europe to standardize performance related testing systems throughout the European community.

- Full-scale accelerated load tests. This is the next step in the performance related testing process. Full-scale accelerated load tests such as the circular track method are in use by France (LCPC, Laboratoire Central des Ponts et Chausstes) and Spain (CEDEX pavements test track). As well, an accelerated load facility (ALF) has been developed in Australia and implemented also in the United States.

- Full-scale field tests. Trial test sections have been constructed and subjected to normal traffic flows. These test sections are closely monitored to determine field performance. One of the largest full-scale field test facilities in the world was constructed recently near Minneapolis, Minnesota. This facility was constructed as a traffic controlled bypass section of an interstate highway.

The approach adopted for this laboratory research program (see figure 3.1 ) is similar to the SHRP plan. Two different mixes have been evaluated in this research. A stone mastic asphalt (SMA) mix incorporating crumb tire rubber was designed to be used as a surface layer. A previously designed Large Aggregate Mix (LAM) was modified by adding crumb tire rubber to be used as a thick base layer for the asphalt concrete pavement system. In the initial mix design phase the Marshall method was used to select 


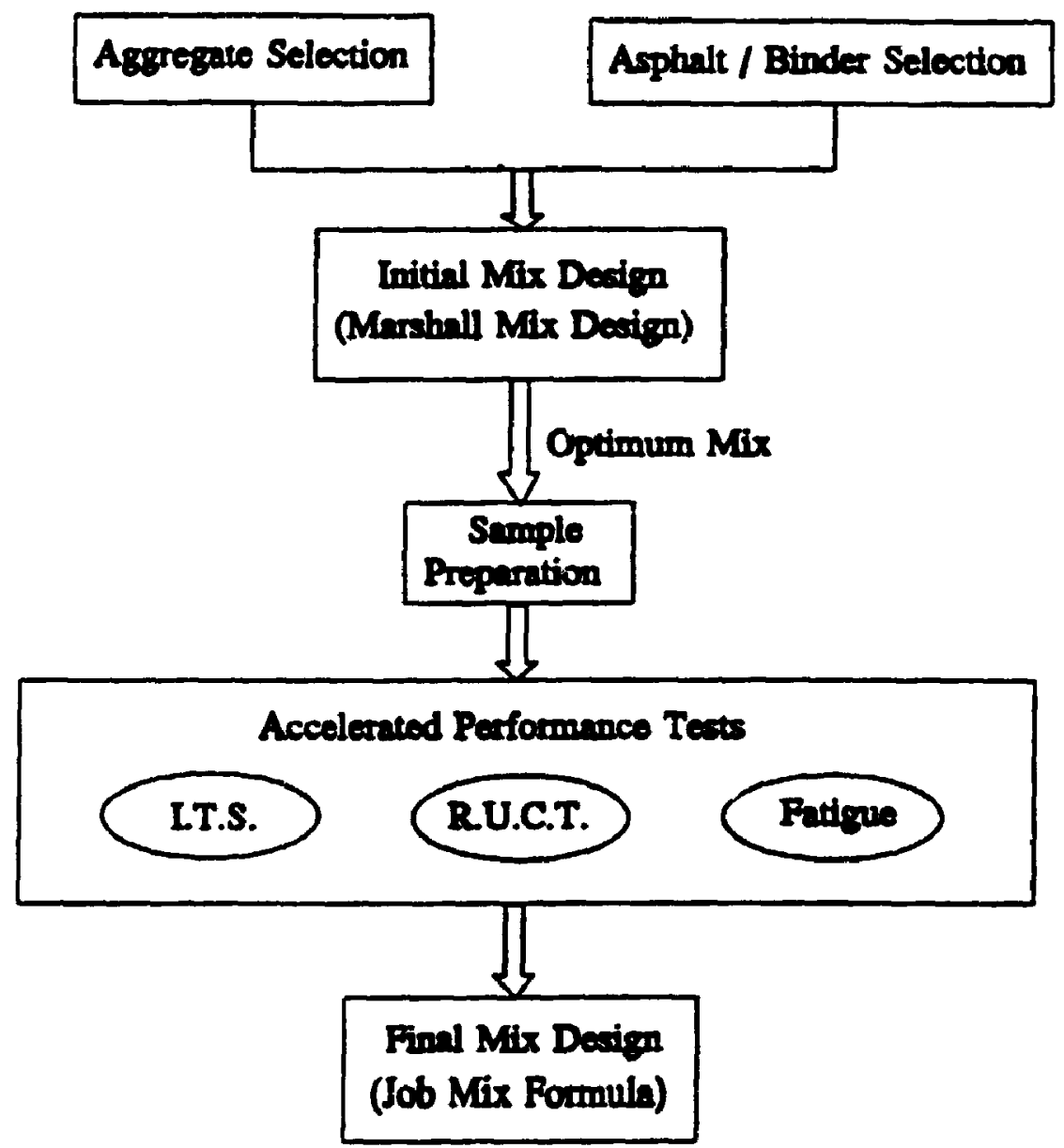

Figure 3.1: Testing Philosophy for SMA mixes

I.T.S. = Indirect Tensile Strength

R.U.C.T. = Repettive Uniaxdal Compression Test 
the optimum asphalt content for each type of SMA mix (control and CRM). When the optimum mix was determined, accelerated performance tests were conducted and comparisons made. The mix design for the LAM has already been evaluated at NRC by El Hussein et al. (1993). Therefore, the mix evaluation started in the sample preparation phase according to the testing philosophy flow chart. The LAM is subjected to the same performance tests and evaluated in the same manner as the SMA mixes.

Full-scale field test are useful for correlating laboratory data to field conditions. However, only laboratory testing was used in this research due to the extremely high costs of field tests and the time consuming nature of this approach. It is, however, expected that field tests of SMA and LAM rubber asphalt will be performed in the near future based on these results. It must be realized that a research program of this type would produce minimal results in the first 3-4 years. Also, it is difficult to draw meaningful comparisons between different roadway sections due to variability in subgrade conditions, traffic patterns, climate, and water table characteristics. In spite of these complications, the observations and results of the performance of real road sections are invaluable and can not be replaced by laboratory testing.

\subsection{Aggregate Gradation Selection for use with CRM Asphait Cement}

It was noted after review of the current literature that gap-graded mix designs are most commonly used when working with CRM asphalt cement mixes. The extra space in the gradation is used to incorporate the rubber particles in the voids of the mix and not in contact between the aggregates. The incorporation of the rubber particies in the voids 
helps to prevert a "spongy" mix that rebounds after compaction. Therefore, an SMA mix was selected for use with a CRM asphalt cement binder. Due to the relatively high cost of this premium mix (it might require special aggregate), it is expected that it will be used in practice as a finishing layer in the pavement system, allowing for application of thin lifts. The large aggregate mix, designed at CSTT/NRC by El Hussein et al. will be used as a base layer. This mix is also a gap-graled mix and is not expected to be as expensive as SMA mixes. Both of these mixes have shown superior rutting resistance and with the incorporation of CRM asphalt cement should provide a very sound and long-lasting roadway. A description of both stone mastic asphalt (SMA) and the large aggregate mix (LAM) follows in the next sections.

\subsubsection{SMA Mlx}

Splittmastixasphalt (SMA) was invented in Germany about 25 years ago to better resist the wear of studded tires (Bellin 1992). Studded tires are forbidden in most of the European countries except for example in Norway, where granite based SMA is used on the entire road network. SMA has been improved and used ever since, and is excellent for resisting permanent deformation (ie. rutting) and wear. Roads in Norway must be rehabilitated every 3-4 years because they allow the use of studded tires.

SMA (generally referred to in U.S. literature as stone matrix asphalt) is a gapgraded, dense, hot-mix asphalt with a large proportion of coarse aggregates (passing $2 \mathrm{~mm}$ ) limited to about 20 percent, all crushed material) and a rich asphalt cementfiller mastic. The course aggregate forms a high stability structural matrix and the engineered 
asphalt cement, fine aggregate, filler and stabiliration additive (fibre) form a maxtic binding the structural matrix together (Emery et al. 1993). The relatively uniform size and shape (preferably cubical) of the aggregate provide for -..-pllent point to point (surfaceisurface) contact which resists permanent deformations (see figure 3.2). It is the SMA requirement for cubical shaped aggregates (hard to obtain locally since most local quarry sources do not crush into cubical shaped particles), and the higher costs involved with SMA (usually around $20 \%$ due to premium materials) that it is not used much in North America. However, SMA trials in Ontario have proven successful with modifications to the European requirements (Emery et al. 1993).

An SMA design modelled on a mix reported by Bellin (1992) and produced with local aggregate supplies will be developed for use with a CRM asphalt cement binder. The mix design is presented in chapter 4 while the results are documented in the fifth chapter.

\subsubsection{Large Agrepate Mix}

The large aggregate mix (LAM) designed at CSTT/NRC (El Hussein et al. 1993) is also a gap-graded mix using aggregate stone with sizes up to $38 \mathrm{~mm}$. This mix was sesigned to resist premature rutting of pavements constructed using hot mix asphalt (HMA). Stone-to-stone contact of the large aggregate provides similar resistance to rutting as SMA mixes (see figure 3.3). Since Marshall compaction and mix design procedures can only support paving mixes with aggregate particles less than $19 \mathrm{~mm}$ (3/4 inch), it was necessary to use a gyratory compactor with $15.2 \mathrm{~cm} \mathrm{(6")} \mathrm{diameter} \mathrm{molds.}$ 


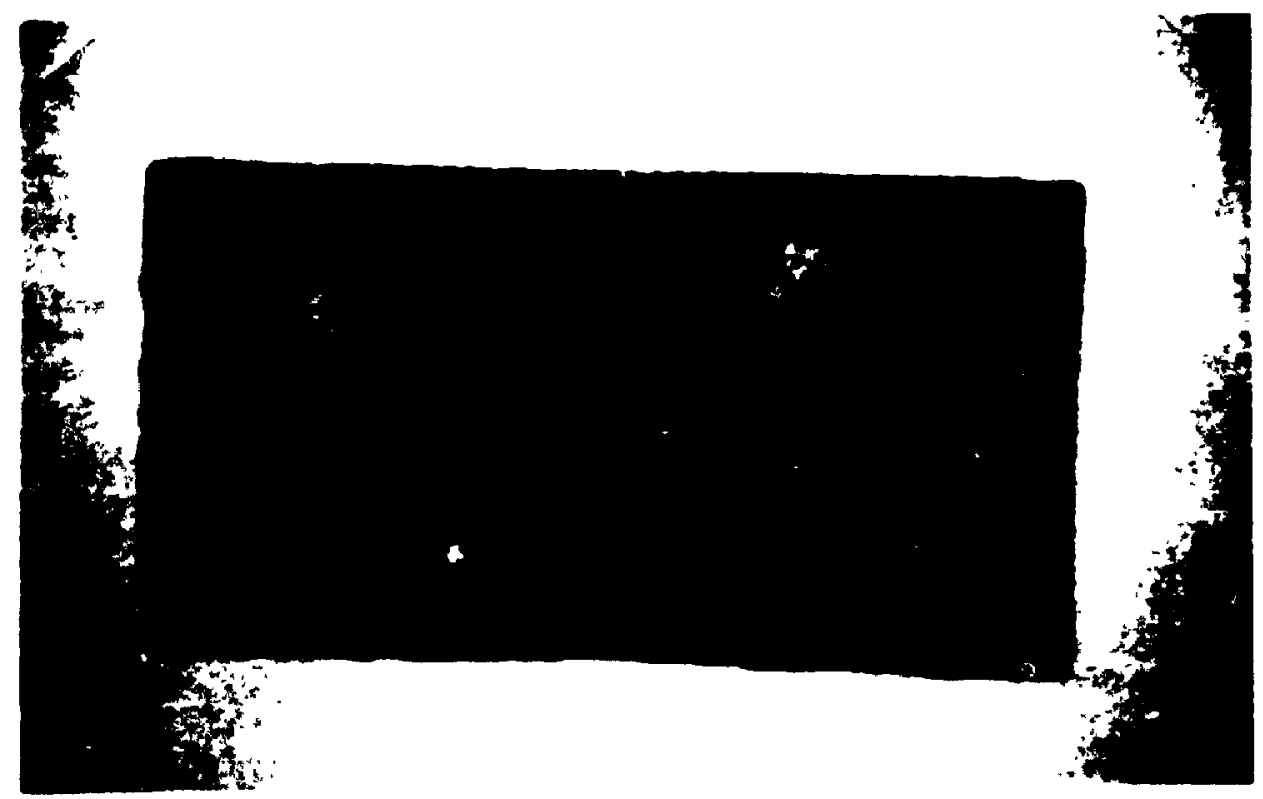

HMA

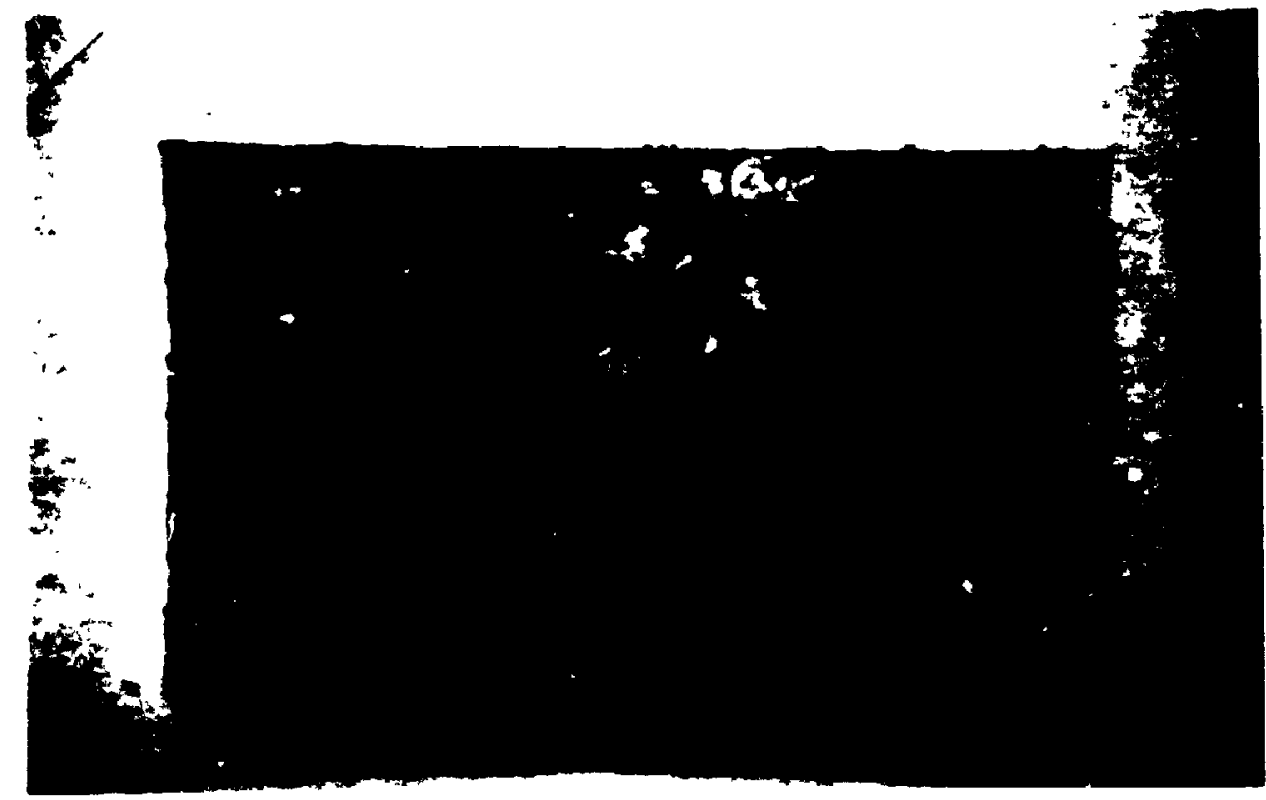

SMA

Figure 3.2: Comparison of Floating Course Aggregate in HMA with Stone-toStone Contact of SMA 


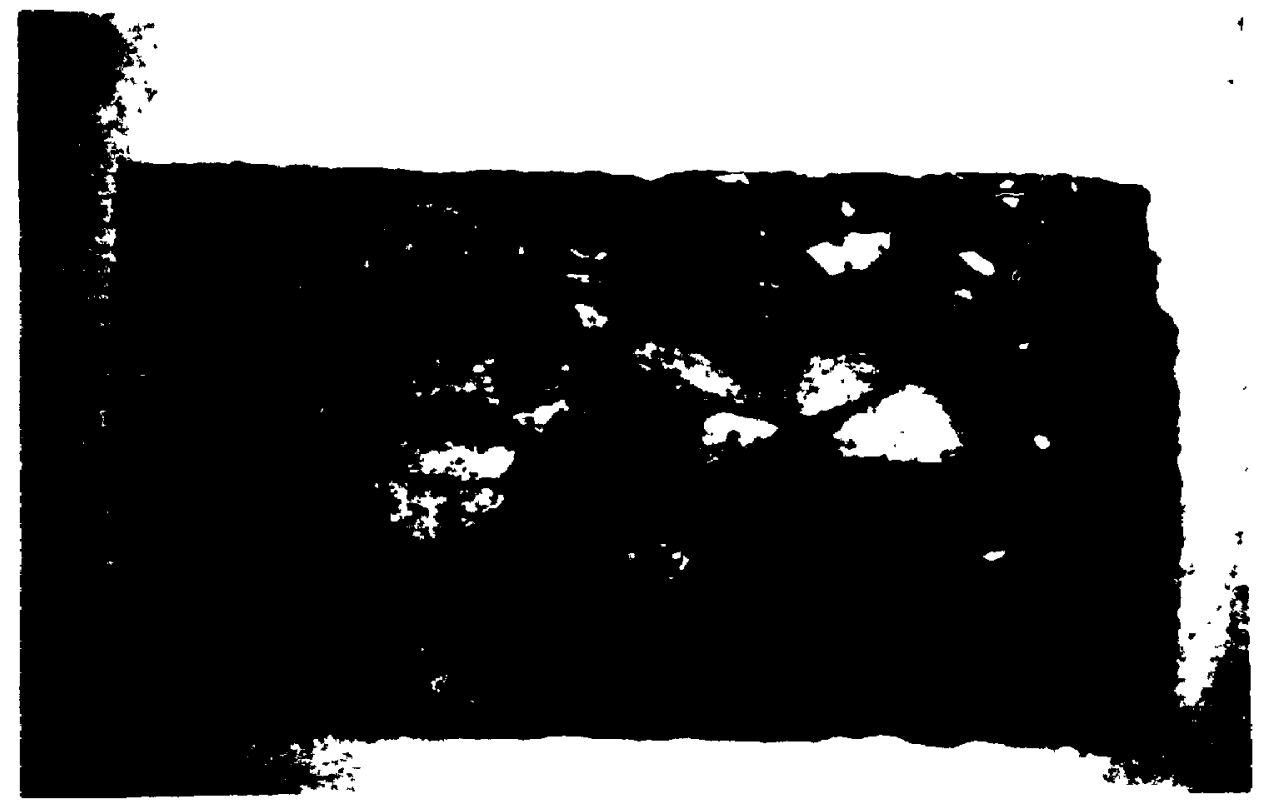

Figure 3.3: Stone-to-Stone Contact of the LAM 
The design of the LAM can be obtained from the report by El Hussein et al. (1993). Aggregate gradations and mix specifications are presented in chapter 6. 


\section{Chapter 4 \\ MARSHALL MIX DESIGN PROGRAM \\ FOR SMA MIX}

In order to design an improved asphalt concrete pavement, mixes must be developed for both the control samples and for samples containing scrap tire rubber. Two of the most popular mix design programs in use today are the Marshall and Hveem methods. A study by Kandhal and Kochler (1985) has shown that the Marshall method is the most commonly used mix design method in the United States with 76 perceni o: all States using it. The Marshall mix design method is employed to produce the SMA mixes for this study due to the availability of equipment and its simplicity. The Asphalt Institute (1988) states that "The overall objective for the design of asphalt paving mixes is to determine an economical blend and gradation of aggregates (within the limits of the project specifications) and asphalt that yields a mix having:

(1) Sufficient asphalt to ensure a durable pavement.

(2) Sufficient mix stability to satisfy the demands of traffic without distortion or displacement.

(3) Sufficient voids in the total compacted mix to allow for a slight amount of 
additional compaction under traffic loading without flushing, bleeding, and the loss of stability, yet low enough to keep out harmful air and moisture.

(4) Sufficient workability to permit efficient placement of the mix without segregation."

This chapter presents the Marshall mix design program and the criteria on how the SMA mixes were designed.

\subsection{Selection of Materials}

A stone mastic asphalt mix (SMA) was used in this study due to favourable characteristics of the mix. SMA, as explained earlier, is a gap-graded, dense, hot-mix asphalt with a large proportion of coarse aggregate and a rich asphalt cement/filler mastic. The coarse aggregate, through point-to-point contact, forms a high stability structural skeleton to resists load-induced shear deformation (Figure 3.2). In a review of practical experience with SMA in Denmark, Finland, Germany, Netherlands, Norway, Sweden and Japan, by Emery et al. (1993), the following advantages of SMA were listed:

"(1) high stability (resistance to rutting) combined with good durability (20 to 40 percent longer life than conventional mixes)

(2) good resistance to studded tir: wear

(3) good '́ictional properties ('skid' resistance)

(4) thin surface course use allows relatively low costs

(5) good placement and compaction characteristics." 
The features outlined above aided in the decision to develop a suitable SMA mix. however the most important characteristic of SMA is the gap gradation of the aggregates. The concept being sought in the new design is that the rubber particles introduced into the mix will reside in the voids around the stone aggregate (without preventing stone to stone contact) and will improve the resistance to rutting of the mix due to increased flexibility. The selection of materials for designing an SMA mix are presented in the following sections.

\subsubsection{Aggregates}

The coarse and fine aggregates used in this investigation were obtained from the H J McFarland Construction Co. in Nepean, Ontario. The stone mix prepared by McFarland to meet MTO specifications for HL3 asphalt concrete, crusher screcnings, and sand used for the mix design had the gradations shown in Table 4.1.

The bulk relative density (BRD) of the coarse aggregate is 2.657 as determined by MTO standard test LS-604 specified in the MTO Laboratory Testing Manual. The fine aggregate has a BRD of 2.658 as resolved by LS-605.

Th: BRD of the limestone filler, which is used to meet the high percentage of aggregate passing sieve $\$ 200(0.09 \mathrm{~mm})$, was determined using a hydrometer analysis. The resulting value was 2.76 and the grain size analysis is presented in Figure 4.1. The filler was obtained from Permanent Lafarge Co. of Navan, Ontario. 
Table 4.1: Aggregate Fractions Gradation

\begin{tabular}{|c|c|c|c|}
\hline \multirow[b]{2}{*}{$\begin{array}{c}\text { Sieve Size } \\
\text { (mm) }\end{array}$} & \multicolumn{3}{|c|}{ Percent Passing } \\
\hline & HL3 & $\begin{array}{l}\text { Crusher } \\
\text { Screenings }\end{array}$ & Sand \\
\hline 16.0 & 100 & - & - \\
\hline 11.0 & 90 & - & - \\
\hline 8.0 & 47 & 100 & - \\
\hline$\# 4$ & 4 & 93 & 100 \\
\hline$\# 10$ & 1 & 56 & 93 \\
\hline$\# 20$ & - & 34 & 80 \\
\hline$\# 40$ & - & 22 & 49 \\
\hline$\# 60$ & - & 15 & 21 \\
\hline$\# 100$ & - & 10 & 5 \\
\hline$\# 200$ & - & 5 & 1 \\
\hline
\end{tabular}




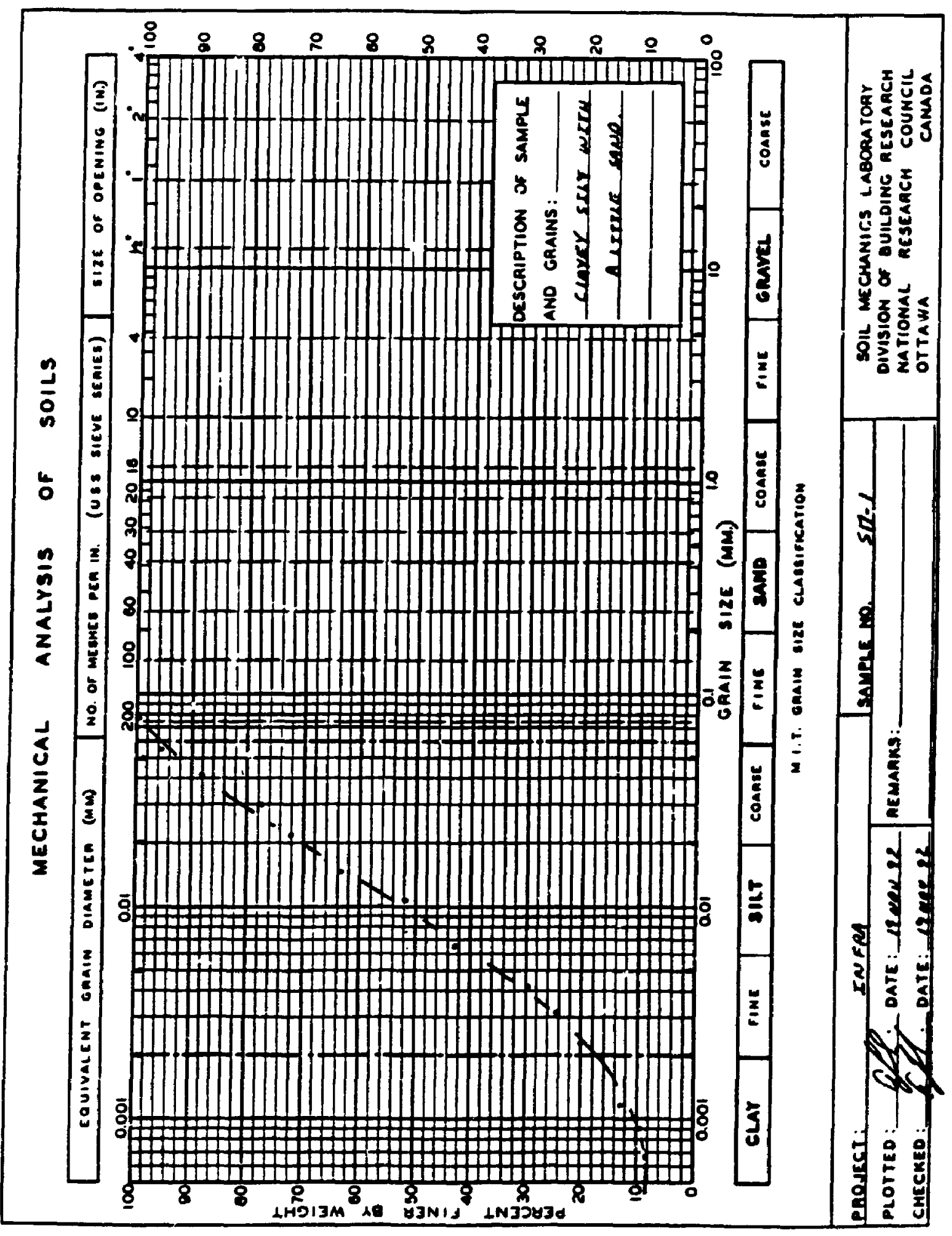

Figure 4.1: Grain Size Analysis of Filler Materia 


\subsubsection{Binder}

The selected asphalt binder, 85/100 Pen Asphalt (CAS 8052-42-4), was supplied by Husky Oil of Calgary, Alberta. This type of asphalt cement was readily available and is the most commonly used type in the Ottawa region. The selected type of asphalt influences its degree of interaction with the rubber. Softer asphalt grades are preferred because of the increased viscosity resulting from the "blending" of asphalt and rubber. Typical grades used for CRM asphalt cement include 6070 up to 200/300 penetration asphalts.

A CRM asphalt cement bjader produced by Bitumar Inc. of Montreal, Quebec was also used for comparison with standard asphalt cement and the laboratory manufactured CRM asphalt cement binder. The Bitumar product is called ECOFLEX $85 / 100$ and contains $10 \%$ recycled scrap rubber. The Ecoflex process involves the complete dissolution of the crumb rubber to ensure permanent and irreversible homogeneity.

\subsubsection{Rubber}

It was determined from the literature review that the selection of rubber can influence the properties of the CRM asphalt cement blend to a significant degree (Chehovits 1989). Chebovits suggested that rubber used for asphalt-rubber should primarily be made from recycled pneumatic tires. It should also be ground on appropriate systems, and should be free from contaminants including mineral matter, fibre and metal. The rubber should be sufficiently dry to prevent foaming when added to hot asphalt. He suso stated that mineral contaminants should not exceed $0.25 \%$, the moisture content must 
be less than $0.75 \%$, and the rubber hydrocarbon content should be between 40 and $50 \%$. Cryogenically ground whole tire rubber produced by Recovery Technologies Inc. (Toronto) was selected for use in this project and meets all the former stated requirements. The suggested gradation of rubber particlo;s by Chehovits along with the gradation chosen (GTR-10) are presented in Table 4.2.

\subsubsection{Fibre}

SMA employs fibrous material to prevent asphalt cement runoff during production and laydown. A cellulosic based fibre was added to the mixture in the amount of $0.3 \%$ by total weight. The addition of cellulose fibres allows for a richer mastic in the mix by soaking up excess asphalt cement. This promotes a thicker film of binder which improves mix durability.

\subsection{Manufacture of Mixes}

The SMA mixes were made using standard Marshall compaction equipment. In determining the optimum asphalt content for each mix, a series of test specimens were prepared for a range of different asphalt contents usually from $2 \%$ below to $2 \%$ above expected optimum in $1 / 2$ percent increments. To provide adequate data, each specimen was made in triplicate for each asphalt content used. Therefore a total of 15 specimens were prepared for each mix ( 3 at 5 different asphalt contents). With six different mixes involved, a total of 90 specimens were compacted for the B.R.D., stability, and flow requirements of the mix design phase. Another 30 specimens of loose uncompacted mix 
Table 4.2: Rubber Gradation Specifications

\begin{tabular}{|cccc|}
\hline & \multicolumn{3}{c|}{ Percent Passing } \\
Sieve Size & Open-graded & Dense-graded & GTR-10 \\
\cline { 2 - 4 } No. 8 & 100 & 100 & 100 \\
No. 10 & 100 & 100 & $97-100$ \\
No. 16 & $75-100$ & $95-100$ & $\ldots$ \\
No. 20 & -- & -- & $0-75$ \\
No. 30 & $25-60$ & $70-100$ & $\ldots$ \\
No. 80 & $0-20$ & $0-20$ & $\ldots$ \\
No. 200 & $0-5$ & $0-5$ & $\ldots$ \\
\hline
\end{tabular}


were required to calculate the maximum relative densities (MRD). The equipment required for the preparation of test specimens can be found in section 3.04 of Manual Series No. 2 of the Asphalt Institute (Asphalt Institute 1988).

\subsubsection{Arpregate Grodition}

The gradation selected for this experiment was modelled according to an SMA gradation presented in a report by Bellin (1992). The aggregate blend and gradation specifications are shown in Table 4.3 and Figure 4.2 respectively.

In order to achieve this gradation, the available aggregates and screenings were sieved and put into designated containers. Each stone size, defined in the aggregate blend down to $2 \mathrm{~mm}$ in size, was kept separately. The requirement for stone size passing the $2 \mathrm{~mm}$ sieve and retained on the $0.09 \mathrm{~mm}$ sieve was satisfied by the use of sand, while the material passing the $0.09 \mathrm{~mm}$ sieve was achieved using limestone filler. Therefore, the required fraction of each aggregate could be portinned and mixed as required. The dashed line in Figure 4.2 represents the resulting gradstion. The gradation of the selected mix tends to the fine side of the gradation limits. This selection was dictated by the economic use of available aggregate in the Otawa region.

\subsubsection{Asphalt-Rubber Binder Preparation}

Lytton and Roberts (1987) stated that reaction time: in the labrratory studies have varied from 0.5 to $2 \mathrm{hrs}$. at temperatures that typirally ranged from $163^{\circ} \mathrm{C}\left(325^{\circ} \mathrm{F}\right)$ to $232^{\circ} \mathrm{C}\left(450^{\circ} \mathrm{F}\right)$. A reaction time of $1 \mathrm{hr}$ at $191^{\circ} \mathrm{C}\left(375^{\circ} \mathrm{F}\right)$ is recommended in their study. 
Table 4.3: Aggregate Blend

\begin{tabular}{|cc|}
\hline Sieve Size & \% Passing \\
\hline $16 \mathrm{~mm}$ & 100 \\
$11 \mathrm{~mm}$ & $90-100$ \\
$8 \mathrm{~mm}$ & $50-80$ \\
$5 \mathrm{~mm}$ & $30-50$ \\
$2 \mathrm{~mm}$ & $20-30$ \\
$0.09 \mathrm{~mm}$ & $8-13$ \\
\hline
\end{tabular}


Sieve Size and Designation No.

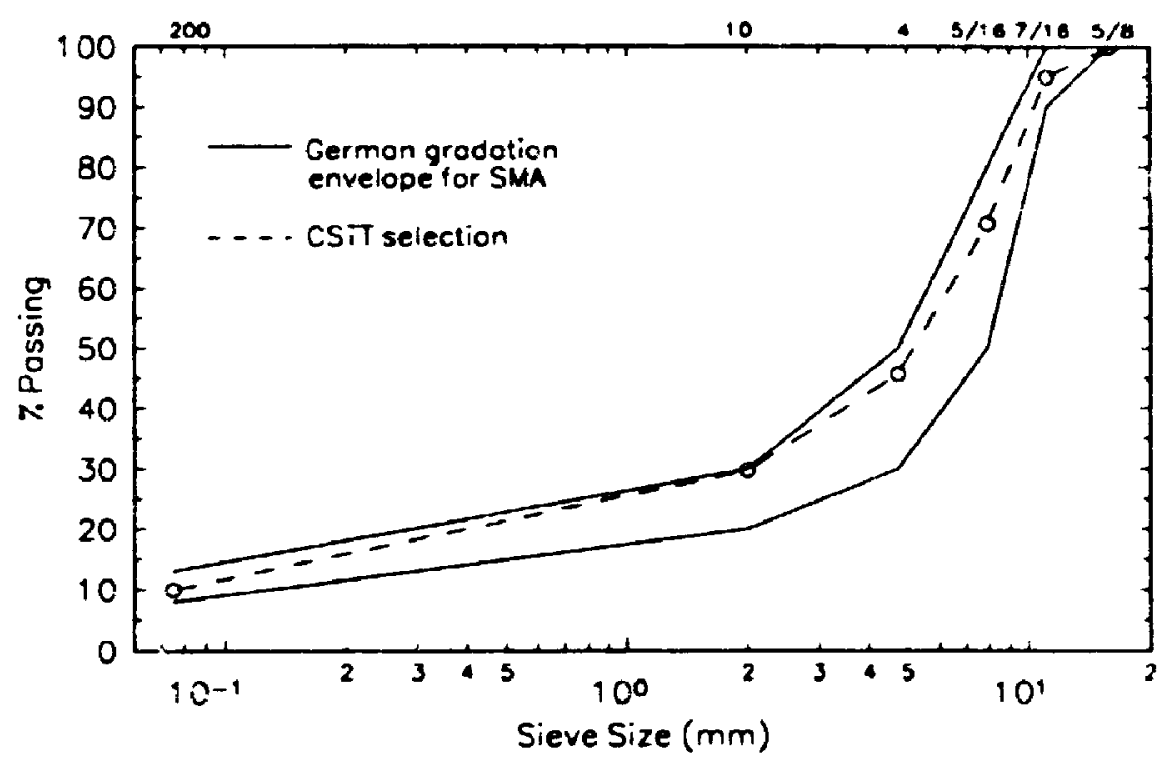

Figure 4.2: Gradation Specincation for Splittmastixasphalt (SMA) Mix Design 
Reaction time is the length of time that the crumb rubber particles are digesting in the asphalt cement at elevated temperatures while undergoing continuous stirring. Therefore, the CRM asphalt cement was produced as follows:

- The asphalt was placed in a $2000 \mathrm{ml}$ beaker and then positioned on a hot plate. The asphalt was heated and stirred until a temperature of $191^{\circ} \mathrm{C}\left(375^{\circ} \mathrm{F}\right)$ was achieved.

- Rubber, in the required proportion, was added to the asphalt and continuously stirred for $1 \mathrm{hr}$. This was accomplished through the use of a two bladed electric stirrer. Partial digestion of the crumb rubber particles occurred at this stage.

- The CRM asphalt cement was then portioned and stored for use at a later date.

Some researchers have been using the CRM asphalt cement as soon as it is produced to manuiacture samples. While this is desirable it is more feasible to batch produce the CRM asphalt cement for reheating. This approach was adopted by Lytion and Roberts (1987) and produces a more uniform and consistent binder from sample to sample.

\subsection{Mbding Conditions}

To produce a quality rubberized SMA mix certain procedures must be followed. Firstly, the mixing temperatures required are higher than for regular asphalt cement mixes. After reviewing the literature it was decided to employ mixing temperatures used by Vallerga (1C81) since approximately these conditions seemed to be used by most 
researchers. The binder and aggregate were heated to $177^{\circ} \mathrm{C}\left(350^{\circ} \mathrm{F}\right)$. Once this had been achieved the aggregate and binder were mixed in a large metal bowl as per MTO standard LS-261. In order to prevent segregation of fines in the mix, the filler was added after partial coating of the aggregates was achicved. Adding the fines (filler) after coating the coarse aggregates with asphalt cement prevents the filler from forming a layer around the coarse aggregates. A coating of filler on the coarse aggregate would result in poor asphalt to aggregate contact which in turn results in ầi inferio- mix.

\subsubsection{Compaction Conditions}

After the corapletion of mixing, the samples were spooned into preheated Marshall molds. The Marshall compactor used allowed for the compaction of two samples simultaneously. The mixture was compacted with seventy-five blows on each side, corresponding to the Asphalt Institute guidelines for heavy traffic conditions. Since the compaction temperature of $163^{\circ} \mathrm{C}\left(325^{\circ} \mathrm{F}\right)$ suggested by Vallerga could not be achieved, a temperature of $149^{\circ} \mathrm{C}\left(300^{\circ} \mathrm{F}\right)$ was settled on. Using Vallerga's sugges ed asphalt and aggregate temperatures resulted in a temperature of around $300^{\circ} \mathrm{F}$ when compaction was commenced. After compaction the samples were allowed to cool and then extracted from the molds. The compaction procedure also followed MTO specification IS-26I. The testing procedure used for selecting the proper asphalt content is outlined in the next section (4.3). 


\subsection{Marshall Testing Procedure}

All tests performed on the samples were conducted in accordance with MTO specifications. A bituminous mix form is shown in LS-262 (Figure 4.3). No special provisions were taken when testing CRM asphalt cement specimens.

\subsubsection{Bulk Relaúve Density}

The specimens were tested in accordance with MTO LS-262 (Bulk Relative Density for Compacted Bituminous Mixtures). This test was performed one week after compaction. All loose particles on wis surface of the specimen were carefully brushed off prior to testing.

\subsubsection{Mndimum Relative Density}

The procedure, as outlined in MTO LS-264 (Theoretical Maximum Relative Density of Bituminous Paving Mixtures), was followed for this test. One sample was tested for each different binder and binder percentage used.

\subsubsection{Stablitity and Flow}

Stability and flow tests were performed as per MTO LS-263 (Method of 'Test for Resistance to Plastic Flow of Bituminous Mixtures using Marshall Afparatus). Three samples were tested for each binder percentage used. 


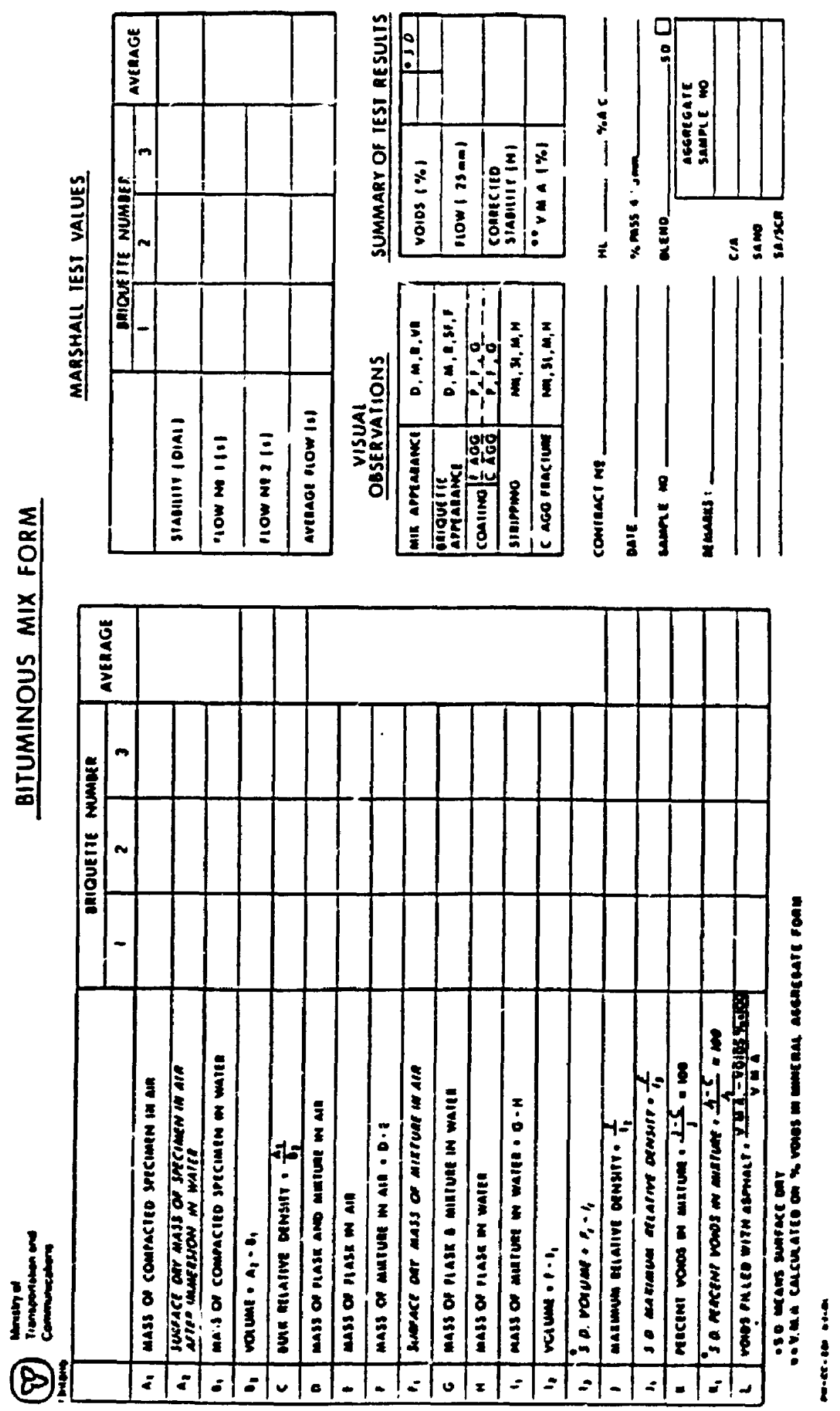

Figure 4.3: MTO Marhall Mix Design Form 


\subsubsection{Air Volds (AV) and Volds in Mineral Aggregate (VMA)}

The AV's were determined by method MTO LS-265 (Determination of Percent Air Voids in Compacted Dense Bituminous Pavemient Mixtures). One AV percentage was calculated for each different binder percentage.

Test method MTO LS-266 (Determination of VMA in Compacted Bituminous Mixtures) was used for VMA calculations. One number was calculated for each binder percentage. 


\section{Chapter 5 \\ MARSHALL MIX DESIGN RESULTS \\ FOR SMA MIX}

This chapter presents the major results of the Marshall mix design program for the control, Ecoflex, and CRM asphalt cement SMA mixes as described in the previous chapter.

The results of each of the mixes (Control, Ecoflex, 5\%, 10\%, 15\%, and 20\% rubber) are presented first with comparisons between the mixes documented in the latter part of this chapter. A more detailed treatment and analysis is carried out in Cnapter 9.

Using the Marshall design criteria (Table 5.1) for heavy traffic and following the procedures for Marshall mix design, the optimum percentage of binder can be determined for the control, Ecoflex, and rubber mixes. The values for BRD, \%AV, \%VMA, stability and flow are then determined at the optimum percentage, and are presented in Table 5.3.

The design criteria have been altered to accommodate CRM asphalt cement mixes as per Chehovits (1989). Also the voids in mineral aggregate criteria may be relaxed to a minimum of 12\% (Foster 1986). Foster has shoivn that VMA does not correlate well with performance and that specifying a minimum VMA as high as $14 \%$ cannot be justified. 
Table 5.1: Marshall Design Criteria

\begin{tabular}{|c|c|c|}
\hline Marshall Method Mix & \multicolumn{2}{|c|}{ Heavy Traffic } \\
\hline Criteria & Min. & Max. \\
\hline \# of blows & & \\
\hline Stability (lbs) & 1800 & - \\
\hline Flow (0.01 in) & 8 & 22 \\
\hline$\%$ Air Voids & 3 & 5 \\
\hline \% VMA (3/4 NMA) & 14 & -- \\
\hline
\end{tabular}




\subsection{Optimum Mix Determination for Control and Rubber Samples}

The mix design results for the control, Ecoflex, and CRM SMA mixes are presented in Table 5.2. These results are subsequently plotted in Figures 5.2 to 5.7 respectively and the values are connected using a "best-fit" curve. From these mix design results the optimum asphalt content for each mix was determined. Once this was accomplished, performance testing was carried out on the optimum sample of each mix and comparisons were made between the various mixes.

Using the Marshall design criteria (Table 5.1) Sor heavy traffic and following the procedures for Marshall mix design, the optimum percentage of binder was determined for the control, ecoflex, and CRM mixes. The optimum binder percentage was obtained by considering the following properties:

- maximum stability

- $\quad$ maximum B.?D

- median of limits given for the percentage of AV.

The optimum asphalt content of the mix was then calculated as the numerical average of the values for the asphalt content determined for each of the above.

The optimum percentage of binder calculations are piesented in Table 5.3. The mix properties, ie. BRD, \%AV, etc., were then determined at the optimum percentage, and are also presented in Table 5.3. A summary of the results at this stage are outined in the next section. 
Table 5.2 - Results from Marshall, BRD and MRD tests.

\begin{tabular}{|c|c|c|c|c|c|}
\hline \multirow[b]{2}{*}{$\%$ Binder } & \multicolumn{4}{|c|}{ 0\% GTR-10 } & \multirow[b]{2}{*}{ \%VMA } \\
\hline & BRD & Stability & Flow & $\% A V$ & \\
\hline $\begin{array}{l}4.5 \\
5.0 \\
5.5 \\
6.0 \\
6.5\end{array}$ & $\begin{array}{l}2.4343 \\
2.4690 \\
2.4623 \\
2.4353 \\
2.4268\end{array}$ & $\begin{array}{l}2679 \\
2425 \\
1886 \\
1597 \\
1438\end{array}$ & $\begin{array}{l}0.1495 \\
0.1345 \\
0.1879 \\
0.2227 \\
0.2074\end{array}$ & $\begin{array}{l}2.5 \\
0.8 \\
0.2 \\
0.1 \\
0.3\end{array}$ & $\begin{array}{l}12.7 \\
11.9 \\
12.6 \\
14.0 \\
14.8\end{array}$ \\
\hline \multicolumn{6}{|c|}{ 5\% GTR-10 } \\
\hline $\begin{array}{l}4.0 \\
4.5 \\
5.0 \\
5.5 \\
6.0\end{array}$ & $\begin{array}{l}2.3500 \\
2.3900 \\
2.4340 \\
2.4310 \\
2.4220\end{array}$ & $\begin{array}{l}3272 \\
3111 \\
3078 \\
2735 \\
2165\end{array}$ & $\begin{array}{c}0.1039 \\
0.1132 \\
0.1076 \\
0.1288 \\
0.1528 \\
\\
\text { GTR-10 }\end{array}$ & $\begin{array}{l}6.8 \\
4.4 \\
2.0 \\
1.3 \\
-\end{array}$ & $\begin{array}{l}15.4 \\
14.3 \\
13.1 \\
13.7 \\
14.5\end{array}$ \\
\hline $\begin{array}{l}4.0 \\
4.5 \\
5.0 \\
5.5 \\
6.0\end{array}$ & $\begin{array}{l}2.3200 \\
2.3790 \\
2.3780 \\
2.3960 \\
2.3760\end{array}$ & $\begin{array}{l}3281 \\
3423 \\
3087 \\
2558 \\
2356\end{array}$ & $\begin{array}{l}0.1222 \\
0.1269 \\
0.1457 \\
0.1413 \\
0.1478 \\
\\
\text { GTR-15 }\end{array}$ & $\begin{array}{l}8.1 \\
5.4 \\
3.9 \\
2.5 \\
3.5\end{array}$ & $\begin{array}{l}16.3 \\
14.6 \\
15.1 \\
14.9 \\
16.1\end{array}$ \\
\hline $\begin{array}{l}4.0 \\
4.5 \\
5.0 \\
5.5 \\
6.0\end{array}$ & $\begin{array}{l}2.2900 \\
2.3200 \\
2.3100 \\
2.3300 \\
2.3300\end{array}$ & $\begin{array}{l}2618 \\
2689 \\
2476 \\
2414 \\
2170\end{array}$ & $\begin{array}{l}0.1300 \\
0.1300 \\
0.1500 \\
0.1400 \\
0.1600 \\
\\
\text { GTR-10 }\end{array}$ & $\begin{array}{l}9.1 \\
7.4 \\
6.9 \\
5.8 \\
4.8\end{array}$ & $\begin{array}{l}17.3 \\
16.7 \\
17.4 \\
17.4 \\
17.6\end{array}$ \\
\hline $\begin{array}{l}4.0 \\
4.5 \\
5.0 \\
5.5 \\
6.0 \\
\end{array}$ & $\begin{array}{l}2.2400 \\
2.2490 \\
2.2805 \\
2.2747 \\
2.2867\end{array}$ & $\begin{array}{l}2205 \\
2039 \\
2478 \\
2057 \\
2082 \\
\end{array}$ & $\begin{array}{l}0.1920 \\
0.1590 \\
0.1371 \\
0.1729 \\
0.1809\end{array}$ & $\begin{array}{l}9.8 \\
7.8 \\
7.9 \\
6.1\end{array}$ & $\begin{array}{l}19.2 \\
19.3 \\
18.6 \\
19.3 \\
19.3\end{array}$ \\
\hline
\end{tabular}


Table 5.3 - Asphalt properties at optimum binder content.

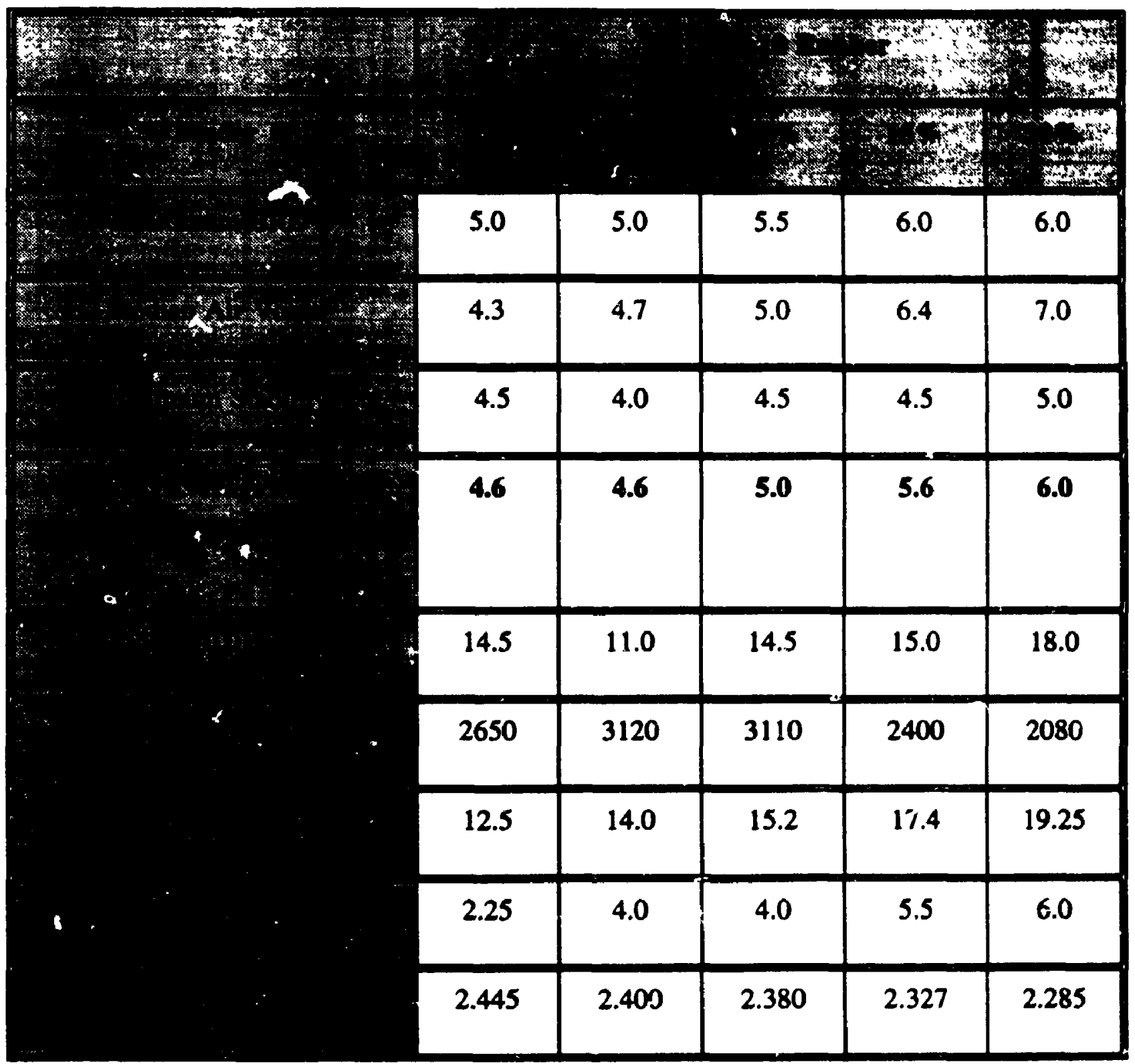




\subsection{Summary of Results}

In order to better visualize the effects of adding rubber to the SMA mix, the results of Table 5.3 are plotted in Figure 5.1. A quick discussion of the results follows. A more detailed analysis is presented in Chapter 9.

\section{S.2.1 Bulk Relative Density}

The BRD of the CRM asphalt cement samples decreased as the percentage of rubber increased. One cause may be due to higher concentrations of scrap rubber and undigested rubber particles occupying spaces meant for aggregates which creates Marsuall specimens that are not as dense due to an increase in height. Although the "gapgradation" is ideal for incorporating a certain amount of rubber particles in void spaces, there may not be enough space for higher concentrations of crumb tire rubber in this particular SMA mix. One method to alleviate such a problem is to remove aggregate fractions of the same size as the rubber gradation to make more space available for the rubber particles. Removing certain aggregate fractions is very time consuming and impractible.

Also, the rubber particles have a lower specific gravity than stones which will reduce the BRD of the specimen.

\section{2 .2 SLability and Flow}

Figure 5.1 shows that the stability of the CRM asphalt cemen: mixes increased with rubber content increases of up to about $10 \%$ and then the stability subsequently 
decreased with further rubber content increases up to $15 \%$ and $20 \%$. The increase in stability is due to the enhanced viscosity and stiffness of the binder due to the addition of rubber. This more viscous binder is at an optimum at $10 \%$ rubber and the extra rubber (ie. 15 and 20\%) might act to destabilize the sample at higher concentrations.

The flow values of the mixes decreased up to approximately $10 \%$ of rubber content and then subsequently increased. This is a mirror process of what happened to the mix stability and is also attributed to a more viscous binder less susceptible to flow.

\subsubsection{Air Voids}

The AV increased linearly as th: amount of nubber was increased. This may be attributed to the rebounding of the sample, due to the presence of rubber particles, after application of the compaction hammer. Although the rebound would be small, it still may be enough to prevent optimal compaction and thus results in increased AV's.

\subsubsection{Volds in Mineral Aggregate}

The VMA also increased as the percentage of rubber increased, however, this can also be attributed to the increase in AV's. Since the VMA is described as "the volume of intergranular void space between the aggregate particles of a compacted paving mirture that includes the air voids and the effective asphalt content, expressed as a percent of the total volume of the sample" (Asphalt Institute 1988), it can be shown that by subtracting the percent of AV's from the percent VMA, the value for the effective asphalt content remains virtually unchanged (Table 5.4). This indicates that the change 

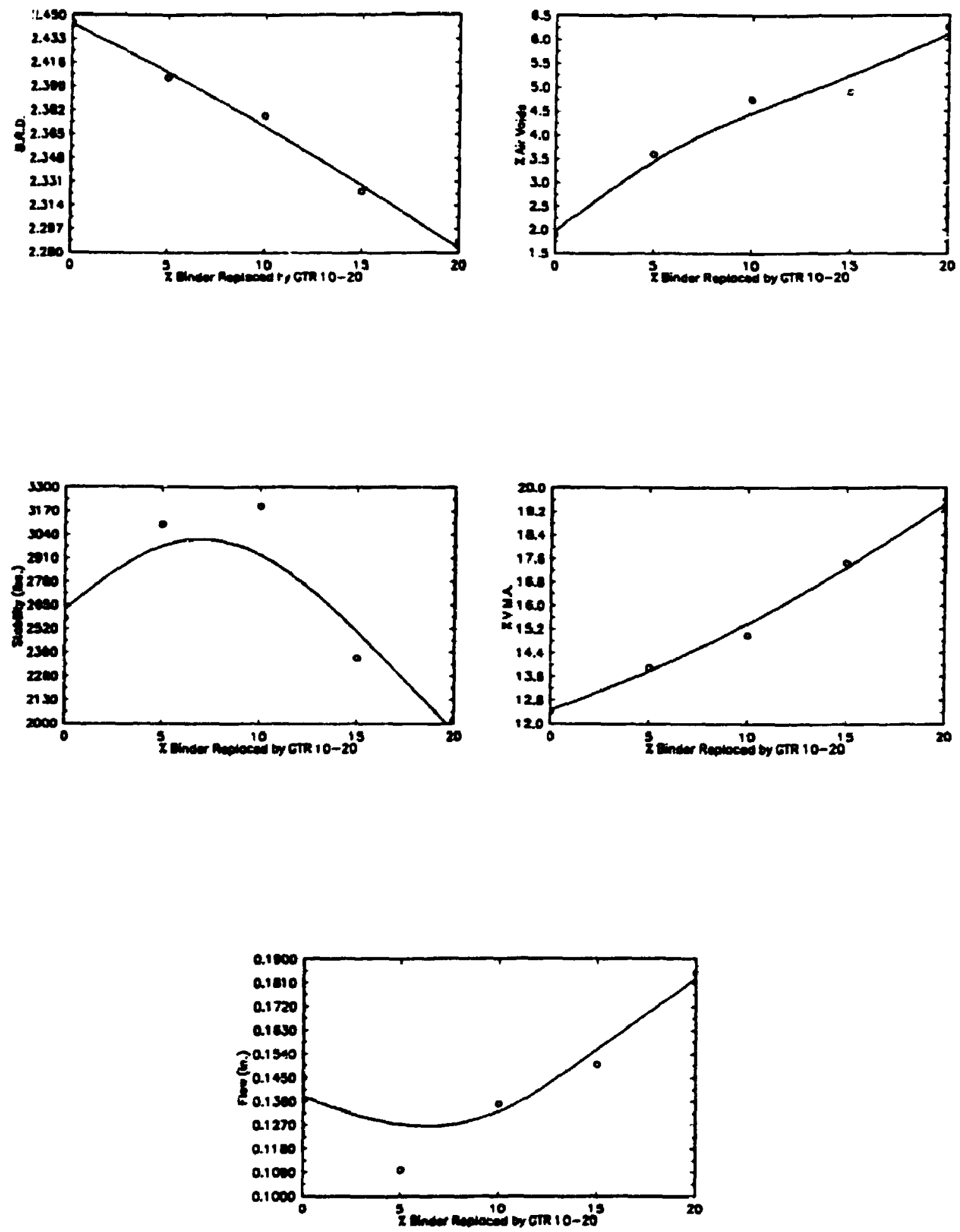

Figure 5.1: Comparison of 5 different SMA Mixes 
Table 5.4 - \%VMA analysis.

\begin{tabular}{|c|c|c|c|c|}
\hline $\begin{array}{l}\text { Optimum } \\
\text { Asphalt } \\
\text { Content }\end{array}$ & $\begin{array}{c}\text { \% Asphait } \\
\text { Replaced by } \\
\text { Rubber }\end{array}$ & $\begin{array}{c}\$ \text { Air Voids } \\
\text { (A) }\end{array}$ & $\begin{array}{c}90 \text { VMA } \\
\text { (B) }\end{array}$ & $\begin{array}{l}\text { Unabsorbed } \\
\text { Asphalt (B-A) }\end{array}$ \\
\hline 4.6 & 0 & 2.3 & 12.5 & 10.2 \\
\hline 4.6 & 5 & 4.0 & 14.0 & 10.0 \\
\hline 5.0 & 10 & 4.0 & 15.2 & 11.2 \\
\hline 5.6 & 15 & 5.5 & 17.4 & 11.9 \\
\hline 6.0 & 20 & 6.0 & 19.3 & 13.3 \\
\hline
\end{tabular}


in VM . is due solely to the increase in AV's. This pattern holds reasonably true for a binder of CRM asphalt cement with up to $20 \%$ rubber particles. The change in this pattern may be attributed to a non optimum amount of nubber in the mix.

\subsubsection{General Results}

From Figure 5.1 it can be concluded that the mix containing $10 \%$ of rubber in asphalt is the most promising thus far. Takallors and Sainton (1993) tested the effect of three different crumb rubber contents on the viscosity, softening point, resilience, and penetrability of CRM asphalt cement binder. Their test results indicate that the optimum properties can be achieved at 10 percent crumb rubber content. It can be speculated that the binder with the optimum properties will produce the optimum mix.

The stability for a binder with 10 percent ground tire rubber is at an optimum while the flow is still quite low (14.5). The AV's and VMA are well in the range of the design criteria. If the Marshall mix design is the only criteria for selecting a mix. CRM asphalt cement containing $10 \%$ recycled crumb rubber would be favoured.

However, the Marshall mix design method is a poor predictor of performance. Performance related testing must be conducted in order to obtain a more accurate comparison between mixes. Chapter 7 outlines a performance related testing program designed for this purpose. Chapter 6 describes the specifications for the large aggregate mixes. These mixes (control and $10 \%$ rubber) will be tested for performance in the same manner as the SMA mixes. 

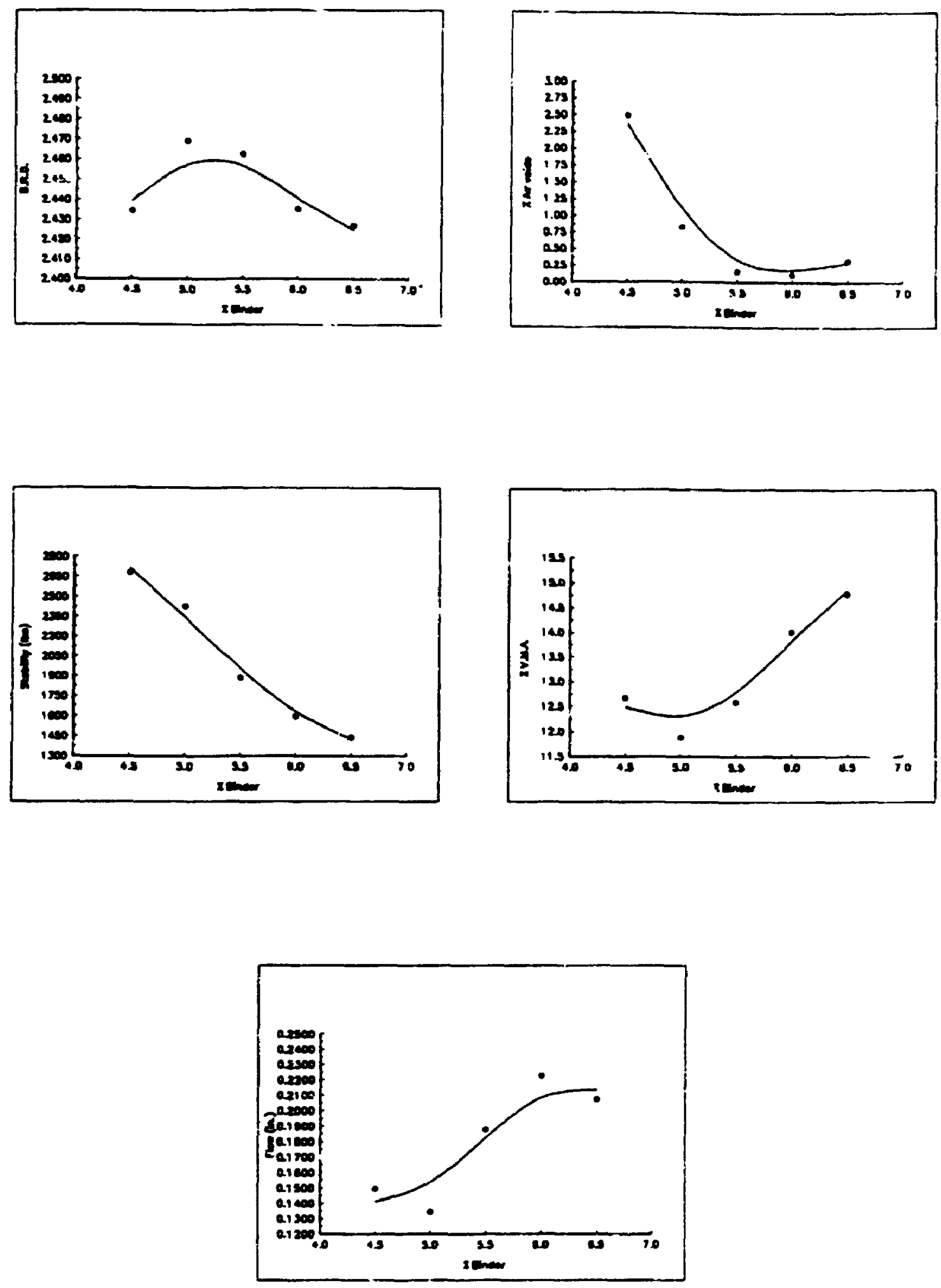

Figure 5.2: Marshall Mix Design for SMA mix (Control) 

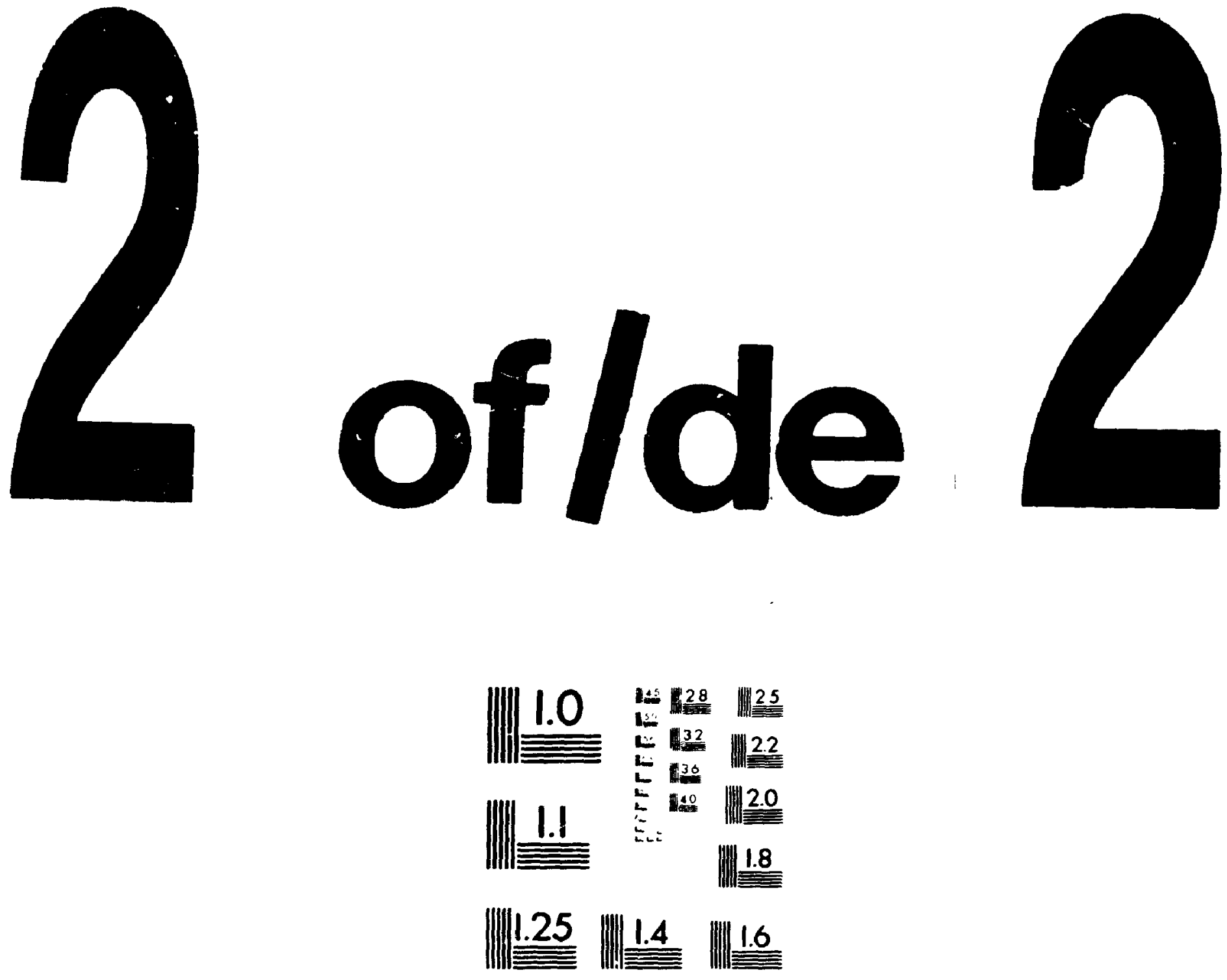

MICROCOPY RESOLUTION TEST CHART

NATIONAL BUREAU OF STANDARDS

STANDARD REFERENCE MATERIAL 1010a

(AN'SI aII ISO TEST CMAR' N:, 21 

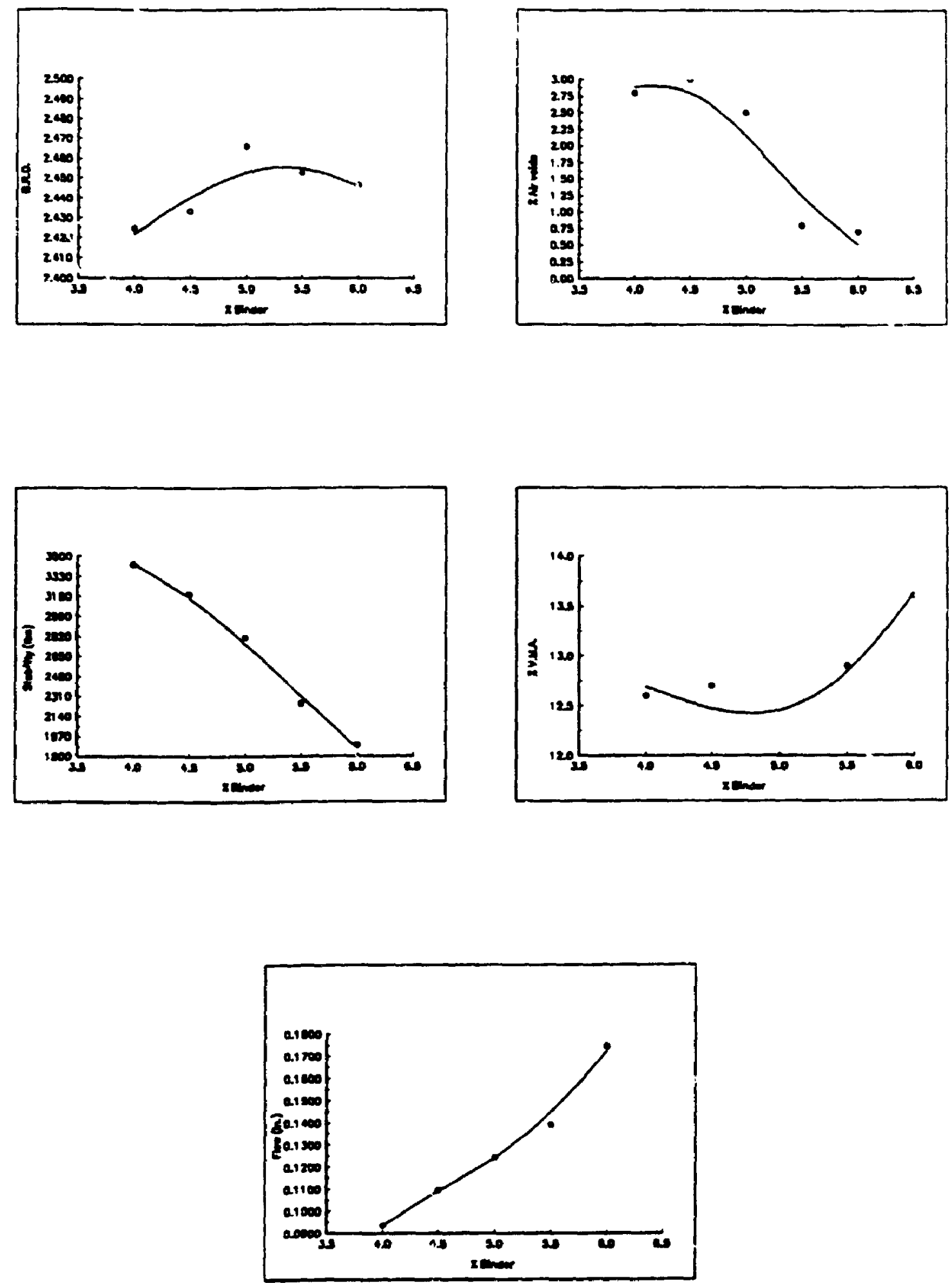

Figure 5.3: Marshal! Mix Design Por SMA Mix (Ecoflex) 

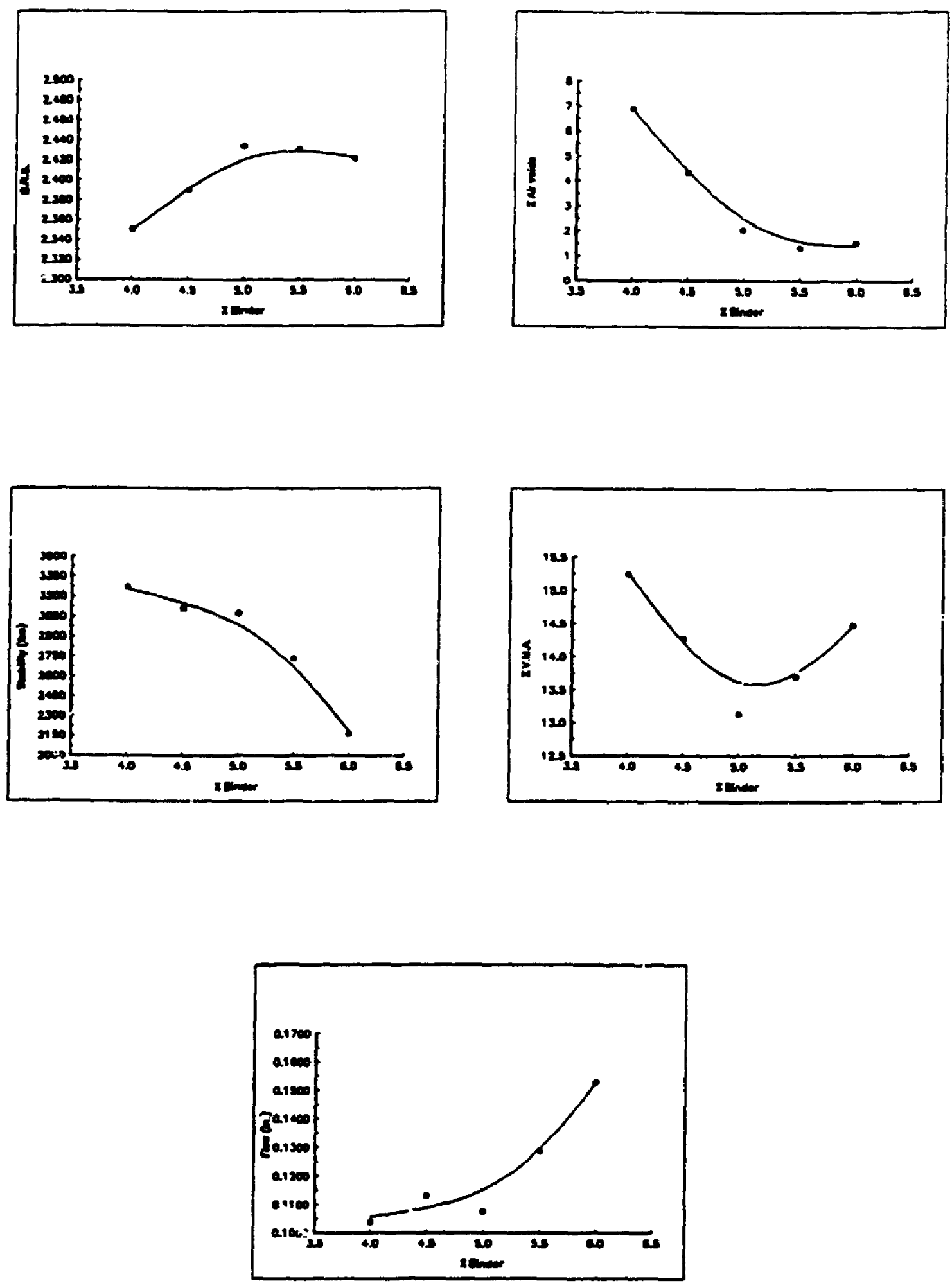

Figur: 5.4: Marshall Mix Design for SMA Mix (5\% Rubber) 

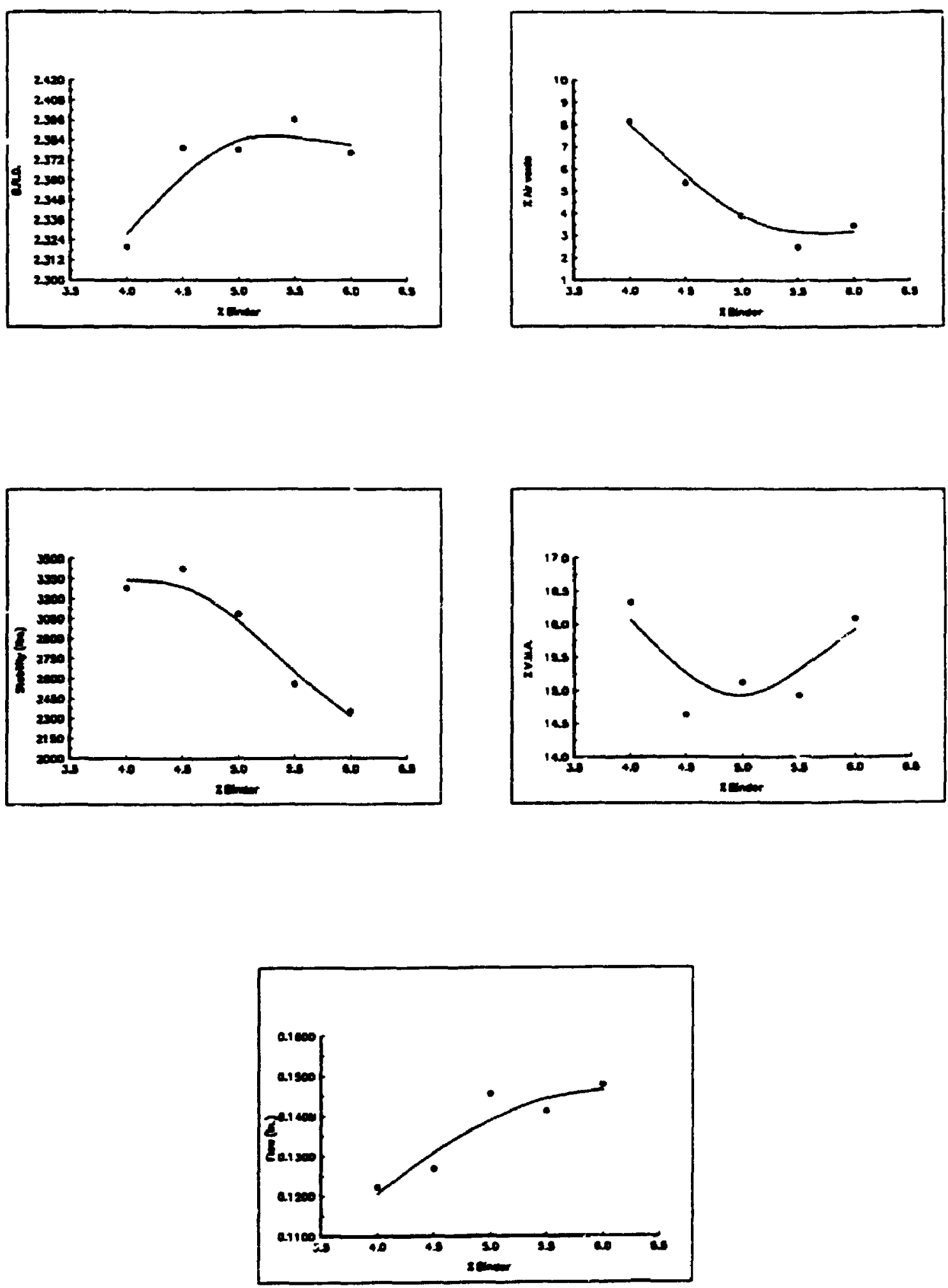

Figure 5.5: Marshall Mix Deafgn for SMA Mix (10\% Rubber) 

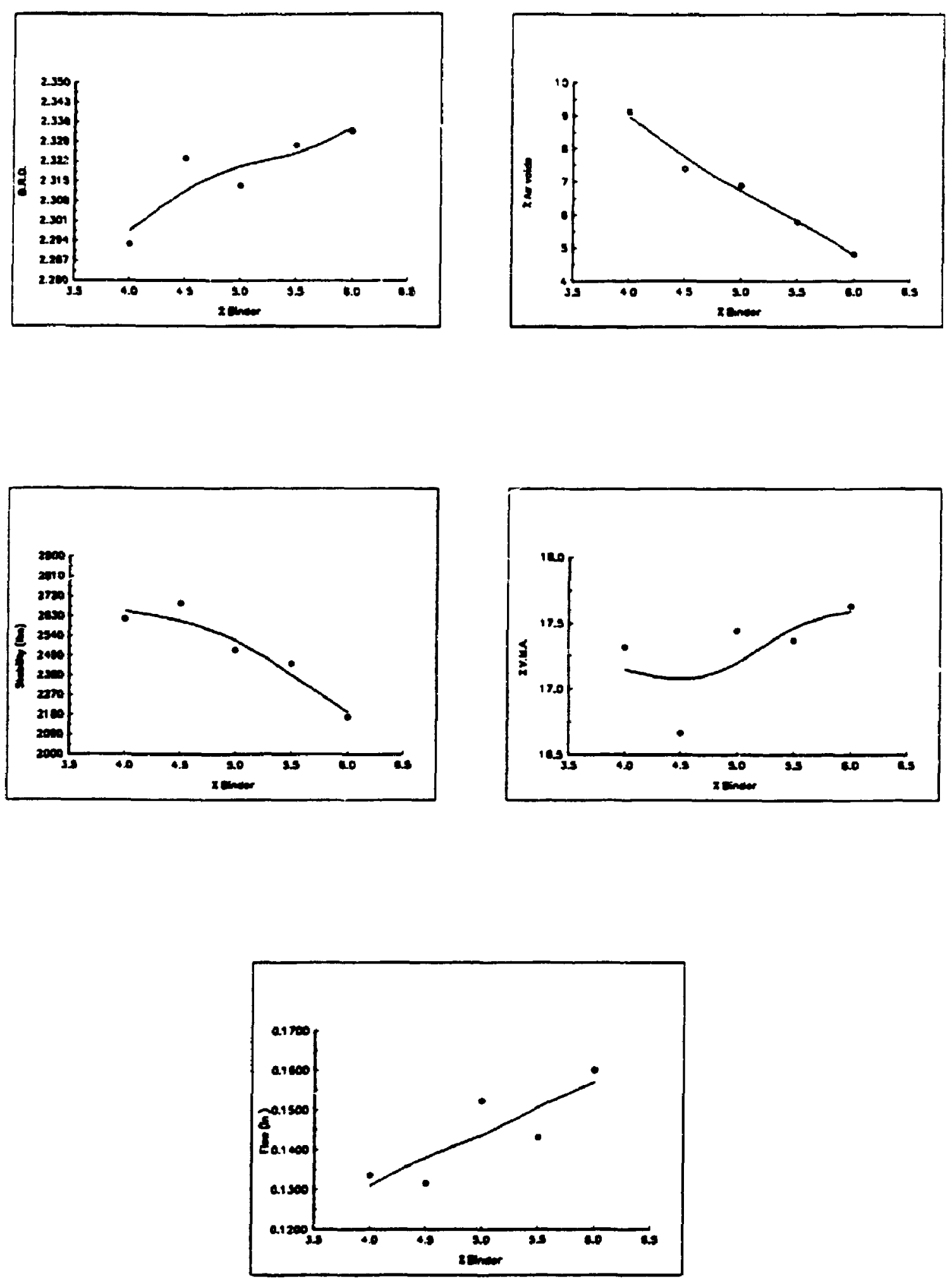

Figure 5.6: Marshall Mix Design for SMA Mix (15\% Rubber) 

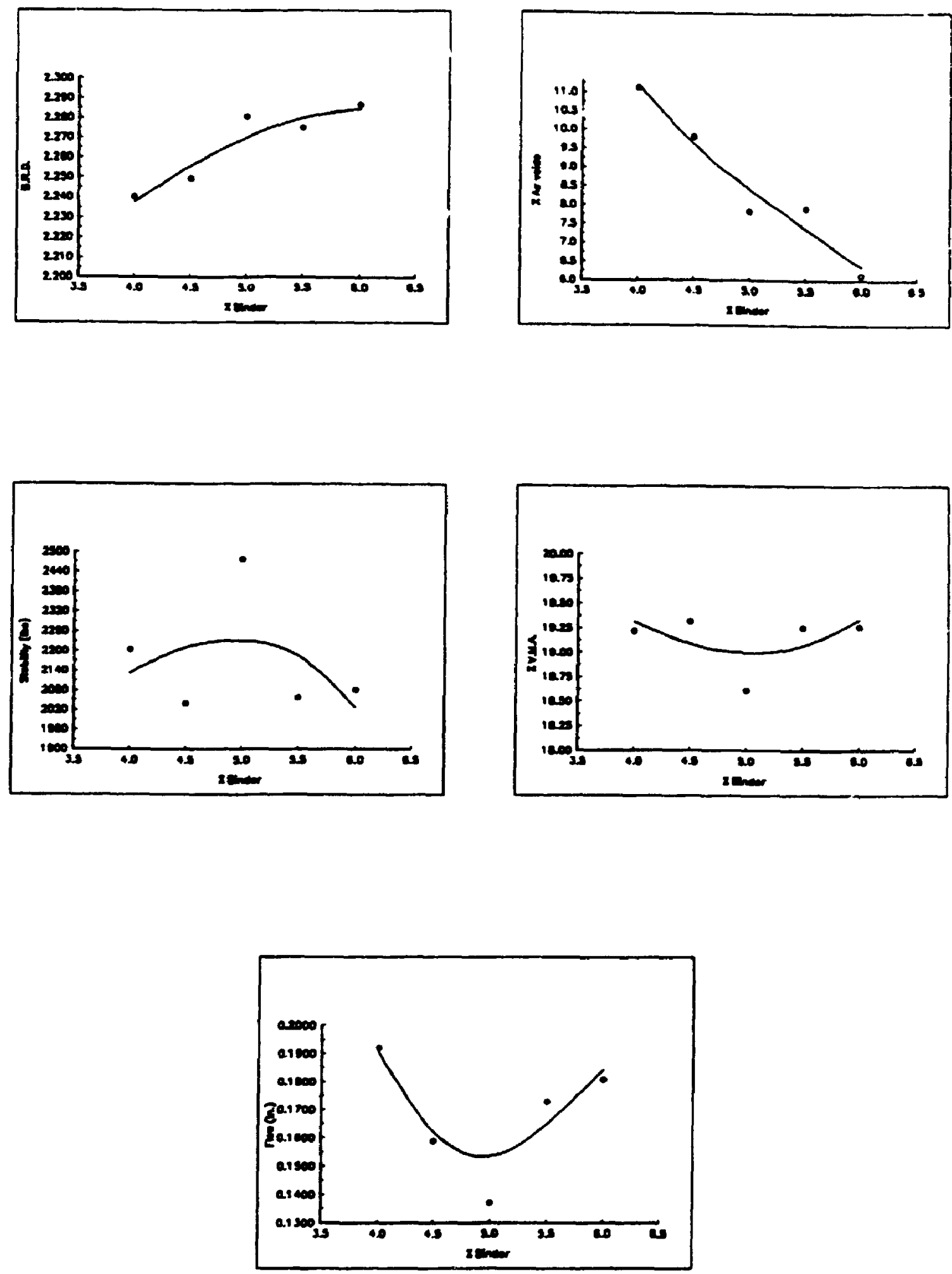

Figure 5.7: Marshall Mix Design for SMA Mix (20\% Rubber) 


\section{Chapter 6}

\section{LAM Specifications}

The large aggregate mix (LAM) was designed at Centre for Surface Transportation Technology at the Canadian National Research Council (CSTT/NRC) by Ei Hussein et al. (1993). The LAM was gyratory compacted in a $15.2 \mathrm{~cm} \mathrm{(6")} \mathrm{diameter} \mathrm{mold} \mathrm{to}$ accommodate the large stone sizes used in this mix. This chapter presents the materials used for the mix, the design asphalt content for the control mix, as well as the selection of a CRM asphalt cement binder for the LAM.

\subsection{Selection of Materials}

The aggregates used in this investigation were obtained from the H J McFarland Construction Co. in Nepean. This is the same aggregate supply used for the SMA mix (section 4.1.1). The gradation of the HIL3, crusher screenings and sand can be seen in Table 4.1. The $38 \mathrm{~mm}$ size aggregate with the gradation presented in Table 6.1 was the only other stone component used for the LAM design.

The binder selected for the LAM was also the same binder used for the SMA mixes. Refer to Section 4.1.2 for details of the binder used. 
Table 6.1: Aggregate Fractions Gradation

\begin{tabular}{|c|c|c|c|c|c|c|c|}
\hline & \multicolumn{7}{|c|}{ Sieve Size (mm) } \\
(Percent Passing) \\
\hline Aggregate & 37.5 & 25.0 & 16.0 & 11.0 & 8.0 & $\# 4$ & $\# 10$ \\
\hline $38 \mathrm{~mm}$ & 100 & 90 & 25 & 5 & 2 & 2 & 1 \\
\hline
\end{tabular}


GTR-10 cryogenically ground tire rubber was used with the SMA mix. Since the size of the sample and of the aggregates was larger for the LAM a larger rubber gradation was also selected. The other reason to use larger and cheaper crumb rubber in this mix was to keep the cost of the LAM as low as possible. The gradation of the GTR-4 ground tire rubber used with the LAM is displayed in Table 6.2.

\subsection{Manufacture of Mix}

The manufacture of the LAM was similar but not identical to the manufacture of the SMA mix (since Marshall equipmeni could not be used) with some exceptions outlined in the following sections.

\subsubsection{Acprepate Gradation}

The gradation selected for this experiment is documented in a report by El Hussein et al. (1993). The aggregate blend and gradation specifications are shown in Table 6.3 and Figure 6.1 respectively.

In order to achieve this sort of gradation, the following fractions of aggregate used was:

$52 \% 38 \mathrm{~mm}$ McFarland Stone

18\% HL3 McFarland Stone

$12 \%$ quarry screening

$18 \%$ field sand 
Table 6.2: Rubber Gradation Specifications

\begin{tabular}{|c|c|c|c|c|c|}
\hline & \multicolumn{5}{|c|}{ Sieve Size (mm) } \\
& \multicolumn{5}{|c|}{ (Percent Passing) } \\
\hline Rubber & No.8 & No.10 & No.16 & No.20 & No.30 \\
\hline GTR-4 & 100 & $0-75$ & -- & -- & $\ldots$ \\
\hline
\end{tabular}


Table 6.3: Aggregate blend for LAM

\begin{tabular}{|c|c|}
\hline Sieve Size & \% Passing \\
\hline $37.5 \mathrm{~mm}$ & 100 \\
\hline $25.0 \mathrm{~mm}$ & 95 \\
\hline $16.0 \mathrm{~mm}$ & 61 \\
\hline $11.0 \mathrm{~mm}$ & 49 \\
\hline $8.0 \mathrm{~mm}$ & 40 \\
\hline$\# 4$ & 31 \\
\hline$\# 10$ & 24 \\
\hline$\# 20$ & 19 \\
\hline$\# 40$ & 12 \\
\hline$\# 60$ & 6 \\
\hline$\# 100$ & 3 \\
\hline$\# 200$ & 1 \\
\hline
\end{tabular}


As can be seen in Figure 6.1, the LAM was designed as gap-graded like the SMA mix. This design was favourable for incorporating ground tire rubber in the voids around the aggregates. The GTR 4 rubber particles are mostly the same size as the openings in the number 10 sieve. Figure 6.1 shows that there is a suitable gap in the gradation for this size of particle.

\subsubsection{CRM Asphalt Cement Binder Preparation and Mixing Conditions}

The preparation of the CRM asphalt cement is identical to the precedure outlined in Section 4.2.2.

The mixing couditions employed during the manufacture of the LAM samples is outlined as follows:

$$
\begin{array}{ll}
\text { Binder Temp. } & : 175^{\circ} \mathrm{C} \\
\text { Aggregate Temp. } & : 175^{\circ} \mathrm{C} \\
\text { Mixing Temp. } & : 160^{\circ} \mathrm{C}
\end{array}
$$

When the binder reached the required temperature it was added to the coarse aggregate (32 $\mathrm{mm}$ and HL3) in a mixing bowl. The mixture was hand mixed with a large metal spoon until the coarse aggregate was sufficiently coated. The fine aggregates (screenings and sand) were subsequently added and mixing was continued until the aggregates were completely coated. The mixture was then spuoned into a preheated mold and tamped, ready for gyratory compaction. 
Sieve Size and Designotior, ivo.

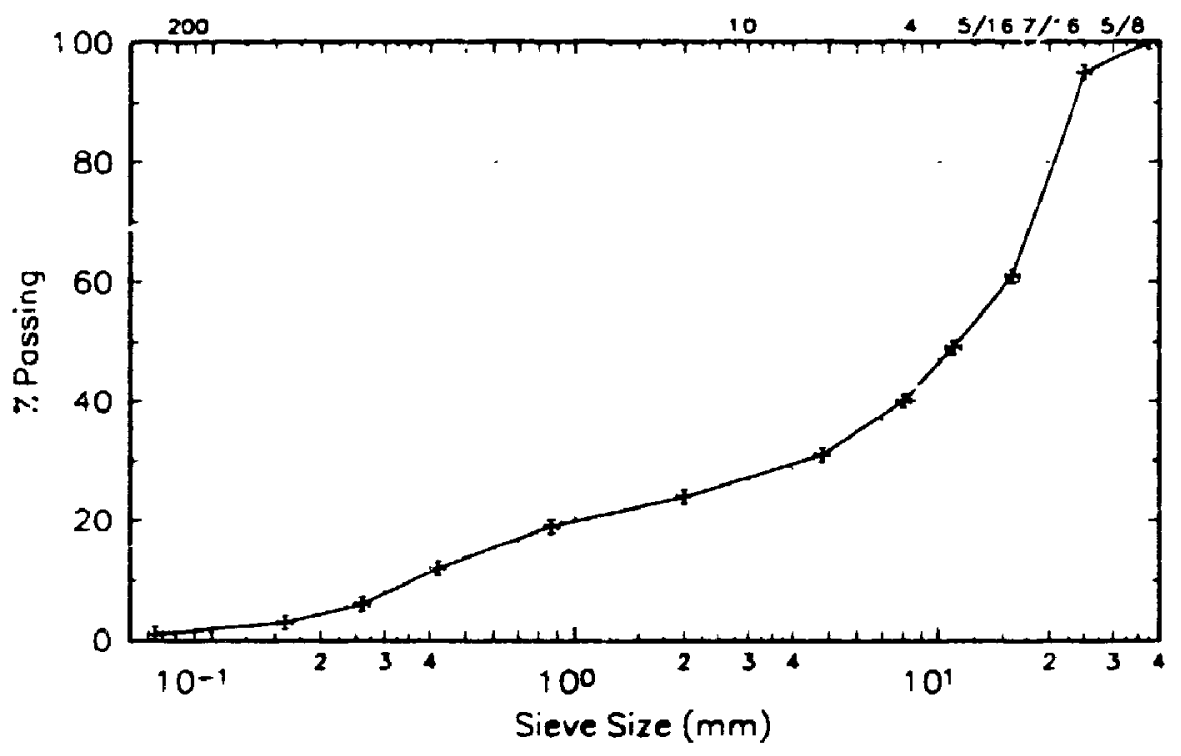

Figure 6.1: Gradation of gap-graded LAM 


\subsubsection{Compection Conditions}

Circular paper discs were used on the top and bottom of the sample to prevent the mixture from sticking to the mold and loading head. The mix was compacted using a Rainhart series 142 gyratory compactor. The gyratoy compactor allows for the compaction of only one sample at a time. The following compartinn conditions were present:

$$
\begin{array}{ll}
\text { Ram Pressure } & : 600 \mathrm{kPa} \\
\text { \# of Gyrations } & : 250 \\
\text { Angle of Gyration } & : 1^{\circ} \\
\text { Compaction Temp. }: 160^{\circ} \mathrm{C}
\end{array}
$$

The refusal density for the LAM was determined by Hussein et al. (1993) to be 250 gyrations. An equal compactive effort was produced for the CRM asphalt cement specimens. The samples were allowed to cool before extrusion from the molds. The gyratory compactor produced cylindrical cores with a diameter of $15.2 \mathrm{~cm} \mathrm{(6").} \mathrm{The}$ cylindrical shape of the samples was preferred for the performance testing involved with this study. Refer to Figure 6.2 fol a schematic of the gyratory compactor.

The gyratory compactor was employed for manufacturing the LAM for two primary reasons. First, the Marshall compactor is not capable of compacting $15.2 \mathrm{~cm}\left(6^{\prime \prime}\right)$ cores required for the production of the LAM. Secondly, a report by Consuegra et al. (1989) shows that the gyratory compactor demonstrated the ability to produce mixtures with engineering properties nearest those determined from field cores. In a final rating of five compaction devices, Consuegra et al. gave the following ranking: 
1. Texas gyratory shear compactor

2. California kneading compactor

3. mobile steel wheel simulator

4. Arizona vibratory-kneading compactor

5. Marshall mechanical hammer.

The Marshall method of compaction displayed the poorest performance with respect to properties nearest those determined from field cores. The absence of the kneading effect during the mix compaction, which is due to the uniform :mpact type load applied by the Marshall hammer, is probably the major reason behind the ponr performance. Kneading of the mix allows for the rearrangement of aggregates which allows for a denser mix. Although Marshall compaction is inferior to the other displayed types it is still very popular in the United States and many other countries. The vast quantity of historical empirical data obtainable from the Marshall mix design make this method attractive. While gyratory shear compaction is proven to be superior, a lack of data correlating results with field trials reduces the widespread usage of un. compaction method. However, increased use of the gyratory shear compactor (expected due to the SHRP program), will provide the necessar! database resulting in the replacement of the Marshall method of compaction in the near future. 


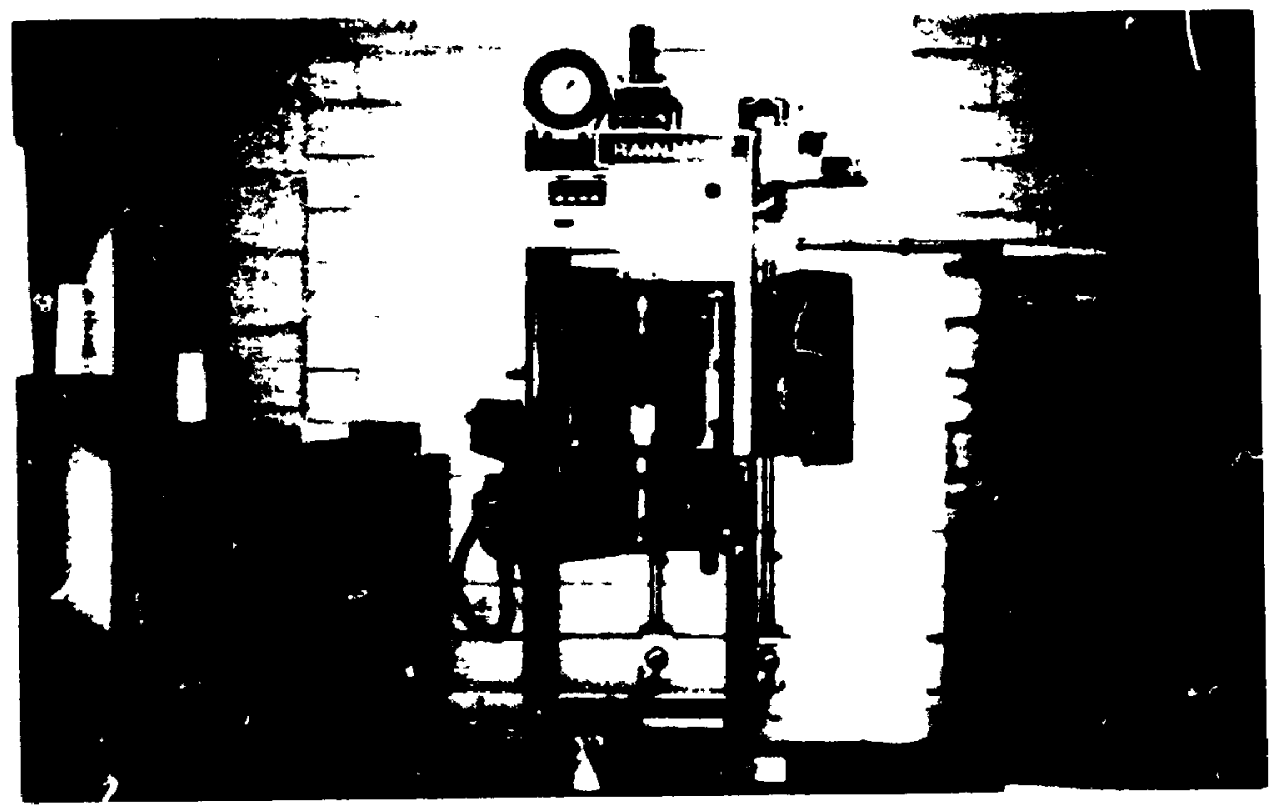

Figure 6.2: Rainhart Series 142 Gyratory inear Compactor 


\subsection{Selection Criteria for Performa nce Based Testing}

The optimum asphalt content for the LAM control mix was determined by El Hussein et al. (1993) to be $4 \%$ by weight of sample. After review of the Marshall mix design for SMA mixes it was determined that the CRM asphalt cement binder containing $10 \%$ ground tire rubber was the optimum asphalt rubber mix. A look at Table 5.3 shows an increase of about $0.5 \%$ for the optimum binder content for each $5 \%$ increase in the amount of rubber in the binder starting at 5\%. Therefore, due to time constraints, a binder with $10 \%$ ground tire rubber was used for comparison with the large aggregate control mix. The optimum asphalt content for the CRM asphalt cement binder was selected at 4.5\%.

In summary, performance tests for the LAM were conducted on a control mix with a 4\% asphalt binder content and on a mix with a CRM asphalt cement binder containing $10 \%$ of recycled crumb tire rubber. The mix with the CRM asphalt cement binder had an optimum binder content of $4.5 \%$ by weight of the samples. 


\section{Chapter 7 \\ PERFORMANCE BASED TESTING PROGRAM}

Once the optimum mixes were designed (Marshall program) for the control and rubber mixes, perfornance tests were utilized to predict field performance of the various samples. After the initial mix design process (Figure 3.1), accelerated performance tests were carried out in order to determine the job mix formula. The Marshall mix design program was useful for determining asphalt content for mixes but it has very limited perfornance prediction capabilities. Perfismance tests, such as rutting and fatigue, are useful for predicting field performance, but they are slow, time-consuming and inappropriate for determining asphalt content. Therefore, the best approach would be to

combine the Marshall mix design for the initial design phase with performance testing to determine the characteristics of the mix and predict it's performance in the field.

This chapter describes the performance tests carried out on the lab specimens as well as the equipment used for this purpose. 


\subsection{Test A pparntus}

A schematic diagram of the test apparatus is shown in Figure 7.1. The apparatus consisted of a hydraulic actuator and controller, monitoring devices, a data acquisition system, and a temperature controlled chamber. These items are described in the following sections.

\subsubsection{Hydraulic Actuntor and Controller}

All performance tests conducted on the specimens used an MTS hydraulic actuator with an MTS 458.20 MicroConsole controller. The hydraulic actuator was equipped with a load cell and an intemal linear variable displacement transducer (LVDT). The actuator controller could be used for displacement or load control depending on the test setup required.

External function controllers were also used due to the limitations of the built in function generator. A Wavetek Model 182A 4-MHz function generator along with a Hewlett Packard 8111A Pulse/Function 20-MHz generator were required to generate haversine and pulsed square waves. A Tektronix $221280 \mathrm{MHz}$ Digital Storage Oscilloscope was employed to ensure that the proper loading function was produced.

\subsubsection{Inotrumentetion and Deta Acqualition System}

The instrumertation part for the experimental investigation can be divided into two groups, load and displacement measurement. The load measurements consisted of monitoring the compressive loads by the built-in load cell of the hydraulic actuator. The 

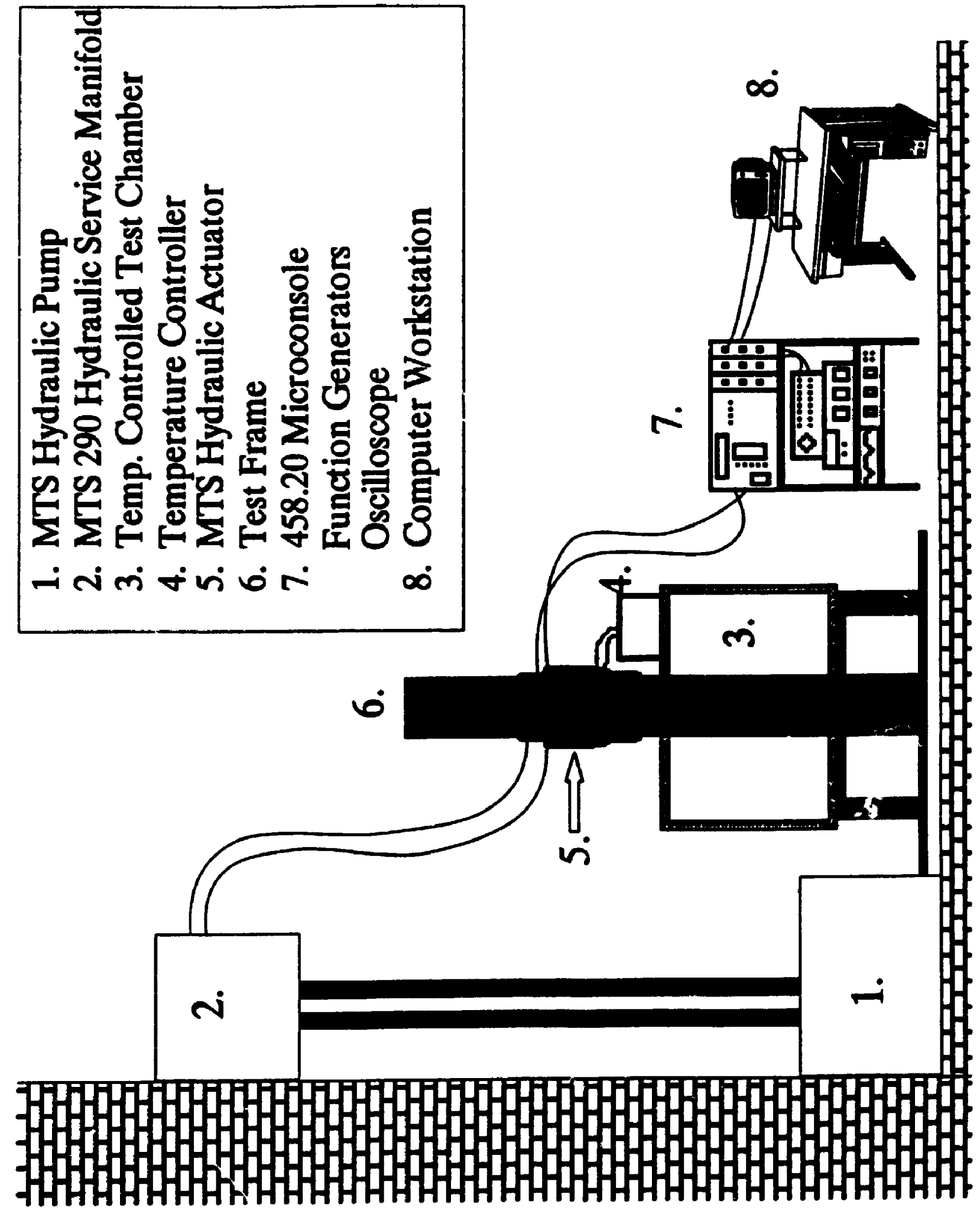

Figure 7.1: Schematic of Performance Tests Setup 
stroke displacement of the hydraulic actuator was measured by the internal LVDT. The data were collected at prescribed intervals and stored in microcomputer files for further data reduction.

The load and dispiucement was monitored using Labtech Notebook software on a 386 microcomputer and displayed on the computer screen for direct observation. The data were also stored on the hard disk to allow further analysis.

\subsubsection{Temperature Controlled Chamber}

A chamber was constructed around the hydraulic actuator to allow samples to be tested under climate control. The chamber was constructed out of wood with styrofoam insulation and a window was installed for visual observation of the specimen under testing. A YSI Model 71A Thermistemp Temperature Controller was employed to control the temperature to a preset level.

\subsection{Description of Testing Methods}

Three different performance related tests were conducted. They were an indirect tensile strength test (ITS), a fatigue test. and a repetitive uniaxial compression test (RUCT) for evaluating rutting resistance. Resilient modulus $\left(M_{R}\right)$ values were not obtained due to unavailability of the required equipment. The tests are discussed in detail in the following sections. 


\subsubsection{Indivect Texisile Strength Test}

The ITS test was conducted by loading a cylindrical specimen with a single compressive load which acts parallel to and along the vertical diametral plane (Figure 7.2). The stress condition developed by this test acts perpendicular to the loading direction and along the diametral plane. The development of stresses within the cylindrical specimen subjected to the compressive load is documented by Kennedy and Hudson (1968a). The reader is referred to the report by Kennedy and Hudson if interest in the strest conditions is present. In order to achieve initial failure from the centre of the specimen and not along the loading zone a curved loading strip is used to distribute the load over an enlarged area.

The ITS test is a strain controlled test and is performed at a loading rate of $51 \mathrm{~mm}$ (2 in.) a minute (Kennedy 1977). The resulting load-deformation relationship was recorded by the data acquisition system. A sample test is displayed in Figure 7.3. The resulting tensile strength $\left(S_{\tau}\right)$ of the specimen was calculated by the following equation from Kennedy:

$$
S_{T}=\frac{P_{r_{L}}}{h} \times A
$$

where $S_{\mathrm{T}}=$ tensile strength in $\mathbf{k P a}$

$$
\begin{aligned}
& P_{\mathrm{Ful}}=\text { maximum load at failure (kgs) } \\
& \mathbf{h}=\text { height of specimen }(\mathrm{cm})
\end{aligned}
$$$$
A_{0}=a \text { constant given as } 6.026 \text { for a Marshall specimen }(10.2 \mathrm{~cm} \text { dia.) }
$$ 

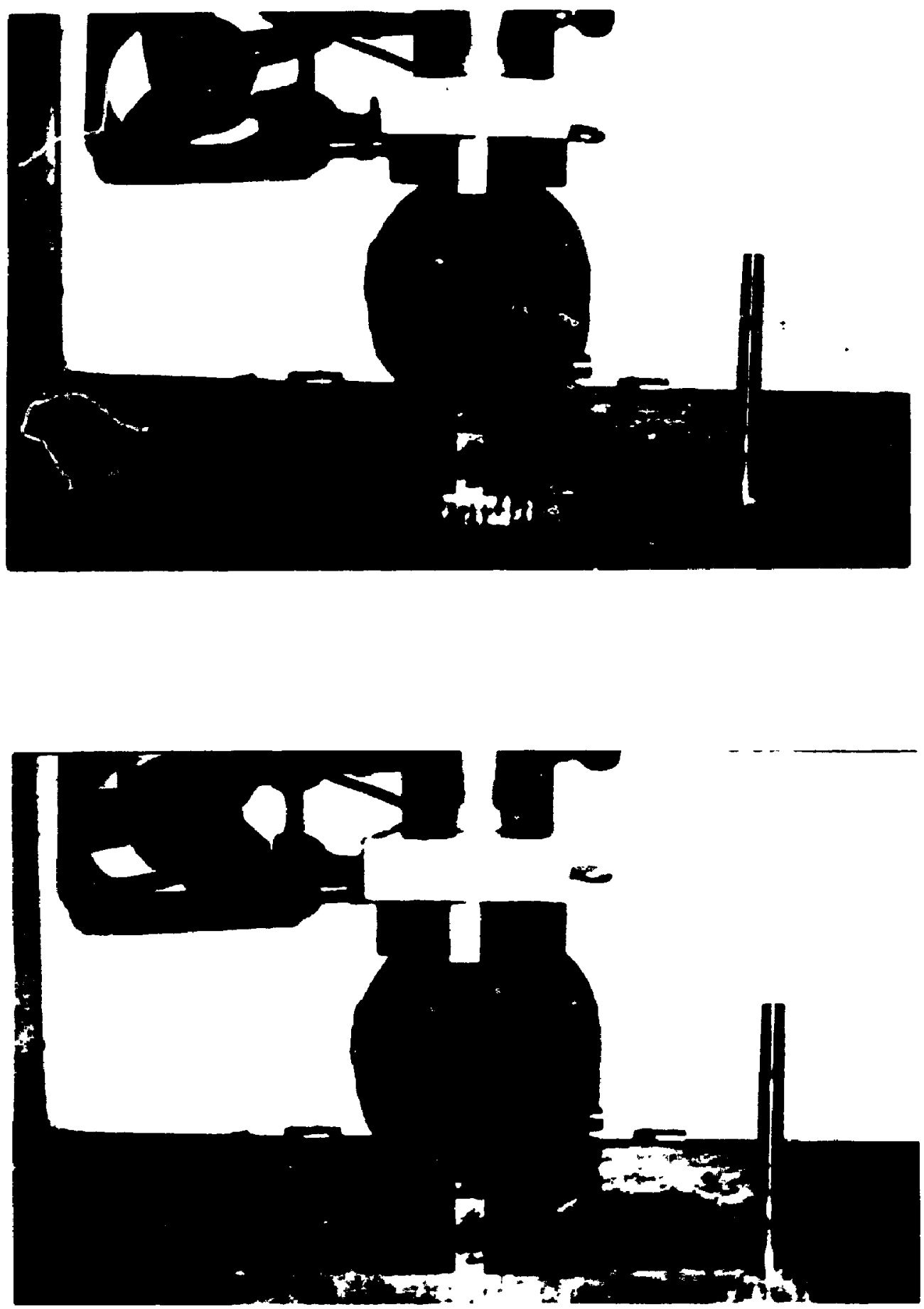

Figure 7.2: Loading Setup for ITS and Fatigue Tests 


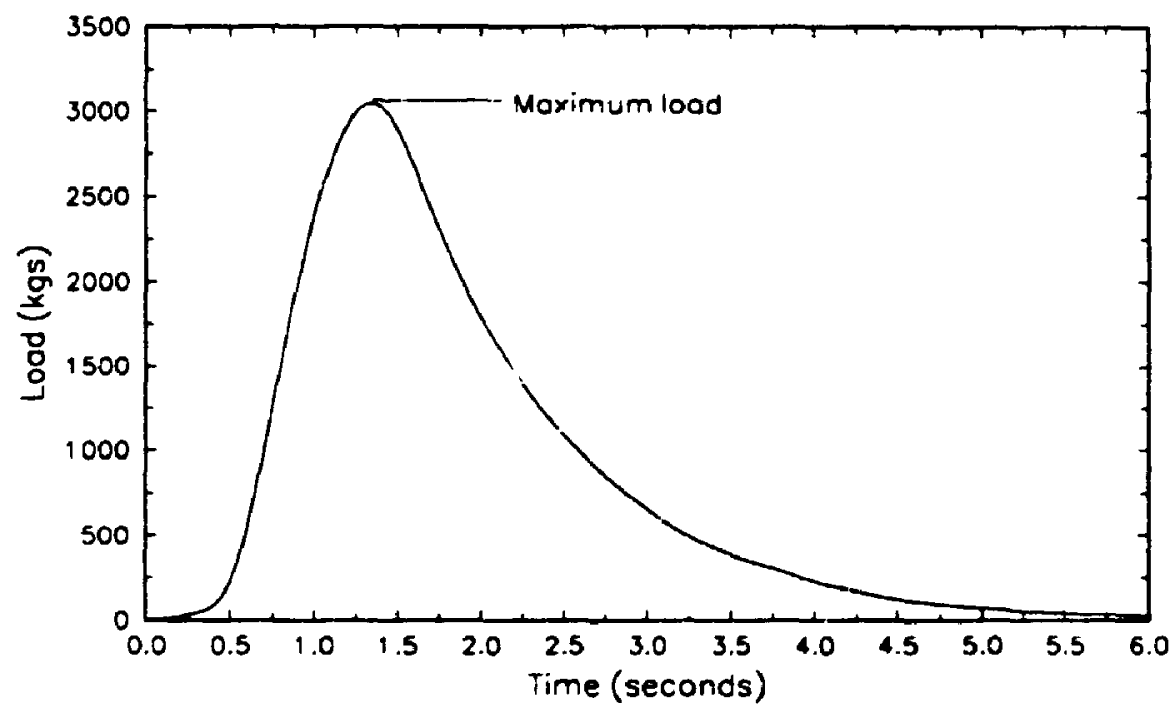

Figure 7,3: Indirect Tensile Strength Test 
The value for the indirect tensile strength was needed to determine loading conditions for fatigue testing. Three specimens were tested for each mix type.

\subsubsection{Fatigue Teating}

The fatigue testing performed on the samples followed the procedure defined by Stolle (1990). Stolle's test method was selected since it incorporated testing cylindrical specimens as opposed to beams recommended by SHRP. The setup for the fatigue test was the same as the indirect tensile strength test. However, the loading for fatigue testing was a stress controlled load. A compressive Haversine wave at a frequency of $1 \mathrm{~Hz}$ was used to maintain uniform cyclic loading (Figure 7.4).

Specimens were failed in a fatigue mode using either $15 \%$ or $30 \%$ of the static strength determined previously. A sample fatigue test graph is shown in Figure 7.5.

Stolle defines the fatigue failure $\left(\mathbf{N}_{\mathrm{f}}\right)$ of the specimen as the point at which the rate of accumulated irrecoverable displacement appeared to accelerate. This point corresponds to the intersection of the lines marking the line of constant accumulated deformation and a line tangent to the curve at the point of maximum curvature. At this stage of the loading history of the specimen a well-defined crack started to develop along the vertical diameter of the sample. Three fatigue tests were conducted at each load for each mix type. The results were subsequently plotted on an applied tensile stress versus cycles to failure graph for comparison (Chapter 8). 


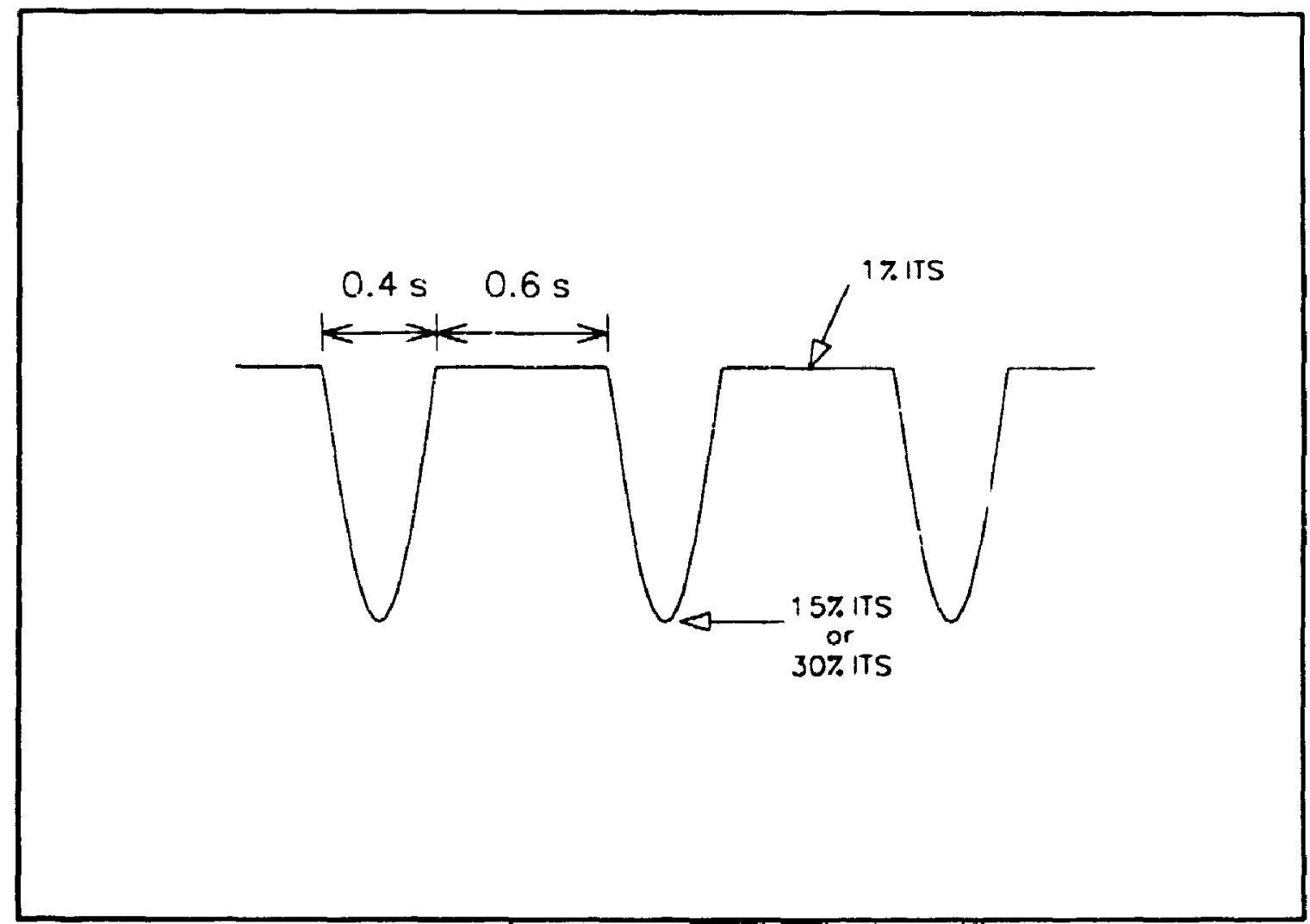

Figure 7.4: Fatigue Test Loading Function 


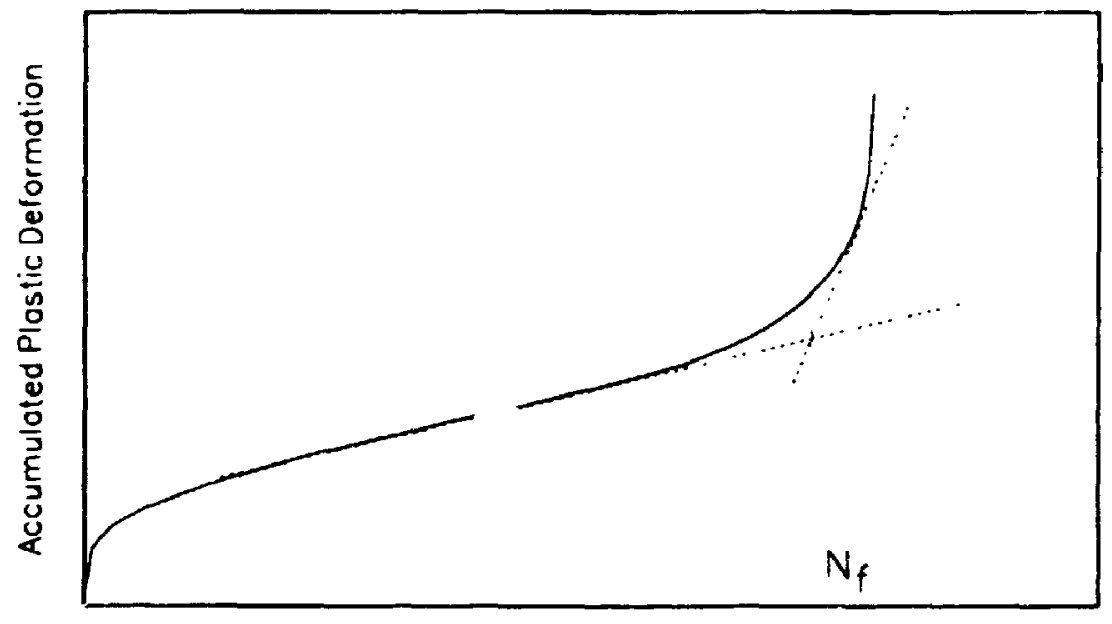

Number of Cycies

Figure 7.5: Sample Fatigue Data 


\subsubsection{Repetitive Uniexial Compression Test}

There are numerous different test setups in use today to analyze permanent deformation or rutting in asphalt samples. One common type of rutting test is a wheeltracking test that involves testing asphalt slabs whose borders are confined. A rubber tired wheel is passed back and forth over the surface and the deformation is measured. This test is intended to simulate field loading and is very time consuming in both execution and sample preparation. Other tests to measure rutting are uniaxial, triaxial, or simple shear tests. A creep test is an example of a simple shear test, however it is not entirely accurate to correlate creep data with field performance. The test selected to determine rutting resistance (through permanent shear deformation) for this study is a repetitive uniaxial compression test (RUCT) normally used at the Centre for Surface Transportation Technology of the National Research Council of Canada (CSTT/NRC). This test is explained in detail in a paper by El Hussein and Yue (i993).

The RUCT uses cylindrical cores and the MTS hydraulic actuator for testing. A cylindrical plate is placed on the flat side of the specimen and a maximum load of 690 $\mathrm{kPa}(100 \mathrm{psi})$ is applied to the sample (Figure 7.6). A thin rubber pad is placed between the loading plate and the specimen. A minimum load of $5 \mathrm{~kg}$ is used on the rest cycle to avoid separation of the loading head which would result in impact loading. The loading function is a square wave load application based on research work conducted at Nottingham University (Brown and Brunton 1984) used to simulate traffic loading (Figure 7.7). 


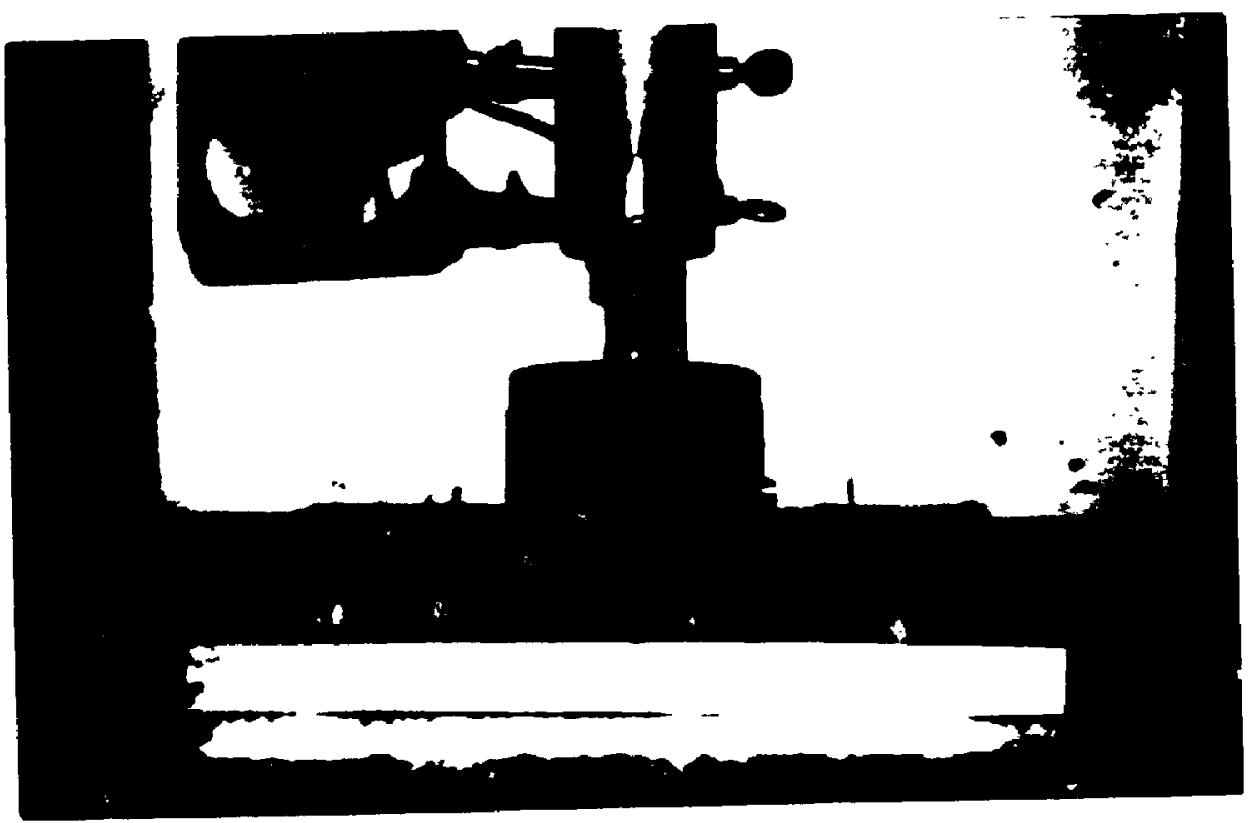

Figure 7.6: Loading Setup for RUCT 


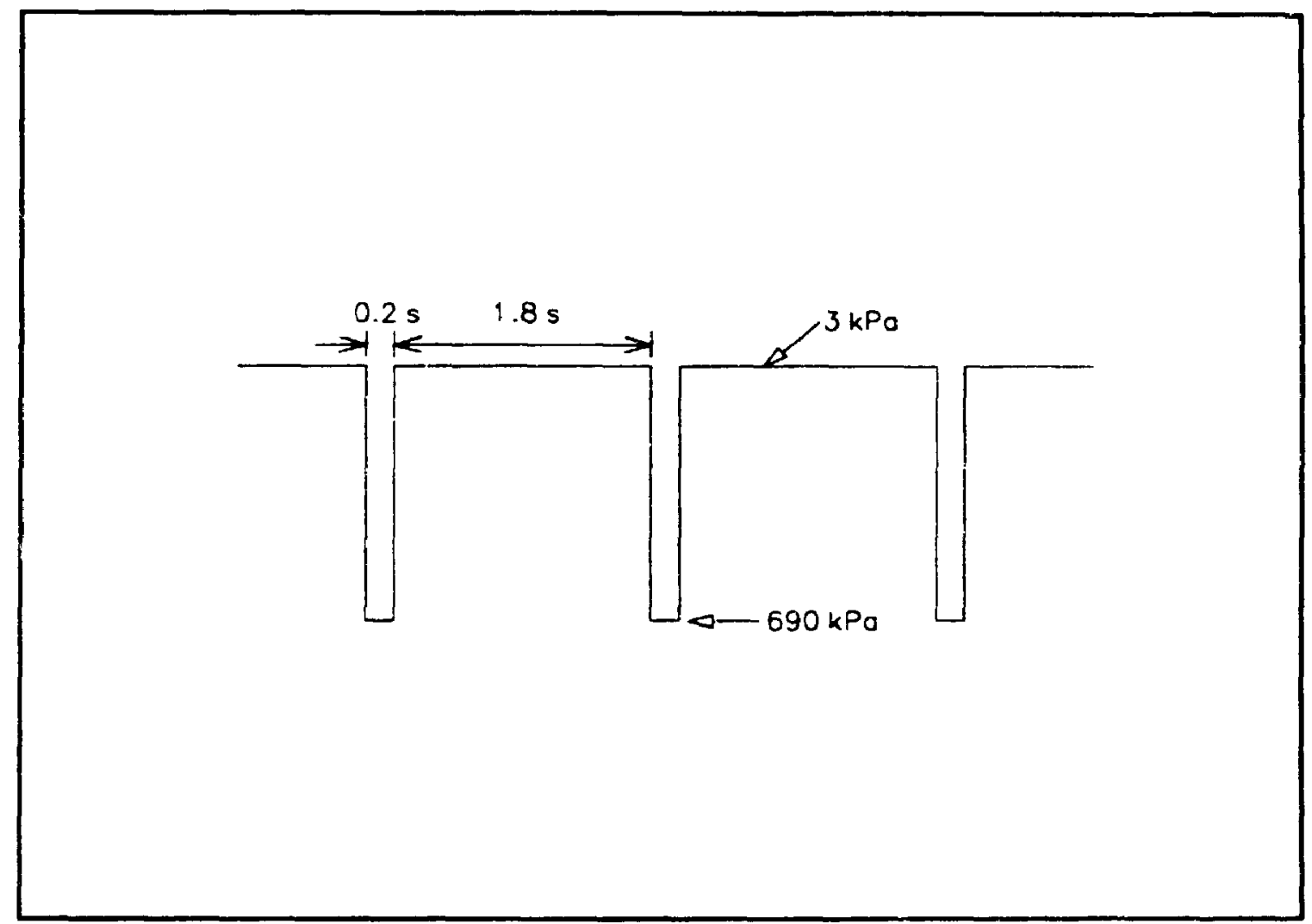

Figure 7.7: RUCT Losding Function 
The square wave consists of a loading period of 0.2 seconds followed by a 1.8 second rest period. The tests were conducted at $25^{\circ} \mathrm{C}$ and $40^{\circ} \mathrm{C}$ to determine the mixes rutting susceptibility to increased temperature. Each mix was tested three times and representative result was selected for comparison.

The output from the RUCT was similar to the sample output shown in Figure 7.8. A Fortran program removed the elastic portion of the deformation from the total deformation acquired during the test to provide a smooth curve. Another coinputer program was used to determine the rate of permanent deformation, $\mathrm{K}$, during the secondary stage using linear regression. El Hussein and Yue (1993) hypothesized that the accumulated permanent axia' strain undergoes three distinct stages; primary, secondary, and tertiary (Figure 7.9). These stages correspond to strain-hardening, shear flow and fracture failure. During the secondary stage (shear flow), the rate of accumulation of permanent deformation is constant and is sensitive to the rutting resistance of the asphalt mix. A brief description of each stage follows:

1. Primary stage: large deformation occurs upon the initial load application stage. This stage lasts only a few cycles whereupon a rapid decrease in the rate of deformation is observed. This initial relatively large deformation may be due to the irregular surface of the sample which leads to stress concentrations at these points. Another factor may be densification of the mix as a result of reduced air voids. 
108 


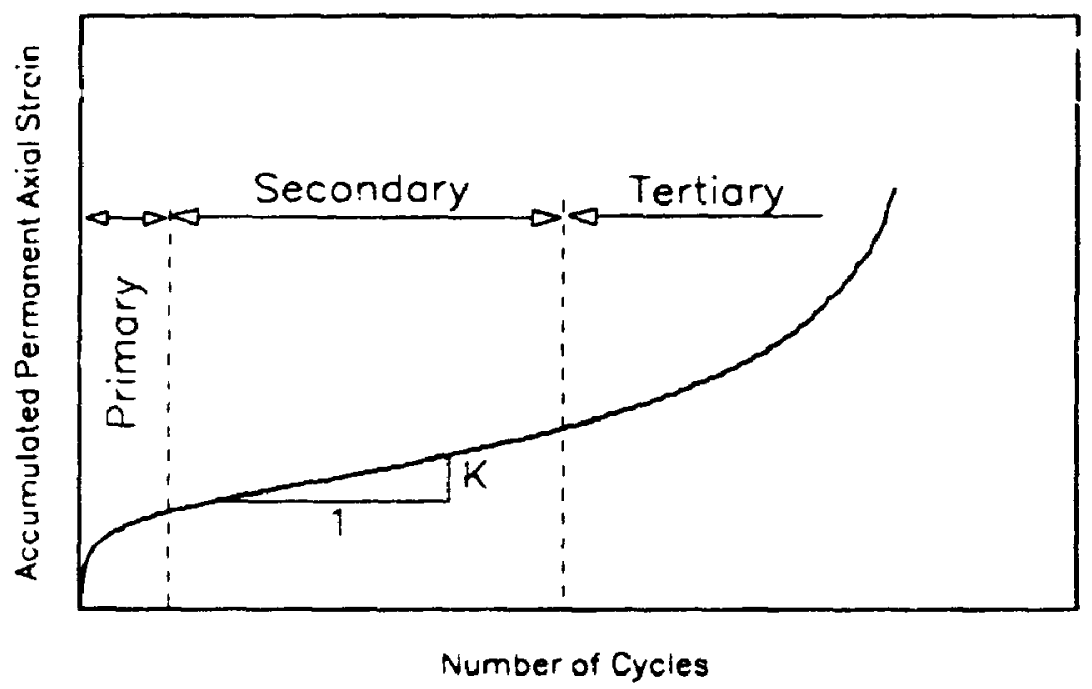

Figure 7.9: Stages of Axial Strain (after Ed Hussein and Yue 1993) 
2. Secondary Stage: During this stage the rate of accumulated permanent deformation remains constant. Once densification has been achieved and surface irregularities have been removed, shear flow is the primary mechanism of deformation. The rate of deformation during this stage is a constant (K) which indicates a mixes ability to resist rutting. A low $\mathbf{K}$ value indicates good rutting resistance.

3. Tertiany Stage: In this stage the rate of deformation increases until complete failure occurs. The formation of cracks is present in this stage which may indicate failure due to fatigue. As of this time it is uncertain what exactly occurs during this stage and further study is in progress by El Hussein and Yue.

In general, further $R \& D$ is necessary in order to improve rutting laboratory tests which could evrntually replace expensive and awkward passing wheel tests.

\subsection{Test Procedure Summary}

A summary of the testing program is given in Table 7.1. A total of six different SMA mixes were tested. To complete the SMA testing program a minimum of ninety samples was required.

On the basis of experience with CRM SMA mixes, only a control and one CRM mix were tested for the LAM. This simplified program added another 30 samples to complete the LAM testing program. Therefore, a total of 120 samples were required for the performance testing component of the thesis. 
Table 7.1: Test Summary

\begin{tabular}{|c|c|c|c|c|c|c|}
\hline \multicolumn{2}{|c|}{ Teet Type } & Temp. & $\begin{array}{l}\text { \%or } \\
\text { semples } \\
\text { required } \\
\text { per mix }\end{array}$ & $\begin{array}{r}\text { Age } 0 \\
\text { (d }\end{array}$ & mple & $\begin{array}{l}\text { Approximate } \\
\text { length of } \\
\text { test }\end{array}$ \\
\hline \multicolumn{2}{|c|}{ ITS } & $25^{\circ} \mathrm{C}$ & 3 & $28-29$ & 8 & 5 min. \\
\hline \multirow[t]{2}{*}{ FATIGUE } & $\begin{array}{c}15 \% \max \\
\text { load }\end{array}$ & $25^{\circ} \mathrm{C}$ & 3 & $28-32$ & 7 & $1-4.5 \mathrm{hrs}$ \\
\hline & $\begin{array}{c}30 \% \max \\
\text { load }\end{array}$ & $25^{\circ} \mathrm{C}$ & 3 & $28-32$ & 7 & 10 - 25 min. \\
\hline \multirow{2}{*}{\multicolumn{2}{|c|}{ Rutting }} & $25^{\circ} \mathrm{C}$ & 3 & $64-68$ & 7 & $\begin{array}{l}\text { stopped } \\
\text { ( } 3 \text { hrs. }\end{array}$ \\
\hline & & $40^{\circ} \mathrm{C}$ & 3 & $62-65$ & 7 & $1.3 \mathrm{hrs}$. \\
\hline
\end{tabular}


The samples were tested at the various ages due to the availability of the test equipment. Rescheduling was required a number of times to work out conflicts. The slight difference in the sample age for a particular test (SMA mixes only) was insignificant to the physical properties of a test specimen due to its advanced age. 


\section{Chapter 8}

\section{PERFORMANCE BASED TESTING}

\section{RESULTS}

This chapter presents the major results of the performance testing program conducted on the control and CRM asphalt cement SMA and large aggregate mixes.

The results obtained from the indirect tensile strength test, fatigue test, and compression test are presented in order. The optimum mix for each mix type was tested. Comparisons between the various optimum mixes were also performed.

This chapter also presents a preliminary discussion of the test results, a more detailed treatment and analysis are carried out in chapter 9.

\subsection{ITS Results}

Three specimens were tested for each SMA mix. The average indirect tensile strength for each mix is presented in Figure 8.1. Figure 8.2 shows the ITS test results for the large aggregate mixes. The following results were observed: 


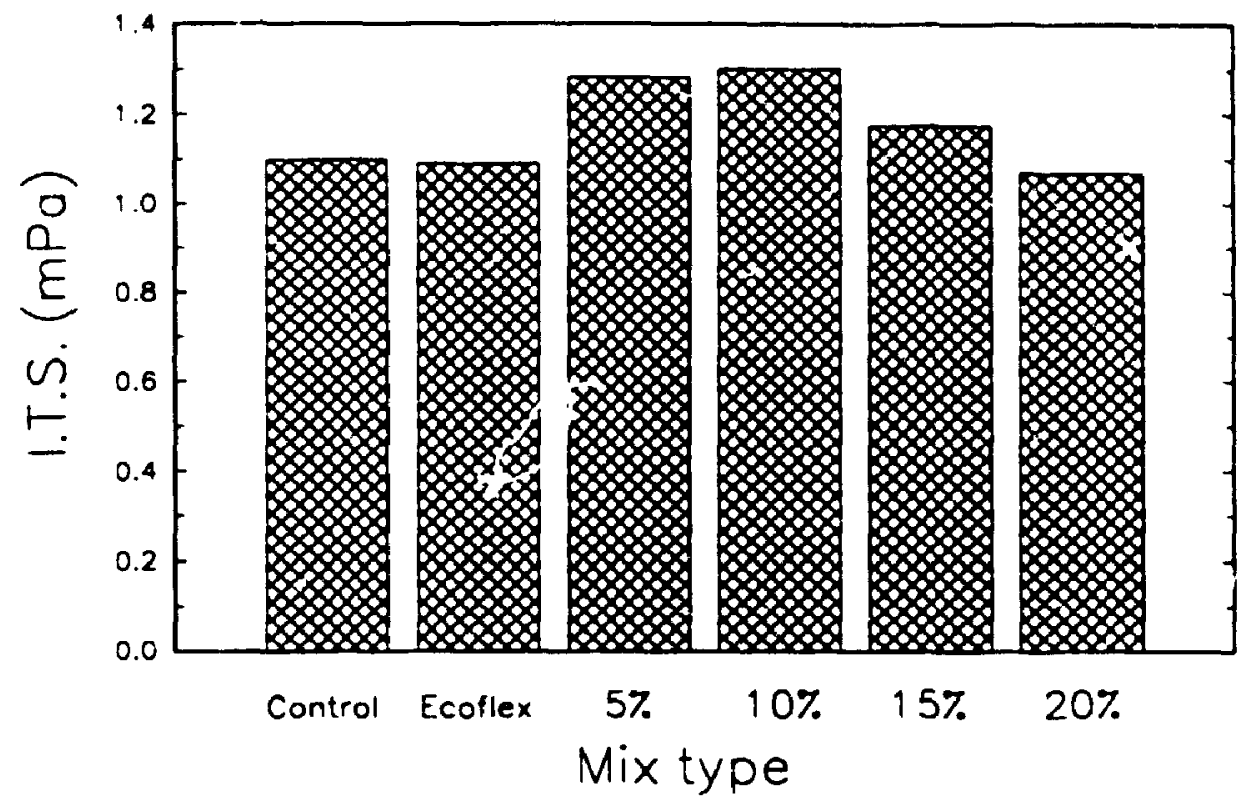

Figure 8.1: Indirect Tensile Strength of Optimum SMA mixes

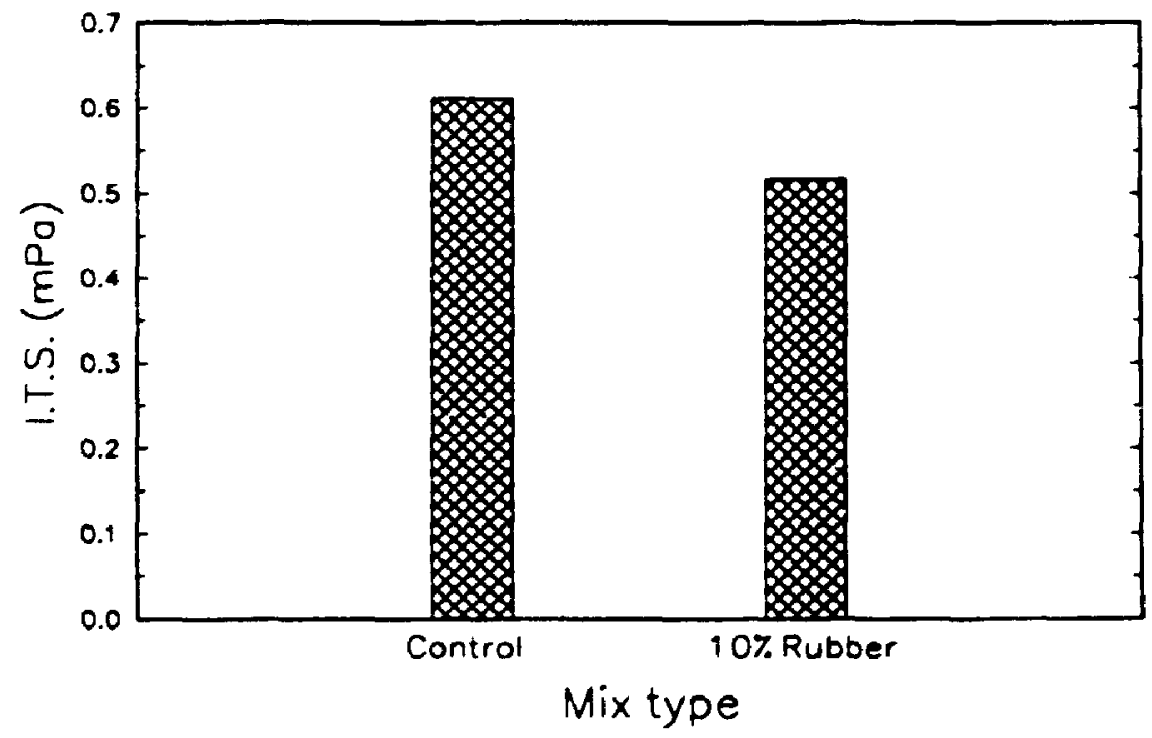

Figure 8.2: Indirect Tensile Strength of Optimum LAM Mixes 


\section{SMA mix}

The addition of crumb tire nubber to the binder has ircreased the indirect tensile strength for three of the four rubber mixes. The strength increased by $16.7 \%, 18.3 \%$, and $7.0 \%$ for the mixes containing $5 \%, 10 \%$, and i5\% crumb rubber respectively. The strength value for the $20 \%$ crumb rubber $\mathrm{mix}$ is very close to the control mix value.

\section{LAM}

The addition of crumb rubber to the binder decreased the indirect tensile strength from 610.4 to $516.6 \mathrm{kPa}$. This $15.4 \%$ decrease in the ITS of the large aggregate mix is not consistent with the SMA results. The addition of the larger rubber particles (GTR 4) has changed the characteristics of the binder. This beha jiour is assumed because a smaller percentage of rubber in the particles is dissolved in the asphalt due to their larger size, thus, there is a failure to change the binder properties to the same extent as occurred with the smaller size particles. The undissolved rubber particles act more as an aggregate when introduced to the mix. Perhaps the introduction of the large size rubber particles changes the tendency of the resultant mix to more closely imitate a dry-process than a wet-process mix. It is fair to conclude that the influence of the size $c$ ₹ crumb rubber particles will be important in further investigations

The maximum selected load used for the fatigue testing was based on a certain percentage of the maximum indirect tensile strength. Therefore, a greater load was used when testing the 5, 10, and 15 percent rubber content SMA mixes in fatigue compared 
to the control SMA mix.. The fatigue tests for the CRM asphalt cement LAM will incorporate a slightly smaller load than the control LAM.

\subsection{Fatigue Testing Results}

Once again three samples were tested for each mix and for each applied tensile load. Figures 8.3 and 8.4 clearly show the effects of adding rubber to the asphalt cement in the SMA mixes. The fatigue results for the LAM are presented in Figure 8.5.

\section{SMA mix}

All the rubber modified asphalt cements display a superior fatigue performance than the control mix. The CRM asphalt cement mixes display a fatigue life of 1.5 to 3 times the life of the control mix at all stress levels. The Ecoflex mix did not show the same levels of improvement compared to the laboratory prepared CRM asphalt cement mixes. The ecoflex asphalt cement is a gel-like homogenous material with completely dissolved rubber particles. Rubber particles are not visible in the mix. This condition will be discussed further in the next chapter.

\section{$\underline{L A M}$}

The fatigue test results for the large aggregate mix are not as conclusive as the SMA mix results. Fatigue life improvement, if any, is not obvious. The only conclusion that might be drawn is that an increase in the fatigue life for the lower stress level of the CRM asphalt cement LAM was observed. 


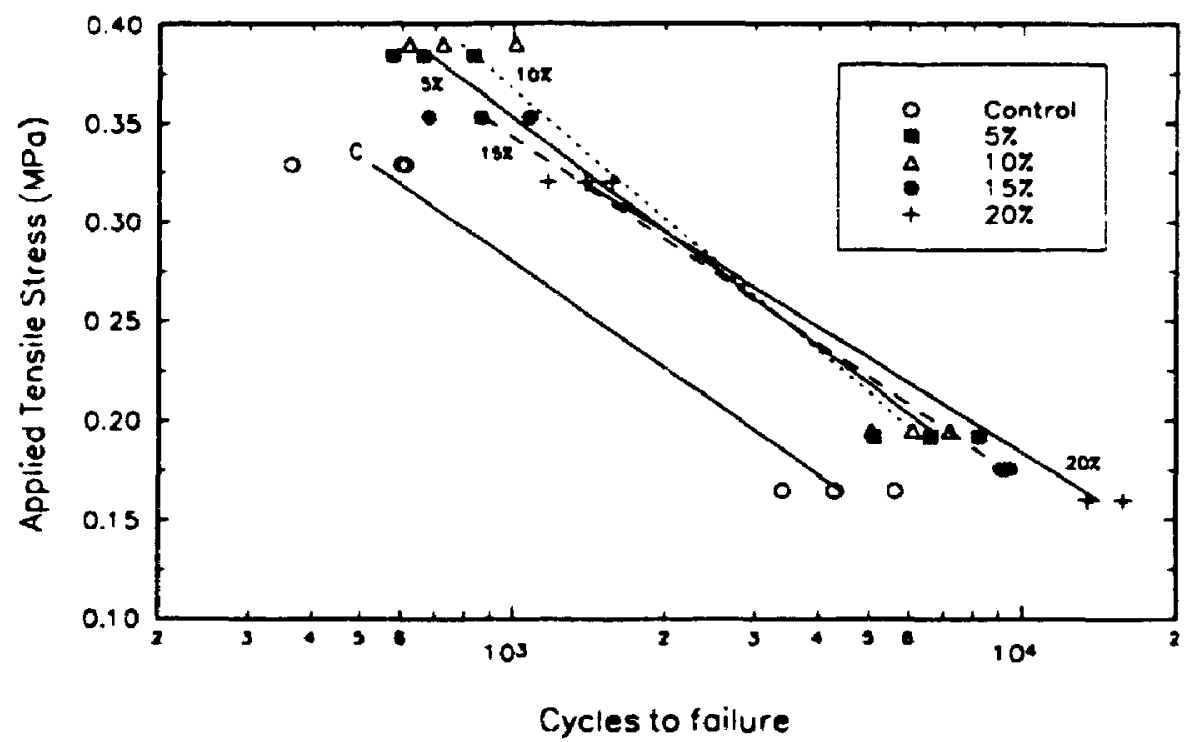

Figure 8.3: Fatigue test results for control and rubber SMA mixes

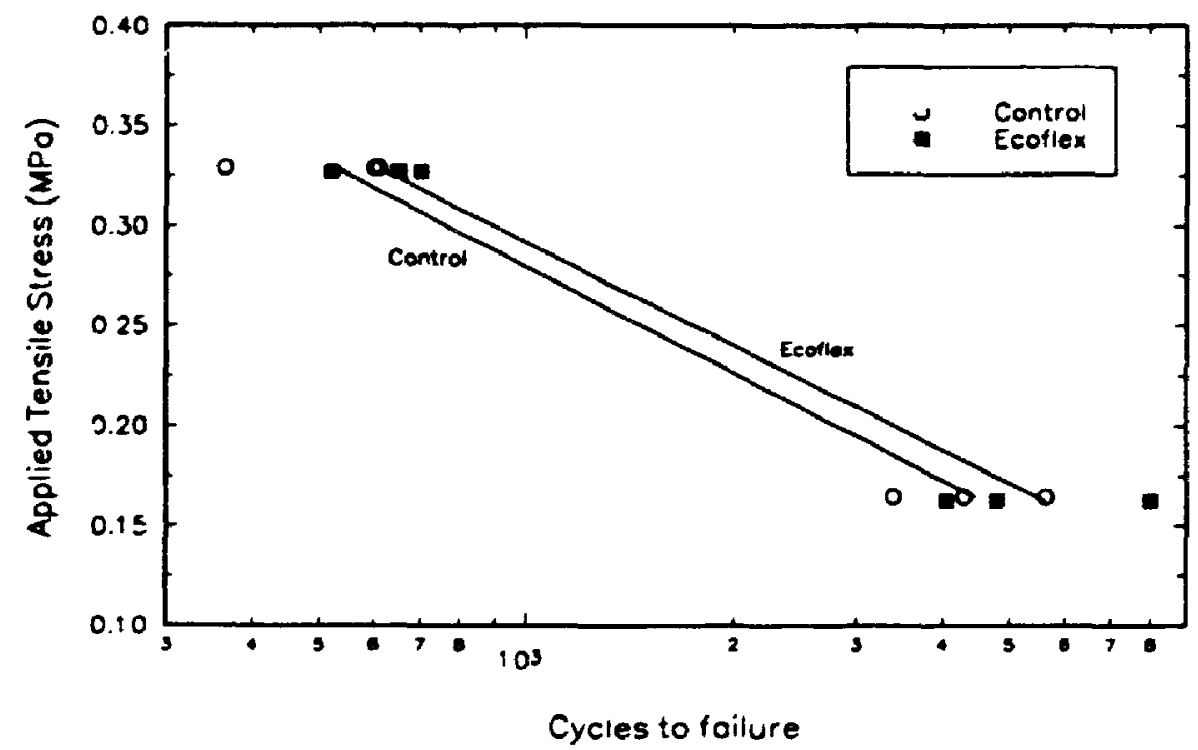

Figare 8.4: Fatigue test results for control and ecoflex SMA mixes 


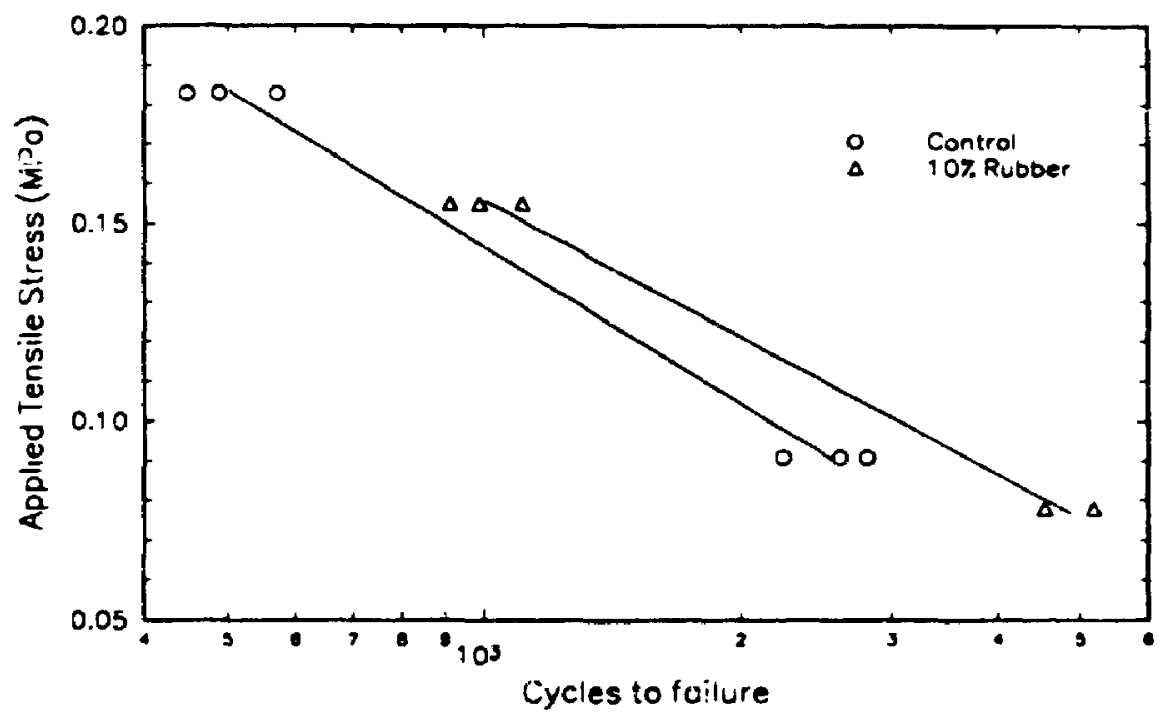

Figure 8.5: Fatigue test results for LAM 


\subsection{Repetitive Uniaxiai Compression Test Results}

As stated earlier the RUCT was performed at temperatu.es of $25^{\circ} \mathrm{C}$ and $40^{\circ} \mathrm{C}$. Three samples were tested for each test condition and a representative test sample was chosen for comparisons between mixes. The results are presented in the following sections.

\subsubsection{Regetitive Uniaxial Compreadion Test at $25^{\circ} \mathrm{C}$}

The CRM asphalt cement and Ecoflex SMA mixes was less susceptible to deformation than the control mix (Figures 8.6 and 8.7). The CRM asphalt cement LAM shows an inferior resistance to rutting than the control LAM (Figure 8.8).

\section{SMA mix}

The 5\% rubber mix showed the least accumulated axial strain of all the mixes. The $10 \%$ rubber mix showed almost equal performance and the $15 \%$ and $20 \%$ rubber mix showed a slight improvement over the control sample. The slopes of the rubber mixes during the secondary stage appear to be equal and smaller than the control mix slope. However, the initial large deformation of the $15 \%$ and $20 \%$ mixes in comparison to the 5\% and $10 \%$ mix seems to be the only factor for their increased permanen ${ }_{L}$ axial strain. This is verified in section 8.3.2. The reason for such a large initial deformation may be due to rubber particles on the surface of the mix providing surface irregularities.

The Ecoflex mix also showed considerable improvement when compared to the control sample. This improvement in permanent deformation may be due to increased 


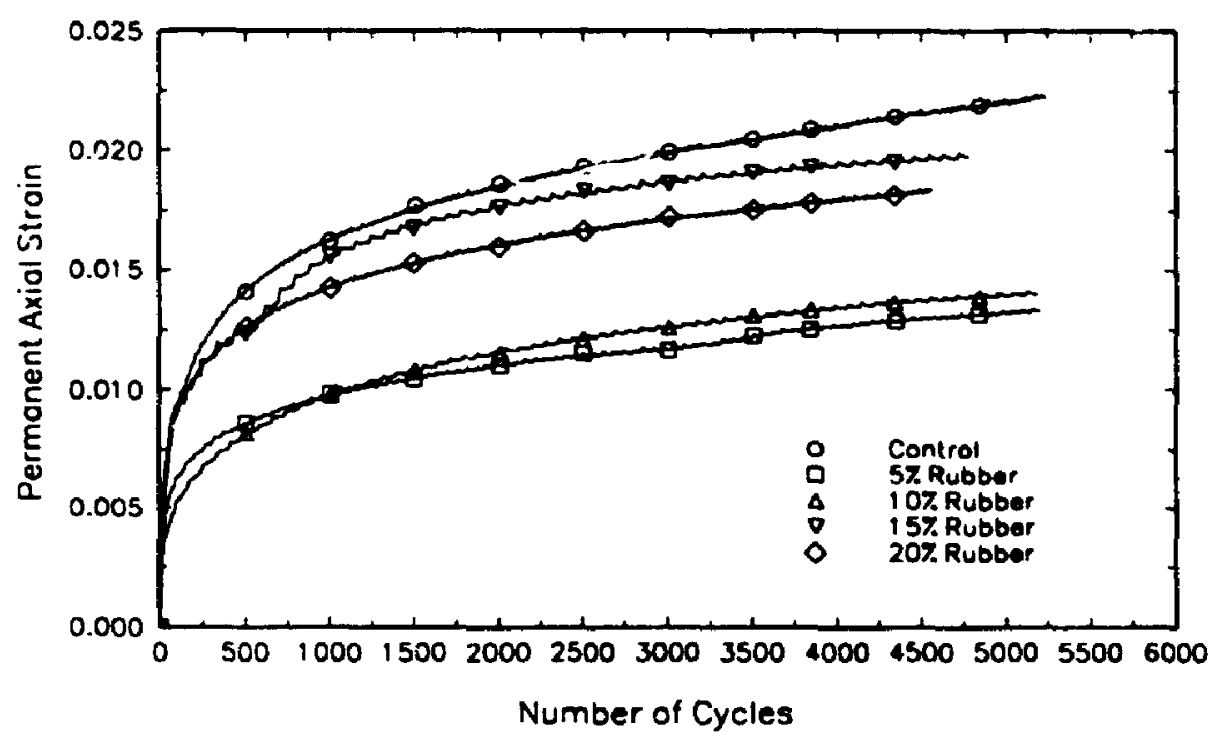

Figure 8.6: Effect of mix type on accumulnted permanent axial strain tested at $25^{\circ} \mathrm{C}$ (SMA mixes)

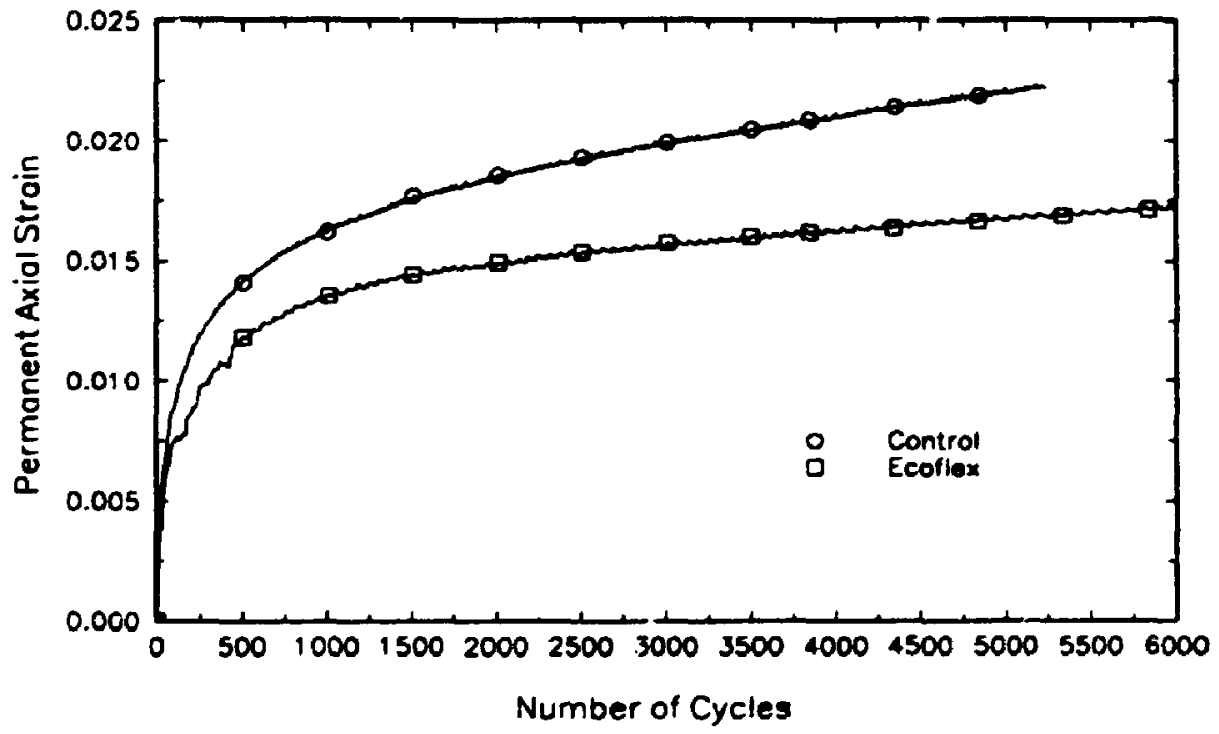

Figure 8.7: Effect of mix type (continued) on accumulated permanent axial strain test at $25^{\circ} \mathrm{C}$ (SMA mires) 


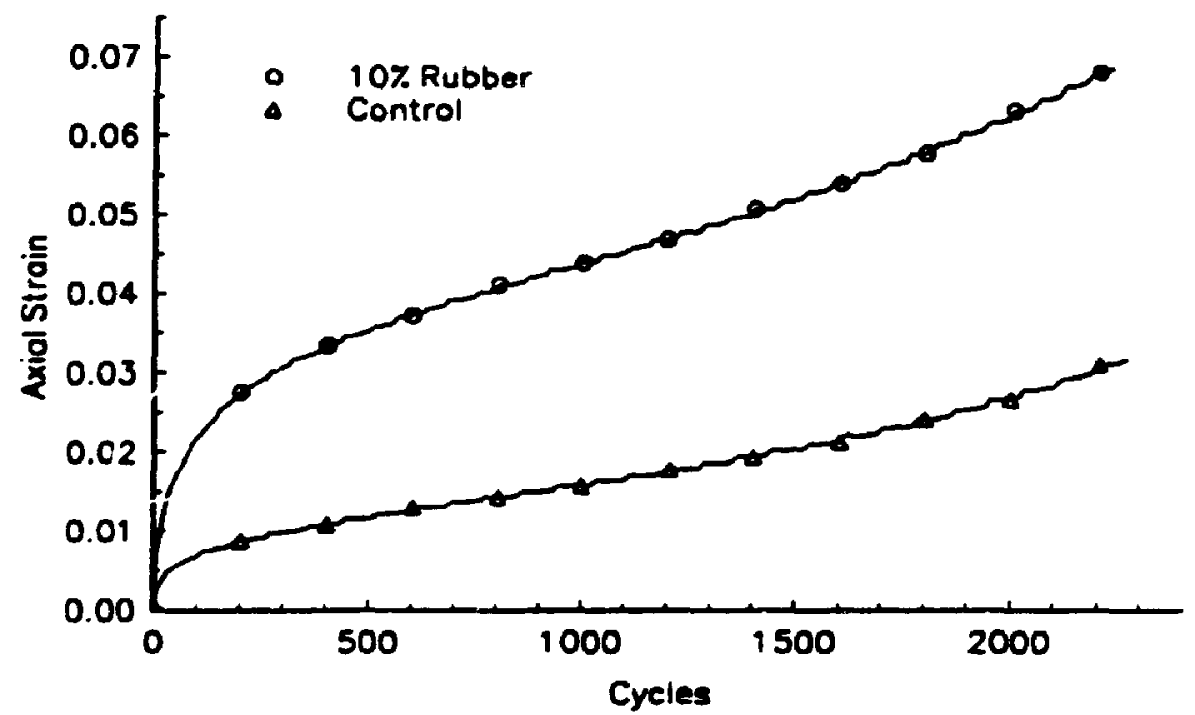

Figure 8.8: Effect of mix type on accumulated permanent axial strain tested at $25^{\circ} \mathrm{C}$ (LAM) 
viscosity of the binder.

\section{$\underline{\text { LAM }}$}

The CRM asphalt cement LAM shows an obvious reduction in rutting resistance. The initial deformation is much larger and the rate of deformation also appears to be greater. It is quite evident that the CRM asphalt cement LAM performs inferior to the control LAM possibly due to the use of larger crumb rubber particles as explained above.

\subsubsection{Repetitive Uniaxial Compression Teat at $40^{\circ} \mathrm{C}$}

\section{SMA mix}

Once again the CRM asphait cement mixes show superior performance to the unmodified SMA control mix. Although a greater initial axial deformation is observed for the $15 \%$ and $20 \%$ rubber mixes (Figure 8.9), probably due to surface irregularities caused by the presence of a greaiei amount of rubber particles, their $\mathbf{K}$ values are still smaller than the $\mathrm{K}$ value for the control mix (Figure 8.12). This indicates that the CRM asphalt cement SMA samples resists permanent deformation to a greater extent than the control mix even at $40^{\circ} \mathrm{C}$.

An improvement is also roted for the Ecoflex mix but not to the extent seen at $25^{\circ} \mathrm{C}$ (Figure 8.10). It seems that there is an improvement only in the primary stage. 


\section{LAM}

The inferior performance of the CRM asphalt cement LAM is even more evident at $40^{\circ} \mathrm{C}$ than it was at $25^{\circ} \mathrm{C}$ (Figure 8.11). The CRM asphalt cement samples deteriorated very quickly under the rutting load at the elevated temperature. 


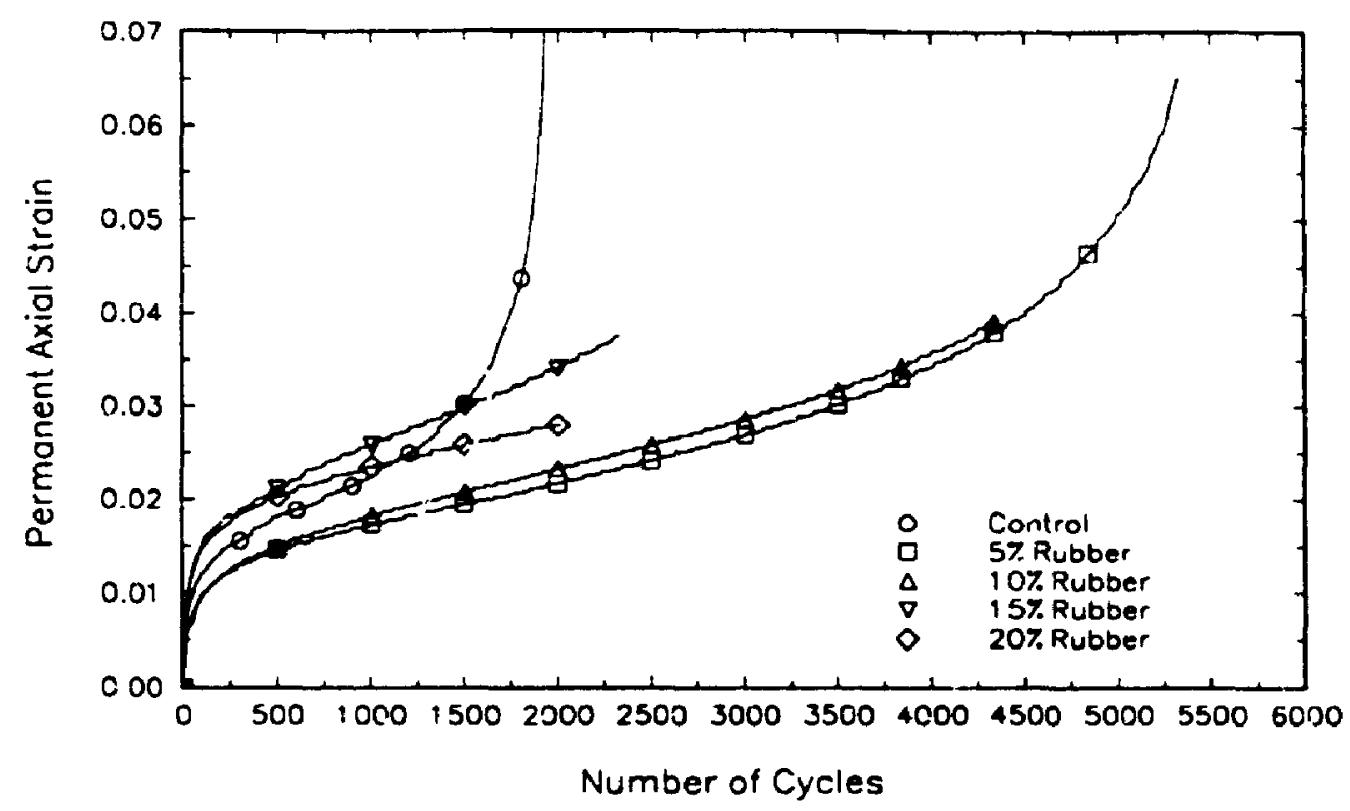

124

Figure 8.9: Effect of mix type on accumulated permanent axial strain tested at $40^{\circ} \mathrm{C}$. (SMA mixes)

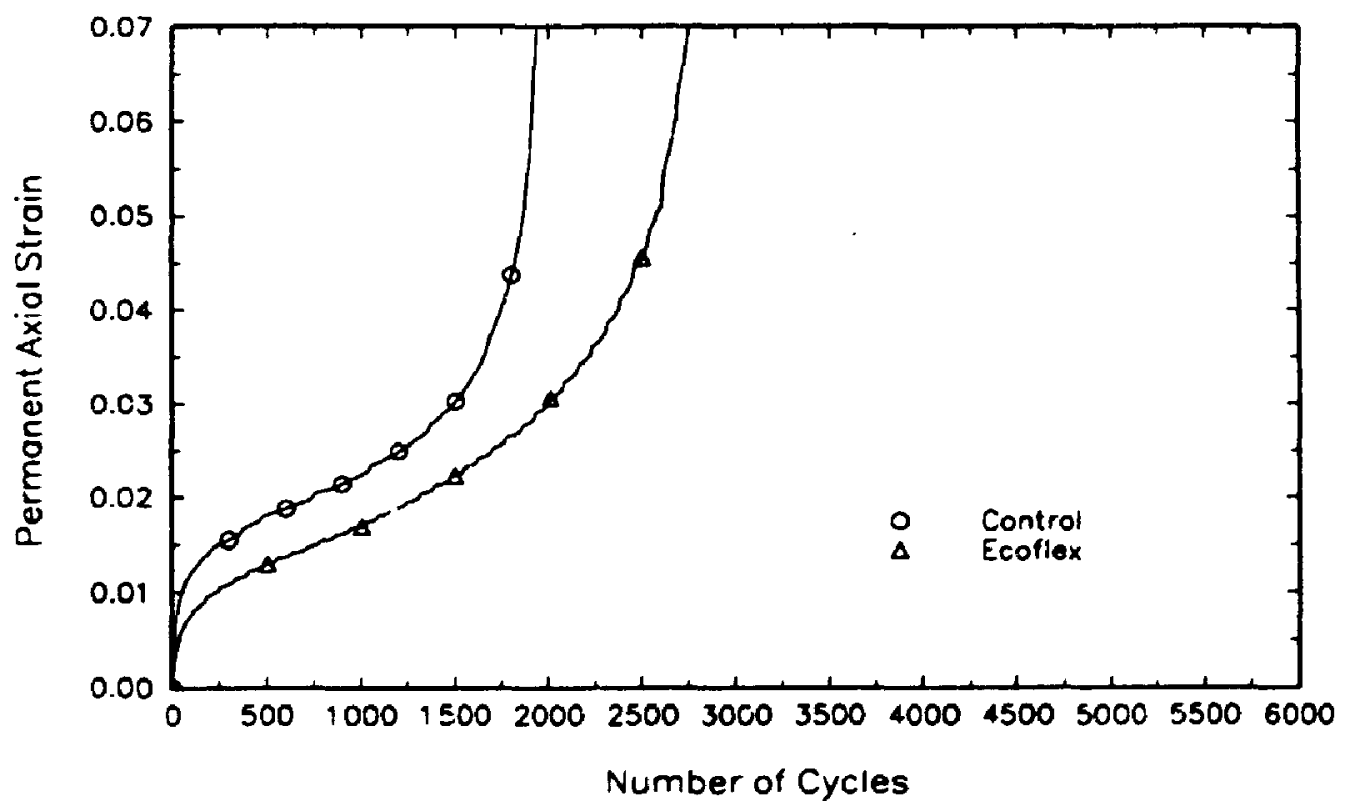

Figure 8.10: Effect of mix type (continued) of accumulated permanent axial strain tested at $40^{\circ} \mathrm{C}$. (SMA mixes) 


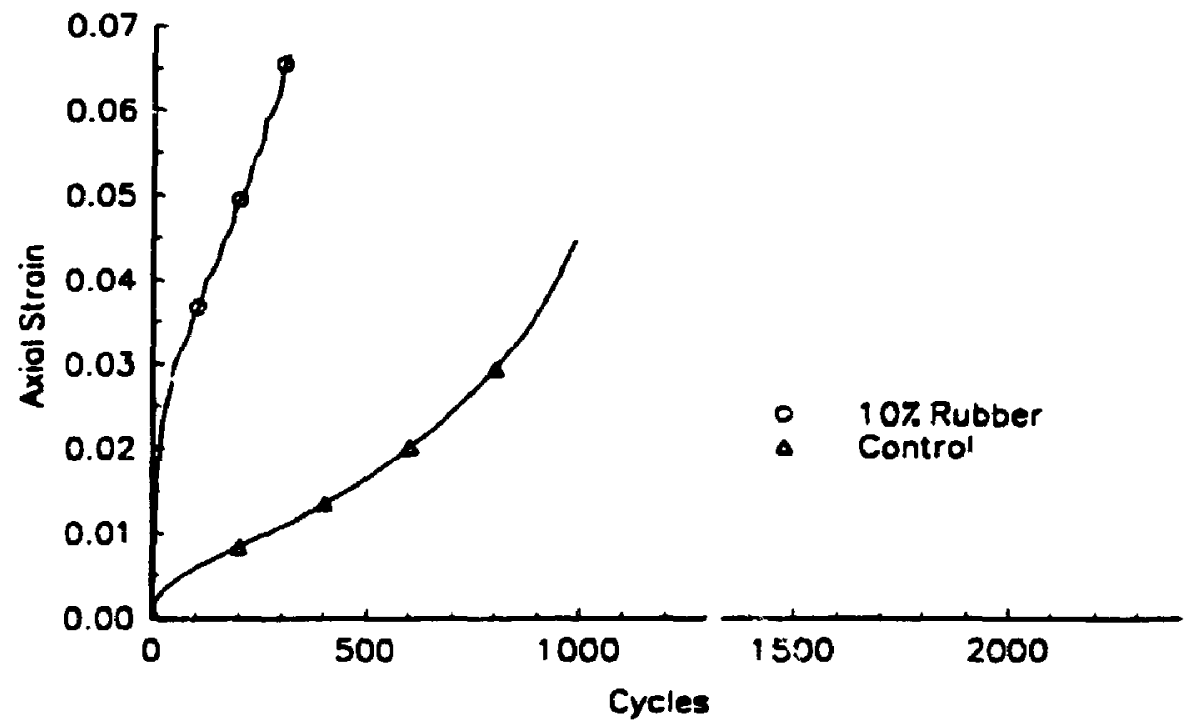

Figure 8.11: Efrect of mix type un accumulated permanent axial strain test at $40^{\circ} \mathrm{C}$ (LAM) 


\subsubsection{K-Value Comparisons}

\section{SMA mix}

Figure 8.12 verifies that the rate of permanent axial strain at $25^{\circ} \mathrm{C}$ for the mixes containing $15 \%$ and $20 \%$ rubber are indeed smaller than the control sample rate though the initial deformation in the primary stage is close. The $5 \%$ and $10 \%$ rubber samples show the highest rutting resistance of the SMA mixes.

The $\mathrm{K}$ values for the $\mathrm{CRM}$ asphalt cement mixes at $40^{\circ} \mathrm{C}$ are clearly superior to the control sample (Figure 8.13). The rate of permanent axial deformation for any CRM asphalt cement mix is superior at both $25^{\circ} \mathrm{C}$ and $40^{\circ} \mathrm{C}$ to the rate of deformation of the control mix. This result indicates an increased elastic resistance to shear flow and should provide better resistance to rutting.

\section{LAM}

Figure 8.14 shows that the rutting resistance of the CRM asphalt cement LAM is comparable to the control $\mathrm{LAM}$ at $25^{\circ} \mathrm{C}$. However, at $40^{\circ} \mathrm{C}$ the $\mathrm{CRM}$ asphalt cement LAM shows an extremely poor resistance to rutting. 


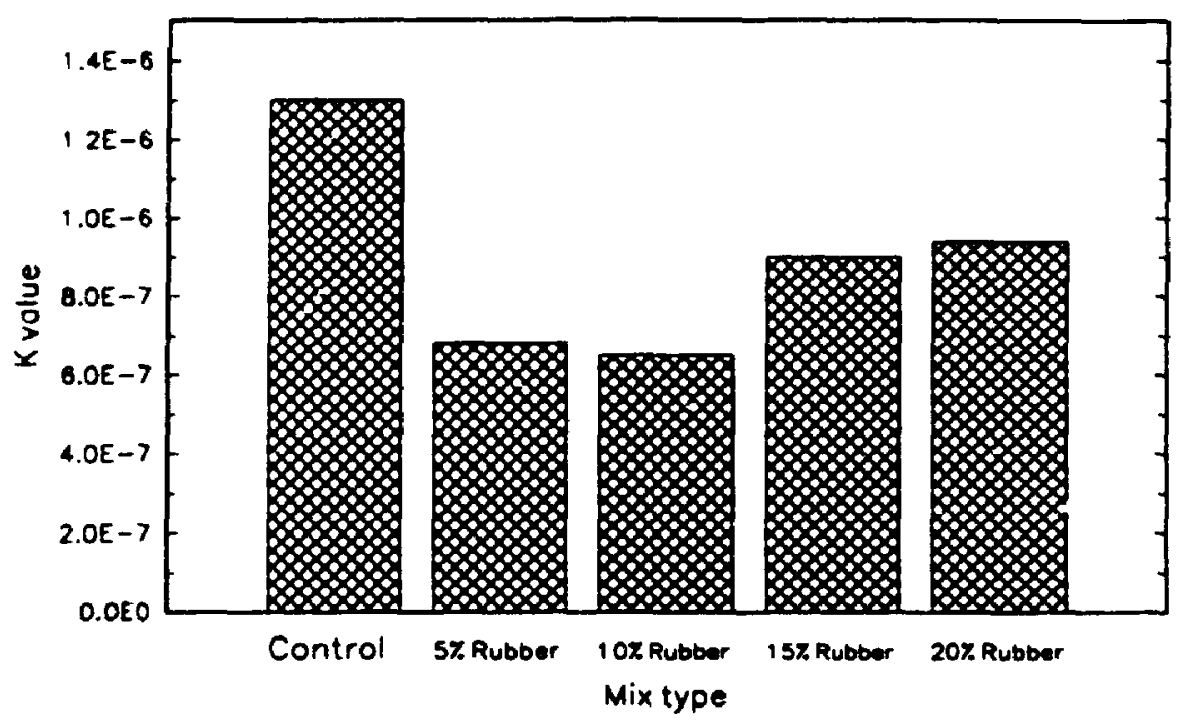

Figure 8.12: K-Values for SMA mixes $\left(25^{\circ} \mathrm{C}\right)$

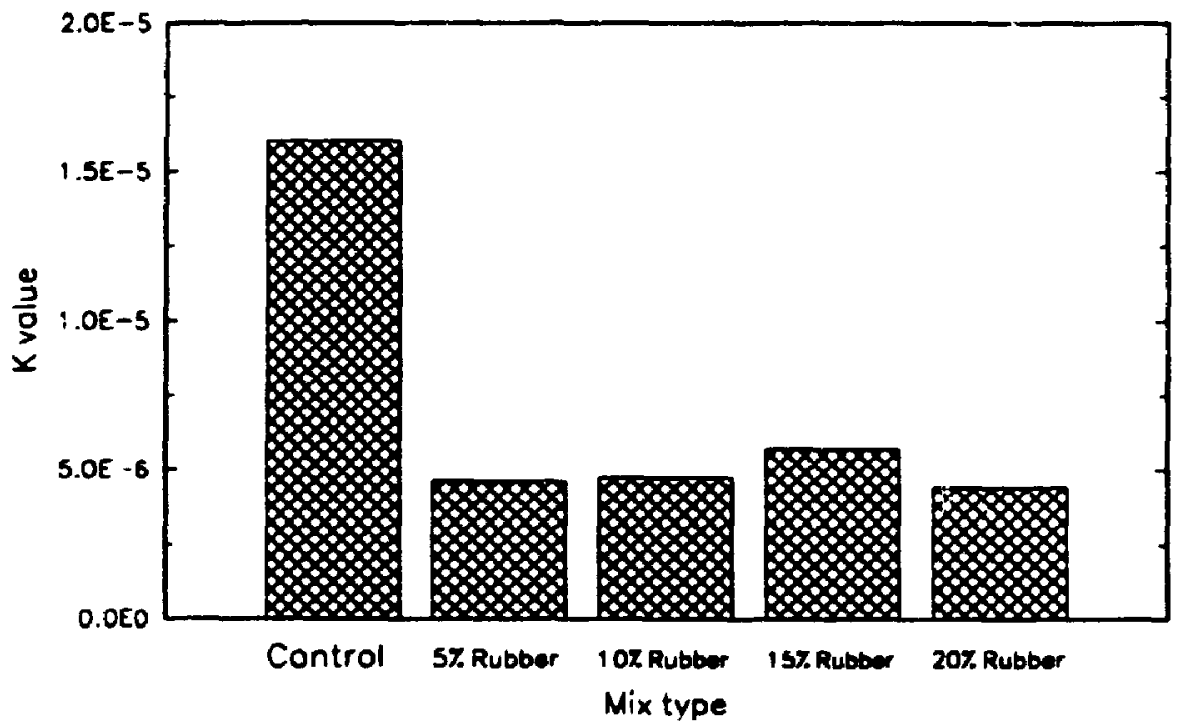

Figure 8.13: K.Values for SMA mbxes $\left(40^{\circ} \mathrm{C}\right)$ 


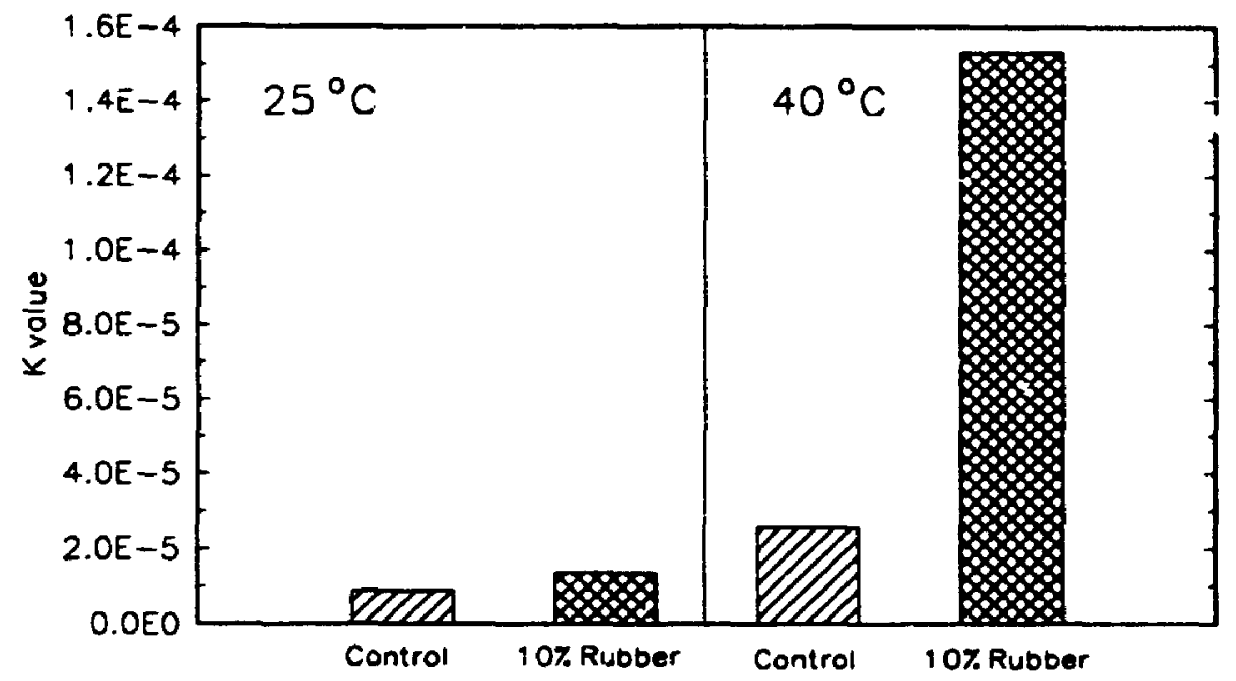

Figure 8.14: K-Vahues for LAM 
129

8.4 Summary of Results

The properties demonstrated by CRM asphalt cement SMA mixes are summarized in Table 8.1. It is quite evident that CRM asphalt cement SMA mixes display superior performance to a regular SMA mix. The opposite is true for the LAM. It is, however, the author's belief that similar performance can be achieved in the case of the LAM compared to the SMA mix, if a focused development is undertaken. To succeed there is a need to further investigate the influence of the compaction method, LAM gradation, size of rubber crumbs, type of bitumen, presence of fines, fibres, etc. 
Table 8.1: Summary of Asphalt Rubber Performance Compared to the Control Mix

\begin{tabular}{|c|c|c|c|c|}
\hline \multirow{2}{*}{$\begin{array}{l}\text { Mix } \\
\text { Type }\end{array}$} & \multirow{2}{*}{ I.T.S. } & \multirow{2}{*}{$\begin{array}{l}\text { Fatigue } \\
\text { Resistance }\end{array}$} & \multicolumn{2}{|c|}{ Rutting Potential } \\
\hline & & & $25^{\circ} \mathrm{C}$ & $40^{\circ} \mathrm{C}$ \\
\hline Ecoflex & $=$ & + & + & + \\
\hline $5 \%$ & ++ & + & + & + \\
\hline $10 \%$ & ++ & + & + & ++ \\
\hline $15 \%$ & + & + & + & + \\
\hline $20 \%$ & - & + & + & + \\
\hline LAM & - & $=$ & -- & -- \\
\hline-1 & e -1 & se $=$ no chenge & all incresse & increase \\
\hline
\end{tabular}




\section{Chapter 9}

\section{ANALYSIS AND DISCUSSION}

\subsection{Introduction}

The purpose of this experimental work was to develop a pavement bared on the asphalt rubber and stone mastic asphalt concept. The basis of the SMA concept is an increased rutting resistance by the mix provided by stone to stone contact of the aggregates. Durable (preferably granite), cubicle, one-size aggregate form the skeleton of the mix. A rich matrix, held in place with filler (passing no. 200), constitutes the remninder of the SMA mix.

A pavement structure is comprised of three layers; subbase, base, and surface. The thicker base layer needs to be resistant to permanent deformation while maintaining a relatively low cost of construction. For this purpose a large aggregate mix (LAM) developed at CSTTARC was employed. The LAM uses the SMA concept of stone to stone contract and is inexpensive to manufacture. The LAM was slightly modified to incorporate crumb rubber particles in the mix. For the surface layer, a finer, more durable, and more expensive SMA mix was developed in this research. This mix is 
highly resistant to rutting and has been improved with the addition of crumb tire rubber.

The Marshall mix design and performance related testing program have revealed interesting results. These are described in detail in the following sections.

\subsection{Discussion of Marshall Test Results for SMA}

With a few exceptions all the SMA mixes met the design criteria presented in Table 5.1. The stability values are well above the minimum requirement of $1800 \mathrm{lbs}$. and flow values are within limits for all 5 mixes. The percentage of air voids (AV) is slightly low for the control mix and is high for the $15 \%$ and $20 \%$ rubber mixes. It was not possible to design a mix that would satisfy the AV requirements for the entire range of binders (control to $20 \%$ rubber). The voids in mineral aggregate (VMA) are slightly lower for the control mix than the design requirements specified by the Asphalt Institute. However, the minimum VMA requirement can be relaxed to at least 12\% (Foster 1986). Foster specified in his report that VMA does not correlate well with performance. Foster states, "The literature that I reviewed indicates that if a minimum VMA is really needed, it is something less than $12 \%$.... I do not think that minimum VMA linits as high as $12 \%$ should be specified as they cannot be justified. If a limit under $12 \%$ is needed then it should be determined."

Other than the four perviously mentioned cases, all requirements for the Marshall mix design are satisfied for the five SMA mixes. The VMA for the Ecoflex mix is 12.75\% which roeets the requirement by Foster. All other requirements are met by the Ecoflex mix. 
Figure 5.7 shows that the bulk relative density (BRD) of the Marshall cores decreases for each increase in the amount of rubber in the binder. This is possibly due to two factors: a lower specific gravity of rubber crumbs compared to stone aggregates and rebound of the mix after each blow of the Marshall hammer. The extra rubber particles in the mix absorb energy of the hammer's blow by tamporary deformation. After the impact the rubber particles resume their original shape. This hypothesis was verified by an equal increase in height for the test specimen for each increase in the arnount of rubber in the mix.

The stability increases with increasing rubber content up to $10 \%$ rubber in asphalt. For mixes containing $15 \%$ and $20 \%$ rubber in the binder, the stability decreased. The flow graphs shows an inverted relationship compared to the stability graphs (Figures 5.2 to 5.7). This increase in strength and decrease in flow can be attributed to the increase' viscosity of the binder. The blending of the rubber into the binder at an elevated temperature increases the binder viscosity, which results in higher stability. The subsequent decrease in stability for $15 \%$ and $20 \%$ CRM asphalt cement binders may indicate that there ir a limit to the amount of crumb rubber than can be properly dispersed into the gaps between the aggregates. The excess amounts of crumb rubber, for this particular SMA mix, could end up residing between the aggregates which would prevent aggregate to aggregate contact. This situation would produce a spongy mix which is not as resistant to loads. Excess rubber in the mix can lead to premature crack generation wader repetitive loads. Visual observation of the samples froduced with higher amounts of rubber supports the idea of the rubber particles preventing proper contact between the 
aggregates (Figure 9.1). The surface of the samples bubbled up slightly and was not as compact as that of specimens with up to $10 \%$ rubber in the asphalt.

The AV increased with an increase in the amount of rubber in the mix. This behaviour is also a result of a mix that is not efficiently compacted due to the elastic properties of the crumb rubber. The decrease in the BRD as a result of energy absorption by rubber crumbs during compaction is evidence of this conclusion and is responsible for the increase in AV. The subsequent increase in the VMA is mostly due to the increase in AV (see Table 5.4). VMA is defined as the amount of AV and effective aspinalt content in the mix. Table 5.4 shows that the effective asphalt content (asphalt not absorbed by aggregate) remains practically unchanged and therefore, indicates that the increase in AV is solely responsible for the increase in the VMA.

The Marshall mix design is easy and efficient at selecting the optimum asphalt content for various mixes. However, performance can not be predicted based on this procedure. Programs, such as SHRP, are developing test methods suitable for standardization and for adoption by state highway departments, other user agencies, and producers of asphalt binders and asphalt-aggregate mixtures to estimate probable field performance of asphait-aggregate mixtures (Mnnismith 1991). Drawbacks of the Marshall mix design include an unrepresentative impact compaction method. Asphalt mixes in the field are compacted mostly by compression, kneading, and shear mechanisms and not by impact hammers. Stability and flow tests do not simulate any fieıd loading conditions and cannot be accurately correlated to performance. These are some good reasons why users are trying to implement other design and performance based testing procedures. 


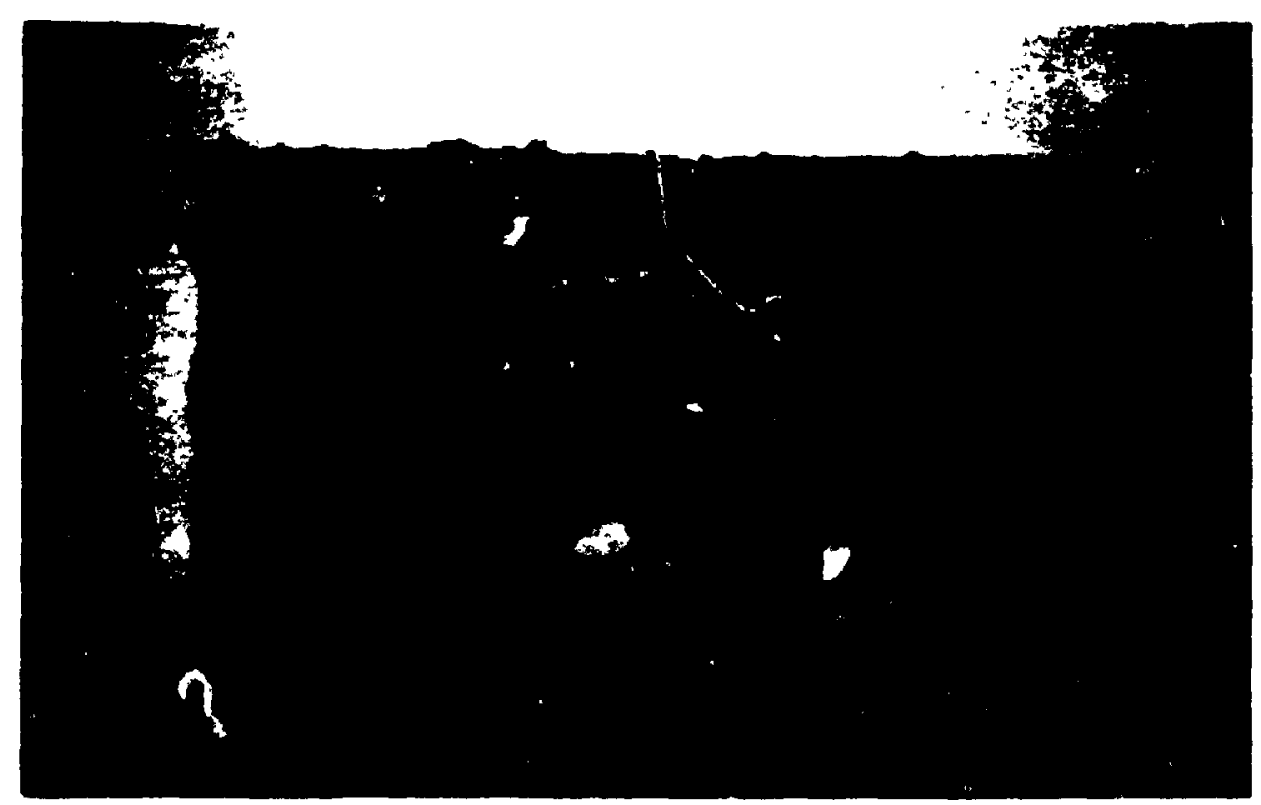

Figure 9.1: SMA Mix Conthining 20\% Crumb Tire Rubber 
Therefore, before any evaluation of the performance of the CRM asphalt cement mixes can be documented, performance related testing must be completed. The results of this testing is given in the next section.

\subsection{Discussion of Performance Related Testing Results}

Performance related testing must be completed before any comparisons between mixes can by evaluated. To achieve this aim four different performance related tests were selected for all SMA and large aggregate mixes. The testing plan was comprised of the following tests:

- indirect tensile strength test (ITS)

- fatigue test

- repetitive uniaxial compression test at $25^{\circ} \mathrm{C}$

- repetitive uniaxial compression test at $40^{\circ} \mathrm{C}$

The LAM samples were compacted by the gyratory equipment in order to better simulate field compaction. Results from these tests are discussed below.

Indirect Tensile Strength Test (TTS)

All mixes, with the exception of Ecoflex and the mix containing $20 \%$ crumb tire rubber, show improved tensile strength for the SMA mixes. This result can be attributed to the increased viscosity of the binder caused by the addition of crumb rubber. Too much rubbe- in the binder resulte in weakening of the mix due to incomplete digestion of the rubber particles. The excess rubber prevents complete coating of the aggregate and 
slightly weakens the asphalt aggregate bond.

The reverse is true for the LAM. The most probable explanation for this large difference in the performance between the SMA and LAM is the large difference in the ratio between the top aggregate size and the sample diameter. The ratio for SMA samples was $0.16(16 \mathrm{~mm} / 100 \mathrm{~mm})$ while for the LAM samples it was $0.25(38 \mathrm{~mm} / 150 \mathrm{~mm})$. It is possible that the strength of such different samples and materials can not be the same or even similar. In addition, laboratory samples have no horizontal confinement. This fact influences the performance of SMA and LAM sample in different ways. Another possible effect is that the addition of $10 \%$ rubber crumbs to the binder weakened the samples in the ITS test. This weakening, perhaps, can be attributed to one factor in the production of the CRM asphalt cement binder: a much larger size of rubi = crumb was used for this particular rubberized binder. This variation was attempted because the stone size in the LAM is much larger than the SMA stone size. However, the increased size of rubber crumb in the binder had two effects. Firstly, due to the decrease in surface area of the crumb rubber (resulting from a coarser gradation) less rubber was dissolved in the hot asphalt cement. This lack of solution resulted in a smaller increase in viscosity than normally experienced by the CRM asphalt cement binder. Secondly, the undissolved relatively large chunks of rubber in the mix tend to act more as an aggregate. These rubber aggregates weaken the mix in the same way that a dry process CRM asphalt cement mix is weakened. It is evident that the same size crumb rubber should be used for the LAM as was used for the SMA mix, even though the aggregates in the LAM are much larger. This modification should improve the mix properties for a CRMi asphalt 
cement LAM. It has to be realized, however, that if smaller size rubber crimbs were to be used, a higher overall pavement cost is to be expected.

\section{Fatipue Testing}

The performance of the CRM asphalt cement SMA mixes are clearly superior tc the control mix in the fatigue tests. The more elastic properties of the binder (due to the presence of rubber particles) helps in absorbing the energy imposed by the fatigue loading. The increased viscosity of the binder along with the elastic properties of the rubber particles (which imparted improved elasticity or flexibility to the asphalt concrete samples) slowed down the crack propagation process through the test specimens.

The fatigue tests for the LAM specimens are inconclusive. The improved elastic properties of the particles of rubber might offset the weakened mix due to the larger size of particles. As mentioned previously, a large aggregate design and testing program has to be undertaken in order to develop a successful crumb rubber LAM. Implementing this type of program has certain design difficulties. A mix design program must be developed for use with a gyratory compactor and a number of different variables must be addressed under laboratory testing before developing well defined laboratory testing conditions. It must be kept in mind that SMA and LAM are completely different mixes that perform differently as was explained previously. 


\section{Repetitive Uniaxial Compression Test}

The repetitive uniaxial compression test was developed to simulate traffic loading. An impact load of $690 \mathrm{kPa}$ is applied for 0.2 seconds of every 2 second cycle. The CRM asphalt cement SMA mixes displayed superior performance at both $25^{\circ} \mathrm{C}$ and $40^{\circ} \mathrm{C}$ compared to the control mix. Again it is postulated that the elastic properties of the CRM asphalt cement binder helped in absorbing some of the impact load energy during the tests. The CRM asphalt cement binder produced a mix with improved rutting resistant properties compared to the control SMA mix. Since the control mix has improved compression (rutting) resistance compared to conventional mixes, it is expected that a CRM SMA mix might display exceptional rutting resistance if used in the field. This expectation can be further explained by the fact that the laboratory sample under the test conditions has $\mathrm{n} n$ horizontal confinement compared to the field situation.

The CRM asphalt cement large aggregate mix displayed the poorest performance in this test. During the test the CRM asphalt cement LAM specimens deteriorated rapidly. Pieces of the mix would crumble off the edges of the specimen after the load was removed. The larger chunks of rubber seemed to disrupt the adbesion of the mix. This problem might be alleviated by using the same CRM asphalt cement binder as was used for the SMA mix. It is obvious that this binder was not performing up to the standard. Another possible explanation of this type of failure is that some of the large rubber crumbs might have clustered together during mixing (ie. at the bottom of the flask), consequenuly the binder would lose its homogeneity. The resulting CRM asphalt concrete mix would be weakened by the loss of stone-to-stone confact of the aggregates 
due to the rubber crumbs.

\subsubsection{Variabillity of Test Data}

Some variability in the test data is evident for each performance test. Since asphalt mixtures are a composite material with many variables affecting their performance, a variability in results is expected. There are many factors that affect the results of the testing. Even after every attempt is made to ensure consistency, it is till not nossible to produce identical laboratory specimens. The following factors affect the consistency of laboratory samples and may contribute to inconsistent final results:

- differences in asphalt, aggregate, mixture, and compaction temperatures. Each oven has hot and cold spots. Also, different ambient temperatures could affect mixing and compaction conditions.

- aggregate orientation. Although every effort is made to produce identical samples the variability in aggregate shape and orientation in the compacted mix has some effect on final properties of each sample.

- placement of the sample under the test head. The orientation of the sample in the joading bead is important since the test outcome could be affected. It is not possible to ensure placement of the sample exactly in the centre of the lording heads test after test. Even small misalignment of the specimen and loading head can be critical when employing the ITS and Fatigue tests.

- worker variability. Samples tested or prepared by different people coulid differ in properties depending on the individual's skill and procedures. 
The individual sample variability was kept to a minimum by preparing more samples if necessary. The general good repeatability shown by the tests is evidence of success.

\subsection{Summary}

Test results reported in this chapter satisfied the main objectives of the experimental program. A CRM asphalt pavement was designed using cwo different mixes. The surface coarse was based on an SMA concept and small size aggregate mix while for the base coarse design, a modified large aggregate mix designed at CSTTNRC was used. The CRM SMA surface course has shown superior performance to the unmodified mix and has aiso displayed extreme resistance to rutting deformation. The base course mix did not perform according to expectations, but it is believed that with further modifications and well supported R\&D, this objective can be achieved. It is also believed that the use of this pavement system (with the re-design of the base coarse) will not only aid in the reduction of discarded tire stockpiles, but also will improve the performance of asphalt pavements. 


\section{Chapter 10 \\ SUMMARY, CONCLUSIONS, AND RECOMMENDATIONS}

This final section of the thesis summarizes the work carried out in the research program and presents the major conclusions resulting from this research. Several recommendations for further research are also presented.

\subsection{Summary}

The main objective of this thesis was to design a CRM asphalt pavement based on two different mixes; (a) a small top size aggregate mix ( $<19 \mathrm{~mm}$ ), and (b) a large top size aggregate mix (up to $38 \mathrm{~mm}$ size stone). The first mix was based on the stone mastic asphalt (SMA) concept while the second was based on a CSTT LAM design. It is expected that the use of CRM asphalt in both mixes will create a durable pavement which will go a long way in helping to reduce the scrap tire disposal problem. The small stone size SMA mix was developed for use with CRM asphalt for a thin top pavement layer and was designed to provide superior rutting resistance. A crumb rubber modified 
LAM was selected to be used for a base layer in the pavement structure. The SMA mixes were designed using the Marshall method of mix design. Both the SMA and LAM CRM mixes were compared with their respective control mixes using performance testing. The four tests used to relate sample performance were: indirect tensile strength test (ITS), fatigue test, and repetitive uniaxial compression (rutting) tests at $25^{\circ} \mathrm{C}$ and $40^{\circ} \mathrm{C}$. These performance tests showei promising results.

The next section iterates the major conclusions of each phase of the research, including the literature review, Marshall mix design, and performance testing of both the SMA and large aggregate mixes.

\subsection{Conclusions}

The conclusions of this research work are divided into three sections. The following major cor:alusions are based on; (a) the literature review, (b) Marshall mix design phase, and (c) performance testing phase.

\section{Litenture Review}

Crumb rubber modified asphalt has been successfully used since the mid 1960's. There are two distinctively different ways to manufacture CRM asphalt: the wet process and the dry process. All methods where rubber crumbs are incorporated into bitumen before rnixing with the aggregates are called the wet process. Methods where rubber crumbs are first mixed with the aggregates and then mixed with hot bitumen is called the dry process. Dry process field applications of CRM asphalt do not appear to be as 
successful as wet process applications. Although wet process CRM asphalt is estimated to cost 1 1/2 to 2 times the cost of HMA 1 avements, it has also been demonstrated to last over twice as long as ifoslar asphalt cement pavements in Phoenix, Arizona. CRM asphalt cement pavements made by the wet proce:- - also been shown to retard reflection cracking, resist rutting and aging, and to improve fatigue properties in both the laboratory and the field. It is because of these characteristics that the wet process was selected as the method to prepare the CRM asphalt for this thesis. Other factors that influenced the choice of the thesis topic include the author's personal interest in the Jevelopment of better roads while addressing an environmental problem and the possibility that Canada mig't follow the lead of the US Congress which passed a bil mandating the use of CRM asphalt cement.

\section{Marsball Mix Design}

The Marshall mix design was successfully employed in the development of six different SMA mixes. The optimum asphalt content of each mix was determined and comparisons were made among them. Although this mix design method is detailed in specifications and is easy to use, several shortcomings have been noticed. They are outlined as follows:

- Marshall compaction does not simulate field compaction

- Marshall tests cannot predict field perfe: ance

- only $101.6 \mathrm{~mm}$ diameter samples can be made. This prevents the design of any mix using aggregates larger than $19 \mathrm{~mm}$. A large aggregate mix cannot be made 
using a Marshall compactor.

Once the SMA mixes had been designed, optimum samples of each mix were compacted using the Marshall compactor. The LAM samples were compacted using a gyratory shear compactor. Subsequently, the samples were subject to performance tests.

\section{Performance Related Testine}

Results of the performance related tests are very promising. The crumb rubber modified asphalt SMA mixes showed superior results compared to the control mixes in all the performance tests. The asphalt rubber with $10 \%$ crumb tire rubber by weight of binder gave the best results. The superior ITS and fatigue properties of this mix indicates an excellent resistance to cracking. Outstanding repetitive uniaxial compression test (rutting) :esults indicates improved rutting resistance of this asphalt rubber mix. It is clear that the addition of GTR-10 crumb tire rubber to the asphalt cement has improved the quality of this particular SMA mix.

The results of the CRM large aggregate mix are disappointing. A decrease in the performance of this mix was evident in the ITS and RUCT tests. No change was noted in the fatigue test. It is very likely that the drop in performance is attributed to the fact that relatively large chunks of rubber were used for manufacturing the asphalt rubber binder. If the same size of rubber that was used in the SMA phase of this research is also used for the large aggregate mixes, a vast improvement in performance should be expected. Further research and development is needed to develop a proper LAM using CRM asphalt. 


\subsection{Recommendations for Future Research}

The testing program overview outlined in Chapter 3 was devised based on equipment availability and the time constraints for this thesis. Allowing more time for further basic research and determining the influence of design variable the following is recommended:

- Prepare all samples using a gyratory shear compactor. The gyratory shear compactor more closely simulates field compaction and provides superior samples. Aggregate cracking is noticeable with Marshall compection due to the confined boundary conditions and impact load of the Marshall hammer. Even under the same boundary conditions, the gyratory shear compacuon allows for ag,gregate reorientation providing for a denser sample. In order to eliminate the Marshall method, a new mix design program must be formulated for use with a gyratory shear compactor. Standards for this type of program are not currently available.

- Study more closely the effects of rubber particle sizes on the mixes. Changing the particle size of the srumb rubber between the SMA and large aggregate mixes has greatly changed the test results. Larger test samples might be needed to pioduce a good quality LAM sample.

- Study interaction conditions (ie. temperature, mixing conditions, etc.) between rubber and bitumen during manufacture of the wet process CRM asphalt. For example, mixing time and temperature have an important effect on the final bitumen viscosicy (which is a function of temperature and time) and resulting CRM asphalt concrete properties. 
- Introduce more performance tests to get a clearer picture of the effect of adding rubber to the binder. Other tests to consider are: resilicist modulus $\left(M_{R}\right)$ tests and cold temperature tests (ITS, and Fatigue) at various temperatures (down to $-40^{\circ} \mathrm{C}$ ); RUCT and, if available, wheel rutting tests at both room and high temperatures $\left(60^{\circ} \mathrm{C}\right)$. moistuire darrage tests (repetition of certain tests after conditioning samples in water for various extended periods of time), and aging tests (both short and long term). The wheel rulting test has an advantage of more closely simulating field loading conditions compared to the repetitive uniaxial compression test.

- Finally, field trials should be used to correlate lab data with actual field conditions and to verify that performance has improved.

- Before this new technology can be recommended for wide field implementation, a detailed pavement life and cost analysis will havé to be made. 


\section{References}

- AASHTO, "Standard Specifications for Transportation Materials and Methods of Sampling and Testing, Part II", Washington, DC, 1978.

- Al-Abdul-Wahab, H., \& Al-Amri, G., "Laboratory Evaluation of Reclaimed Rubber Asphaltic Concrete Mixes", Joumal of Materials in Civil Engineering. . ¿SCE, Vol. 3 No. 3, August 1991, pp. 189-203.

- Allen, H.S. \& Turgeon, C.M., "Evaluation of 'Plus Ride" TM, (A Rubber Modified Plant Mixed Bituminous Surface Mixture)", Physical Research Unit, Office of Materials and Research, Minnesota Department of Transportation, Janvary 1990.

- Allison, K., "Those Ainazing Rubber Roads, Part II", Rubber World, March, April 1967.

- Allison, R.E., "PlusRide (Trade Name) Asphalt Concrete Pavement. Experimental Feature WA-84-01", Washington State Department of Transportation, January 1990.

- Arizona DOT, "Summary of Arizona Department of Transportation Experience with Asphalt Rubber", ADOT, August 1988.

- Bellin, P.A.F., "Use of Stone Mastic Asphalt in Germany: State of the Art", paper submitted to the 71st TRB Annual Meeting, 1992. 
- Bergh, A.O., Thompson, H.C., \& Nel, A., "Bitumen Rubber Asphalt (Dry Process)", Proceedings, Sth Conference on Asphalt Pavements for Southern Africa (CAPSA 89), Swaziland, 5-9 June, 1989.

- Brink, R.H., "Use of Waste Sulfate on Transpo '72 Parking Lot", Proceedings, 3rd International Ash Utility Symposium, March 13-14, 1973.

- Brown, S.F. \& Brunton. J.M., "Improvements to subgrade strain criterion", Joumal of Transportation Engineering, ASCE, Vol. 110, No. 6, pp. 551-567, 1984.

- Charania, E., Cano, J.O., \& Schnormeier, R.H., "A Twenty Year Study of AsphaltRubber Pavements in the City of Phoenix, Arizona", report produced by the Asphalt Rubber Producers Group, Phoenix, Arizona, undated.

- Charania, E., Cano, J.O., \& Schnormeier, R.H., "Rubberized Asphalt -- Still Sound After 20 Years", Better Roads, Vol. 61, No. 8, August 1991, p. 35.

- Chehovits, J., "Design Methods for Hot Mixed Asphalt-Rubber Concrete Paving Materials", Asphalt Rubber Producers Group, Proceedings of the National Seminar on Asphalt Rubber, Kansas City, Missouri, October 30-31, 1989, pp. 151190.

- Consuegra, A., Little, D.N., Von Quintus, H. and Burati, J., "Comparative Evaluation of Laboratory Compaction Devices Based on their Ability to Produce Mirtures with Engineering Properties Similar to those Produced in the Field", Transportation Research Record 1228, TRB, National Research Council, Washington, D.C., pp. 80-87, 1989. 
- Dickson, E.J., "Assessment of the Deformation and Flow Properties of Polymer Modified Paving Bitumens", National Seminar on Asphalt-Rubber, Demonstration Projects Divisiom, FHWA, U.S. Department of Transportation, Oct. 1981, pp. 265272.

- Doty, R.N., "Flexible Pavement Rehabilitation Using Asphalt-Rubber Combinations: A Progress Report", Califormia Department of Transportation, January 1988.

- Eaton, R.A., Roberts, R.J. \& Blackburn, R.R., "Use of Scrap Rubber in Asphalt Pavement Surfaces", Special Report 91-27, Cold Regions Research and Engineering Laboratory, U.S. Army Corps of Engineers, December, 1991.

- El Hussein, H.M., Svec, O.J. \& Zanzotto, L., "Performance of Asphalt Concrete Mixes Containing Large Size Mineral Aggregates", Proceedings, Annual Conference of CSCE, Fredericton, N.B., June 8-11, 1993.

- El Hussein, H.M. \& Yue, Z., "A Criteria for Evaluation of Rutting Potential of Asphalt Concrete Based on Repetitive Uniaxial Compression Test", Accepted for Presentation at the 73rd Annual Meeting of the Transportation Research Board, Washington, D.C., January 9-13, 1994.

- Emery, J.J., Davidson, J.K., Schenk, W., Carrick, J.J., \& Macinnis, W.K., "Stone Mustic. Asphalt Trials in Ontario", Presented at the 72nd Annual iafesting of the Transportation Research Board, Washington, D.C., January 10-14, 1913.

- Environmental Protection Agency, "Markets for Scrap Tires", EPA/53C-SW-90074B, September 1991. 
- Foster, C.R., "The effects of Voids in Mineral Aggregate on Pavement Performance", Information Series 96/86. National Asphalt Pavement Association, Riverdale, Maryland, 1986.

- Heitzman, M.A., "Design and Construction of Asphalt Paving Materials with Crumb Rubber Modifier", Transportation Research Record 1339, TRB, National Research Council, Washington, D.C., pp. 1-8, 1993.

- Hoyt, D.M., Lytton, R.L., \& Roberts, F.L., "Criteria for Asphalt-Rubber Concrete in Civil Airport Pavements. Mixture Design", Final Report DOT/FAAPM-86/39, Federal Aviation Administration, Washington, D.C., July 1986.

- Hoyt, D.M., Lyttor, R.L., \& Roberts, F.L., "Performance Prediction and CostEffectiveness of Asphalt-Rubber Concrete in Airport Pavements", Transportation Research Record 1207, TRB, National Research Council, Washington, D.C., pp. 83-99, 1988.

- Hughes, C.S., "Scrap Tire Utilization Technologies", National Asphalt Pavement Association and State Asphalt Pavement Association Executives, Information Series 116, February 1993.

- Jacobson, C.C., \& Schnormeier, R., "Cost Effectiveness of Asphalt-Rubber", Asphalt Rubber Producers Group, Proceedings of the National Seminar on Asphalt Rubber, Kansas City, Missouri, October 30-31, 1989, pp. 33-42.

- Jimenez, R.A., "Testing of Asphalt Rubber and Aggregate Mixtures", Report FHWAAZ-79/111, Arizono. Department of Transportation, Phoenix, October 1979. 
- Jimenez, R.A., "Laboratory Measurements of Asphalt-Rubber Concrete Mixtures", Transportation Research Record 843, TRB, National Research Council. Washington, D.C., 1982, pp. 4-11.

- Jimenez, R.A, "Viscosity Measurements of Asphalt-Rubber Binders", Asphalt Rubber Producers Group, Proceedings of the National Seminar on Asphalt Rubber, Kansas City Missouri, October 30-31, 1989, pp. 120-150.

- Jimenez, R.A., Morris, G.R., \& DaDeppo, D.A., "Tests for a Strain-Attenuating Asphaltic Material", Proceedings, AAPT, vol. 48, 1979, pp. 163-187.

- Joseph, P.E. \& Kennepohl, G.J., "Trial Sections with Polymer-Modified Asphalts on Highway 400", Canada Research and Development Branch. Ontario Ministry of Transportation, Toronto, June 1991.

- Kandhal, P.S. \& Koehler, W.S., "Marshall Mix Design Method: Current Practices", Proc., Association of Asphalt Paving Technologists, Vol. 54, St. Paul, Minn., 1985, pp. 284-303.

- Kennedy, T.W. \& Hudson, W.R., "An Indirect Tensile Test for Stabilized Materials", Research Report 98-1, Center for Highway Research. University of Texas at Austin, January, 1968a.

- Kennedy, T.W. \& Hudson, W.R., "Application of the Indirect Tensile Test to Stabilized Materials", Highway Research Record No. 2354, Highway Research Board, pp. 36-48, 1968 b.

- LaGrone, B.D., "Rubber Used in Asphalt-Rubber Applications", National Seminar on Asphalt Rubber, Demonstration Projects Division, FHWA, U.S. Department of 
Transportation, Oct. 1981, pp. 221-232.

- Lalwani, S., Abushihada, A., \& Halasa, A., "Reclaimed Rubber-Asphalt Blends Measurement of Rheological Properties to Assess Toughness, Resiliency, Consistency and Temperature Sensitivity", Proceedings, Association of Asphalt Paving Technologists, Vol. 51, 1982, pp. 562-579.

- Larsen, D.A., "Eight-Year Performance Evaluation of an Asphalt-Rubber Hot Mix Pavement", Report No. 116-3-89-8, Connecticut Department of Transportation, 1989.

- Lawrence, C.E., Killackey, B.J., \& Lynch, D.F., "Experimental Hot Mix Pavement with Scrap Tire Rubber at Thamesville, Ontario: Report \#1", Ontario Ministry of Transportation, 1991.

- Lytton, R.L. \& Roberts, F.L., "FAA Mixture Desizn Procedure for Asphalt-Rubber Concrete", Presented at 66th Annual Meeting of the Transportation Research Baki-d, Washington, D.C., 1987.

- Maine Department of Transportation, "The Use of Tire Rubber in Pavements. Preliminary Report", Techrical Services Division, March 1990.

- Manhole Messenger, Special Edition, Volume 3, No.1, January, 1992.

- Masters, M., "Cost Comparisons between Asphalt-Rubber Systems and Conventional Construction Methods", Asphalt Rubber Fioducers Group, Proceedings of the National Seminar on Asphalt Rubber, Kansas City, Missouri, October 30-31, 1989, pp. 43-81. 
- McQuillen, J.L., Takallou, H.B., Hicks, R.G., \& Esch. D., "Economic Analysis of Rubber-Modified Asphalt Mixes", Joumal of Transportation Engineering. Proceedings of the ASCE, Vol. 114, No. 3, May 3 1988, pp. 259-277.

- Ministry of Transportation, Ontario, "Laboratory Testing Manual; Volume 1 and 2", Engineering Materials Office, Highwan Engineering Division, rev. 1989.

- "Mix Design Methods for Asphalt Concrete and Other Hot-Mix Types", Manual Scries No. 2 (MS-2), The Asphalt Institute, College Park, Md., 1984.

- Monismith, C.L., Hicks, R.G., \& Finn, F.N., "Accelerated Load Tests for AsphaltAggregate Mixtures and their Role in AAMAS", AAPT, 1991.

- National Asphalt Pavement Association (NAPA), Nev's Release May 12, 1993.

- Oliver, J.W.H., "Modification of Paving Asphalt by Digestion with Scrap Rubber". Transportation Research Record 821, TRB, National Research Council. Washingtou, D.C., 1981, pp. 37-44.

- Ormsby, W.C. \& Fohs, D.G., "Use of Waste and By-Products in Highway Construction", Transportation Research Record 1388, TRB, National Research Council, Washington, D.C., pp. 47-57, 1990.

- "The Quarterly R \& D digest", New York State Department of Transportation, No. 41, 1990.

- Renshaw, R.H., Strauss, P.J., \& Kleyn, E.G., "Review of the Performance of a Bitumen-Rubber Over a Six-Year Period", Proceedings, 5th Conference on Asphalt Pavements for Southem Africa (CAPSA 89), Swaziland, 5-9 June, 1989. 
Sainton, A., "Advantages of Asphalt rubber Binder for Porous Asphalt Concrete", Transportation Research Record 1265, TRB, National Research Council, Washington, D.C., pp. 69-81, 1990.

- Salter, R.J. \& Mat, J., "Some Effects of Rubber Additives on Asphalt Mixes", Transportation Research Record 1269. TRB, National Research Council, Washington, D.C.. pp. 79-86, 1990.

- Sandberg, U., Ejsmount, J.A., \& Gustavson, E., "Tire Road Noise on Rubberized Asphalt and Cement Concrete Surfaces in Sweden", Statens Vag-Och Trafikinstitut, Sweden, 1990.

- Stevens, J.E., "Recycled Rubber in Roads - Final Report", Connecticut Department of Transportaticn, April, 1981.

- Stolle, D.F.E., "Silane Coupling Agents to Reduce Moisture Susceptibility of Asphalt Concrete", The Research and Development Branch, Ontario Ministry of Transportation, November 1990.

- Takallou, H.B. \& Hicks, R.G., "Development of Improved Mix and Construction Guidelines for Rubber-Modified Asphalt Pavements", Transportation Research Record 1171, TRB, National Research Council, Washington, D.C., pp. 113-120, 1988.

- Takallou, H.B., Hicks, R.G., \& Takallou, M.B., "Use of Rubber Modified Asphalt for Snow and Ice Control", Proceedings, Strategic Highway Research Program and Traffic Safery on Two Continents, Gothenburg, Sweden, 27-29 September, 1989, pp. 49-68. 
156

- Takallou, H.B.. Sainton, A., "Advances in Technology of Asphalt Paving Materials Containing Used Tire Rubber". Transportation Research Record 1339. TRB, National Research Council, Washington, D.C., pp. 23-29, 1993.

- Vallerga, B.A., "Design and Specification Changes for Paving Mixes with Asphuit-Rubber Binders", National Seminar on Asphalt Rubber, Demonstration Projects Division, FHWA, U.S. Department of Transportation, Oct. 1981, pp. 209217.

- Zaniewski, J.P., "Summary of Arizona Department of Transportation Experience with Asphalt-Rubber", Arizona Department of Transportation. August, 1988. 


\section{APPENDIX}


Marshall dara for control SMA mix

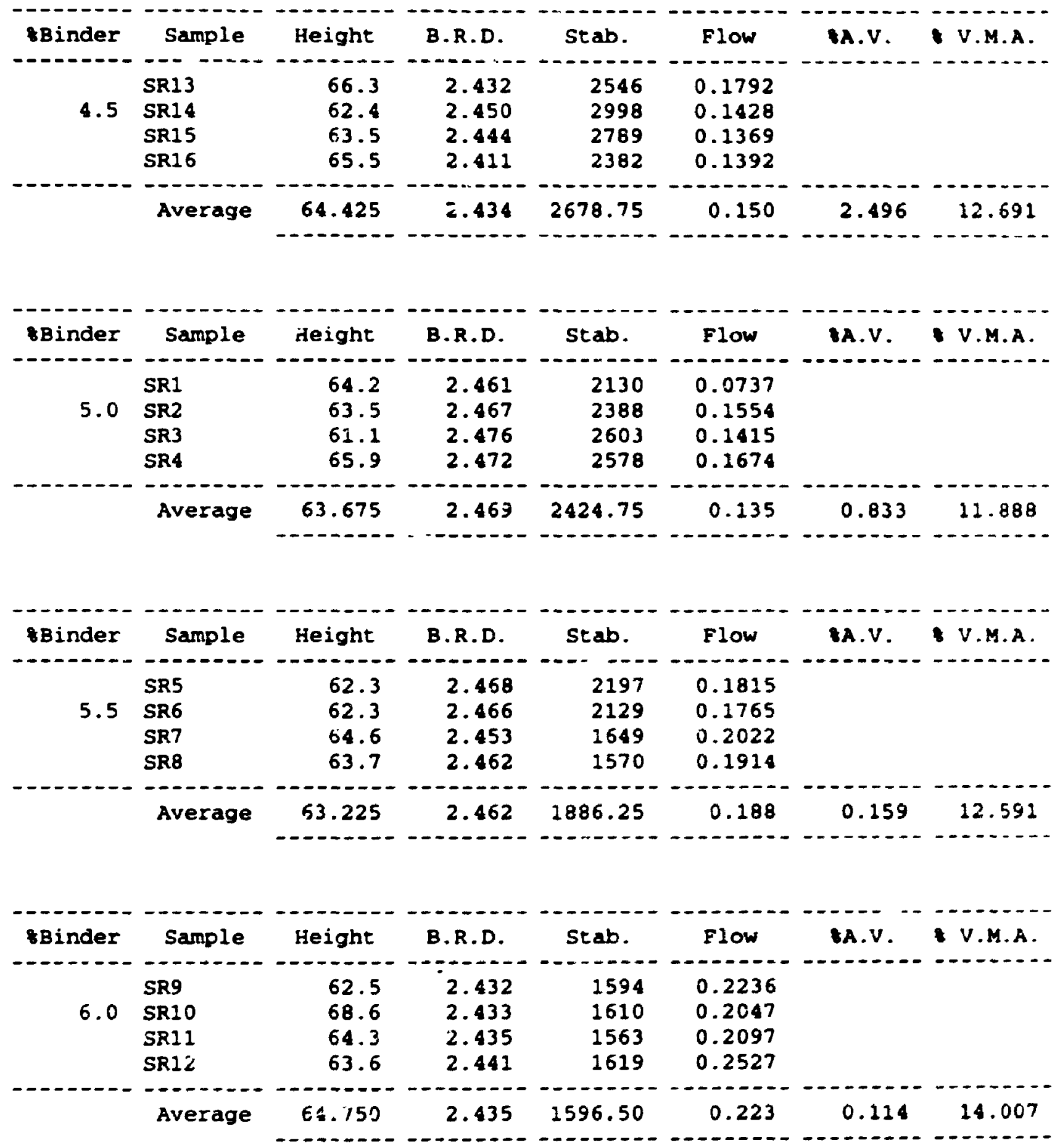




\begin{tabular}{|c|c|c|c|c|c|c|c|}
\hline B Binder & Sample & Height & B.R.D. & stab. & Flow & \$A. $Y$. & \& V.M.A. \\
\hline 6.5 & $\begin{array}{l}\text { SR17 } \\
\text { SR18 } \\
\text { SR19 } \\
\text { SR20 }\end{array}$ & $\begin{array}{l}64.1 \\
64.6 \\
60.6 \\
68.3\end{array}$ & $\begin{array}{l}2.428 \\
2.423 \\
2.432 \\
2.424\end{array}$ & $\begin{array}{l}1390 \\
1459 \\
1405 \\
1498\end{array}$ & $\begin{array}{l}0.1878 \\
0.2171 \\
0.2163 \\
0.2085\end{array}$ & & \\
\hline & Avera & 64.400 & 2.427 & 1438.08 & 0.207 & 0.331 & 14.763 \\
\hline
\end{tabular}


Marshall data for Ecoflex SMA mix

\begin{tabular}{|c|c|c|c|c|c|c|c|}
\hline sBinder & Sample & Height & B.R.D. & stab. & Elow & \&.V. & B V.M.A. \\
\hline 4.0 & $\begin{array}{ll}\text { ECO } & 1 \\
\text { ECO } & 2 \\
\text { ECO } & 3\end{array}$ & $\begin{array}{l}62.54 \\
64.39 \\
64.59\end{array}$ & $\begin{array}{l}2.428 \\
2.434 \\
2.412\end{array}$ & $\begin{array}{l}3579 \\
3528 \\
3178\end{array}$ & $\begin{array}{l}0.0832 \\
0.0960 \\
0.1013\end{array}$ & & \\
\hline & Average & 63.507 & 2.425 & 3428 & 0.0935 & 2.797 & 12.559 \\
\hline
\end{tabular}

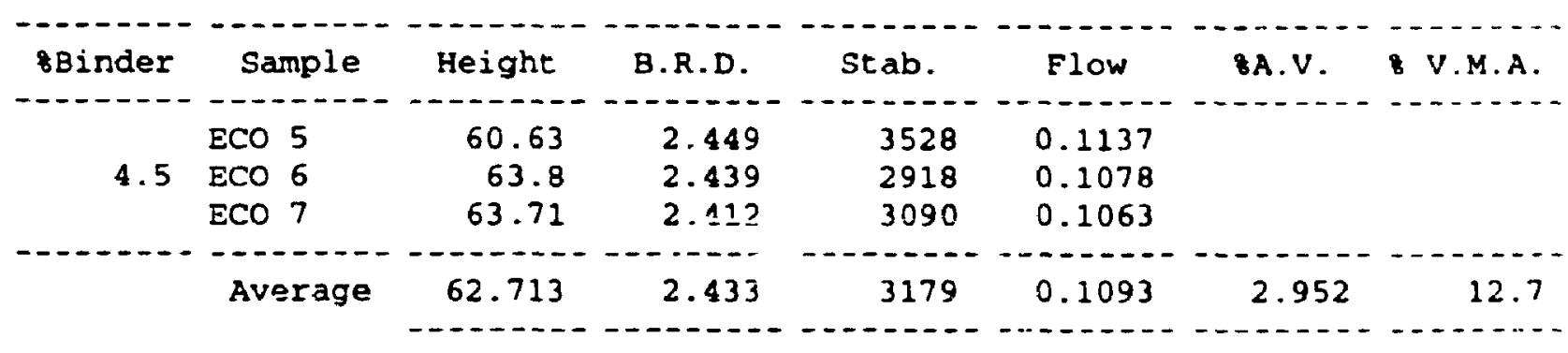

\begin{tabular}{|c|c|c|c|c|c|c|c|}
\hline \& Binder & Sample & Height & B.R.D. & Stab. & Flow & B.V. & V.M.A. \\
\hline & $\ldots \ldots$ & $\cdots \cdots$ & 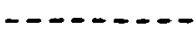 & ---- & & & \\
\hline \multirow{4}{*}{5.0} & ECO 9 & 62.24 & 2.465 & 2683 & 0.1190 & & \\
\hline & ECO 10 & 61.53 & 2.466 & 2688 & 0.1379 & & \\
\hline & ECO 11 & 63.3 & 2.467 & 3070 & 0.1158 & & \\
\hline & Average & 62.357 & 2.466 & 2814 & 0.1242 & 2.468 & 11.99 \\
\hline & & -- & --- & $\cdots-$ & -- & 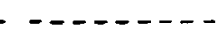 & 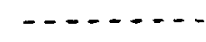 \\
\hline
\end{tabular}

\begin{tabular}{|c|c|c|c|c|c|c|c|}
\hline sBinder & Sample & Height & B.R.D. & Stab. & Flow & A.V. & V V.M.A. \\
\hline 5.5 & $\begin{array}{ll}E C O & 13 \\
E C O & 14 \\
E C O & 15\end{array}$ & $\begin{array}{r}66.1 \\
60.71 \\
61.54\end{array}$ & $\begin{array}{l}2.449 \\
2.451 \\
2.459\end{array}$ & $\begin{array}{l}2436 \\
2054 \\
2265\end{array}$ & $\begin{array}{l}0.1411 \\
0.1221 \\
0.1537\end{array}$ & & \\
\hline & Avr rage & 62.817 & 2.453 & 2252 & 0.1390 & 0.789 & 12.92 \\
\hline
\end{tabular}

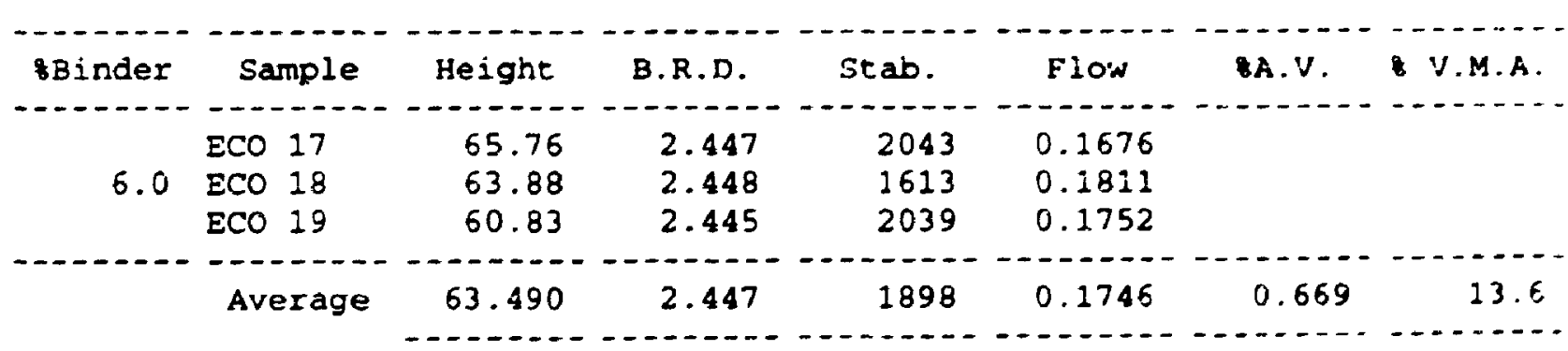


Marshall data for 58 CRM SMA mix

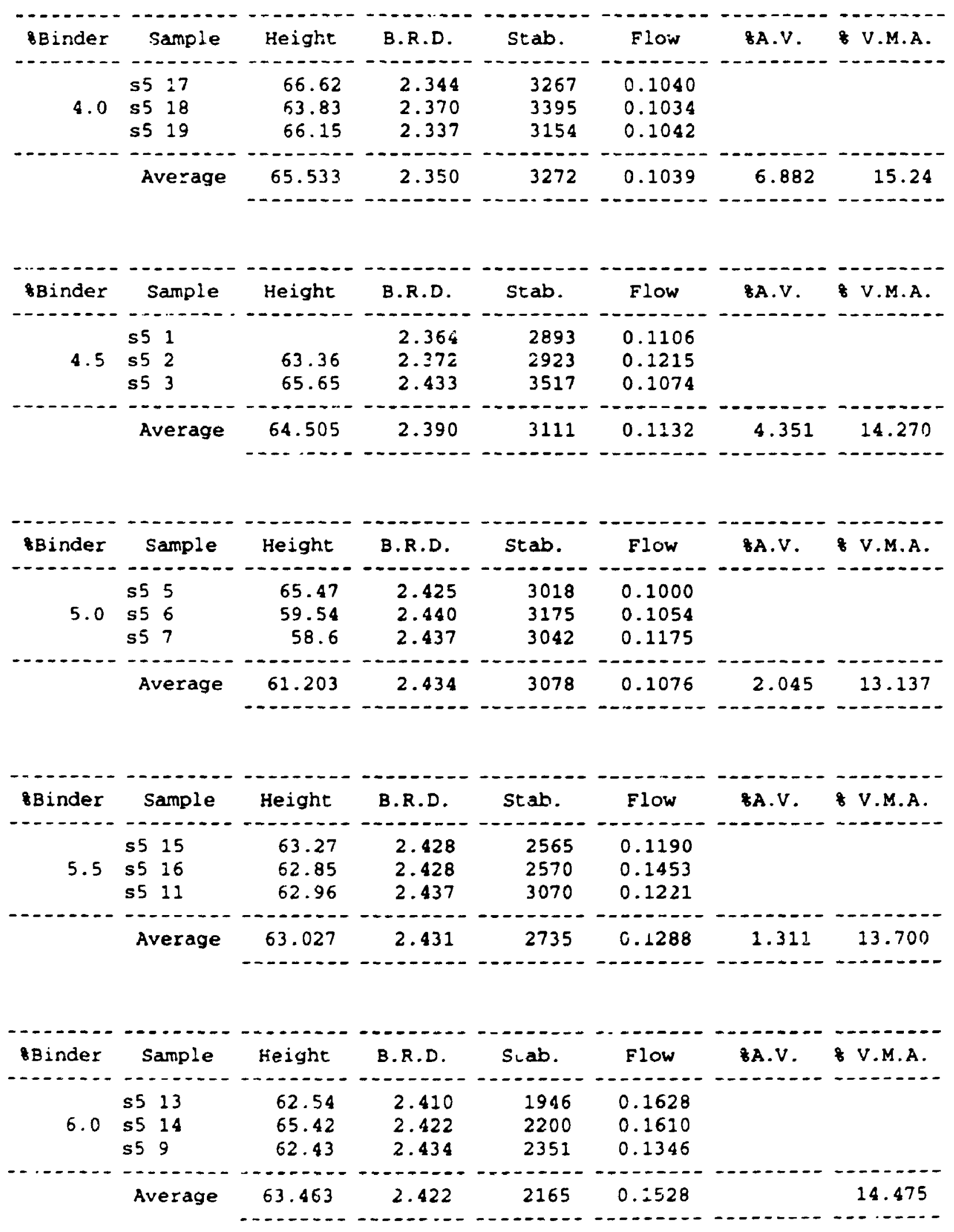


Marshall data for 108 CRM SMA mix

\begin{tabular}{|c|c|c|c|c|c|c|c|}
\hline sBinder & Sample & Height & B.R.D. & Stab. & Flow & 8A.V. & \& V.M.A. \\
\hline 4.0 & $\begin{array}{ll}\mathrm{s} 10 & 17 \\
\mathrm{~s} 10 & 18 \\
\mathrm{~s} 10 & 19\end{array}$ & $\begin{array}{r}66.98 \\
64.2 \\
66.39\end{array}$ & $\begin{array}{l}2.326 \\
2.341 \\
2.293\end{array}$ & $\begin{array}{l}3195 \\
3659 \\
=: 2 ?\end{array}$ & $\begin{array}{l}0.1253 \\
0.1159 \\
0.1245\end{array}$ & & \\
\hline & Average & 65.8567 & 2.320 & 3281 & 0.1222 & 8.135 & 16.334 \\
\hline
\end{tabular}

\begin{tabular}{|c|c|c|c|c|c|c|c|}
\hline Binder & Sample & Height & B.R.D. & Stab. & Flow & 8A.V. & \& V.M.L. \\
\hline \multirow{6}{*}{4.5} & 5101 & 57.25 & 2.357 & 3109 & 0.1394 & & \\
\hline & s10 2 & $6: .01$ & 2.384 & 3454 & 0.1148 & & \\
\hline & 5103 & 64.27 & 2.397 & 3706 & 0.1265 & & \\
\hline & $-\ldots$ & & & & -- & & \\
\hline & Average & 64.51 & 2.379 & 3423 & 0.1269 & 5.376 & 14.641 \\
\hline & & - & -. & & --- & & \\
\hline & & & -------- & $\cdots$ & - & - & --- \\
\hline Binder & Sample & Height & B.R.D. & Stab. & Flow & A.V. & \& V.M.A \\
\hline & $\ldots-\ldots$ & - & 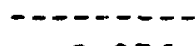 & $-\cdots--$ & 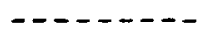 & - & \\
\hline & s10 5 & 63.07 & 2.376 & 3196 & 0.1436 & & \\
\hline 5.0 & 5106 & 66.32 & 2.373 & 3019 & 0.1475 & & \\
\hline & 5107 & 66.72 & 2.386 & 3045 & 0.1459 & & \\
\hline & Average & 65.37 & 2.378 & 3087 & 0.1457 & 3.894 & 15.12 \\
\hline
\end{tabular}

\begin{tabular}{|c|c|c|c|c|c|c|c|}
\hline \&Binder & Sample & Height & B.R.D. & stab. & Flow & \&.V. & \& V.M.A. \\
\hline 5.5 & $\begin{array}{ll}\text { s10 } & 9 \\
\text { s10 } & 10 \\
\text { s10 } & 11\end{array}$ & $\begin{array}{l}63.58 \\
65.03 \\
66.38\end{array}$ & $\begin{array}{l}2.420 \\
2.399 \\
2.370\end{array}$ & $\begin{array}{l}2612 \\
2614 \\
2449\end{array}$ & $\begin{array}{l}0.1506 \\
0.1415 \\
0.1318\end{array}$ & & \\
\hline & Average & 64.9367 & 2.396 & 2558 & 0.1413 & 2.505 & 14.93 \\
\hline
\end{tabular}

\begin{tabular}{|c|c|c|c|c|c|c|c|}
\hline \&inder & Samr.le & Height & B.R.D. & stab. & Flow & BA.V. & V.M.A. \\
\hline 6.0 & $\begin{array}{ll}\mathrm{s} 10 & 13 \\
\mathrm{~s} 10 & 14 \\
\mathrm{~s} 10 & 15\end{array}$ & $\begin{array}{l}63.83 \\
67.77 \\
65.65\end{array}$ & $\begin{array}{l}2.372 \\
2.338 \\
2.419\end{array}$ & $\begin{array}{l}2772 \\
1773 \\
2523\end{array}$ & $\begin{array}{l}0.1491 \\
0.1506 \\
0.1438\end{array}$ & & \\
\hline & Average & 65.75 & 2.376 & 2356 & 0.1478 & 3.455 & 16.08 \\
\hline
\end{tabular}


Marshai: data for 158 CRM SMA mix

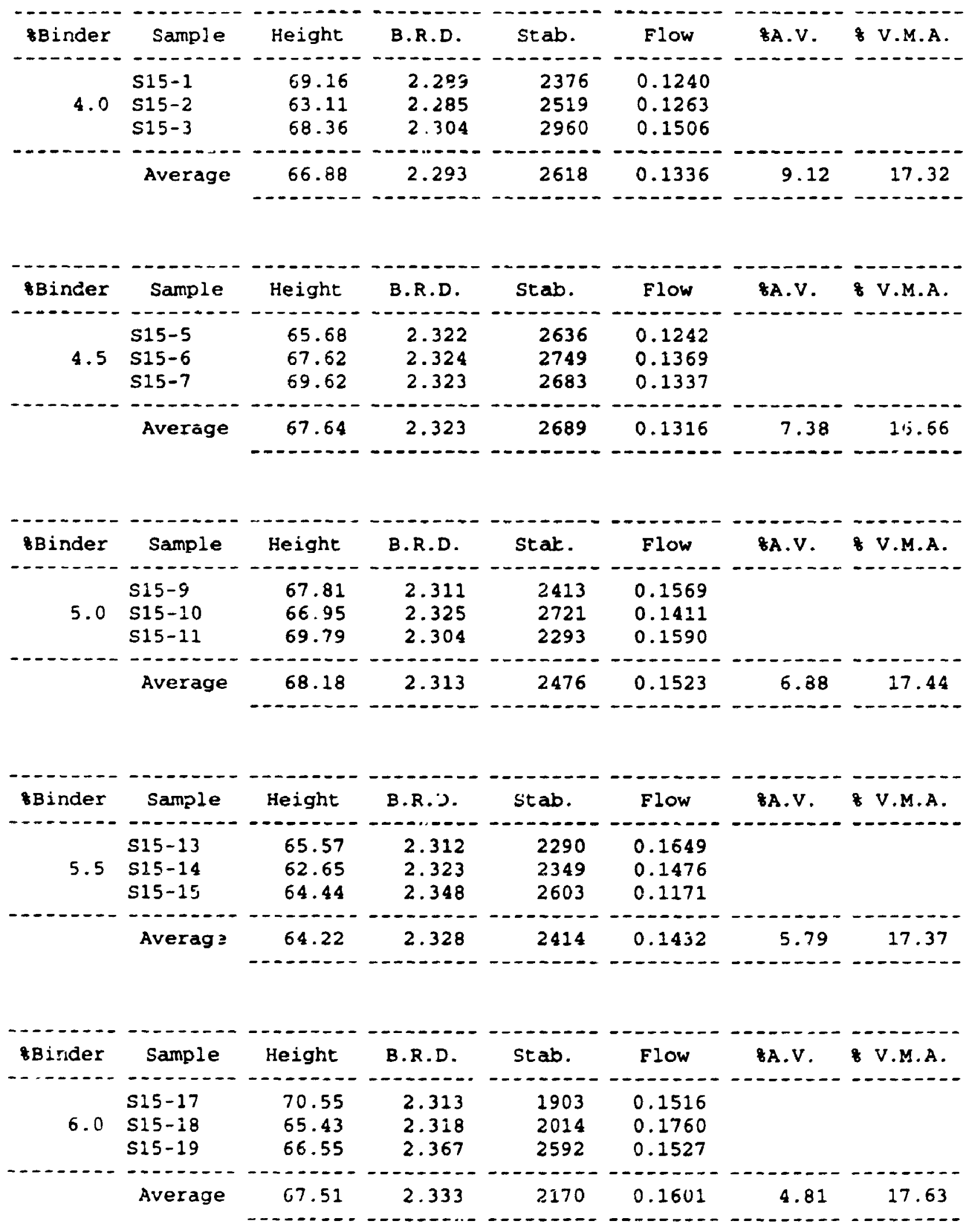


Marshall data for 208 CRM SMA mix

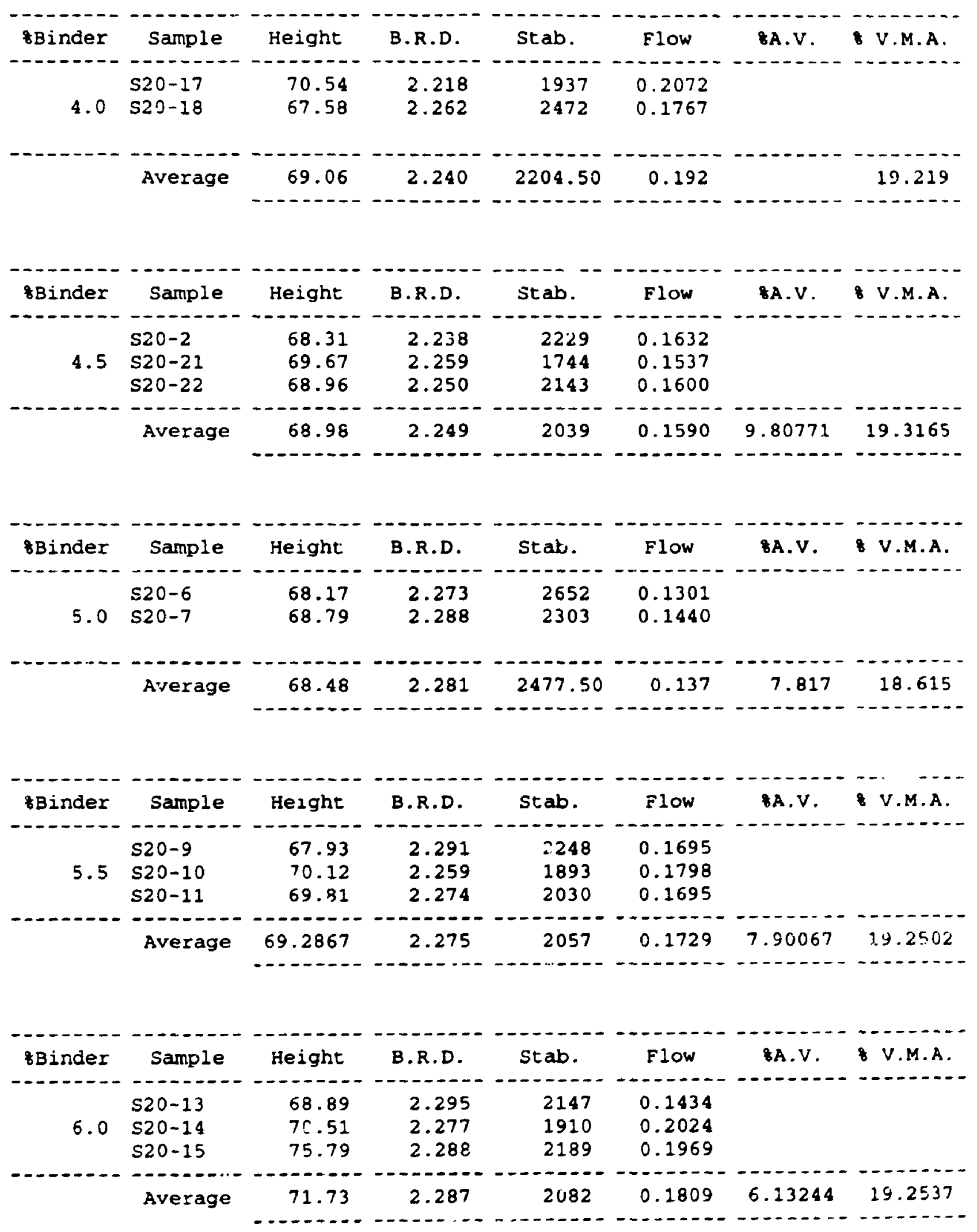


Fatlgue test results for SMA

\begin{tabular}{|c|c|c|c|}
\hline Type & $\begin{array}{l}\text { Loading } \\
\text { condittons }\end{array}$ & Sample & $\begin{array}{l}\mathrm{Nf} \\
\text { (cycles) }\end{array}$ \\
\hline Control & $15 \%$ & $\begin{array}{l}\text { tcll } \\
\text { tcl3 } \\
\text { tc15 }\end{array}$ & $\begin{array}{l}5650 \\
3400 \\
4300\end{array}$ \\
\hline & $30 \%$ & $\begin{array}{l}\text { tc2 } \\
\text { tc6 } \\
\text { tc8 }\end{array}$ & $\begin{array}{l}610 \\
600 \\
365\end{array}$ \\
\hline Ecoflex & $15 \%$ & $\begin{array}{l}\text { te7 } \\
\text { tell } \\
\text { tel3 }\end{array}$ & $\begin{array}{l}8000 \\
4800 \\
4050\end{array}$ \\
\hline & $30 \%$ & $\begin{array}{l}\text { te2 } \\
\text { te4 } \\
\text { tes }\end{array}$ & $\begin{array}{l}700 \\
650 \\
520\end{array}$ \\
\hline $5 \%$ & $15 \%$ & $\begin{array}{l}+59 \\
+58 \\
+57\end{array}$ & $\begin{array}{l}5100 \\
6600 \\
8240\end{array}$ \\
\hline & $30 \%$ & $\begin{array}{r}+52 \\
+54 \\
+56\end{array}$ & $\begin{array}{l}660 \\
575 \\
830\end{array}$ \\
\hline $10 \%$ & $15 \%$ & $\begin{array}{l}+109 \\
+108 \\
+107\end{array}$ & $\begin{array}{l}6100 \\
7200 \\
5050\end{array}$ \\
\hline & $30 \%$ & $\begin{array}{l}+102 \\
+104 \\
+106\end{array}$ & $\begin{array}{r}725 \\
620 \\
1010\end{array}$ \\
\hline $15 \%$ & $15 \%$ & $\begin{array}{l}+159 \\
+1510\end{array}$ & $\begin{array}{l}9450 \\
9050\end{array}$ \\
\hline & & $\begin{array}{l}+154 \\
+156 \\
+158\end{array}$ & $\begin{array}{r}860 \\
1080 \\
680\end{array}$ \\
\hline
\end{tabular}




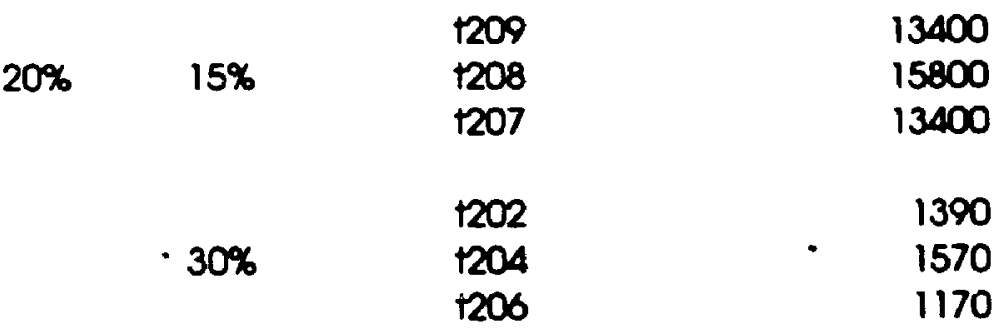

Fatigue test results for LAM

$\begin{array}{cccc}\text { Control } & & c 10 & 2610 \\ & 15 \% & c 11 & 2240 \\ c 12 & 2810 \\ & & c 4 & 570 \\ & & c 5 & 447 \\ 10 \% & c 6 & 488 \\ & & & \\ & & 18 & 4550 \\ & & 19 & 5200 \\ & & & 496 \\ & & 110 & 1108 \\ & & 11 & 912\end{array}$


ITS results for SMA mixes (PSI)

Sample

ITS

$\begin{array}{cr} & 168.8 \\ \text { Control } & 160.4 \\ & 148.3 \\ & 160 \\ \text { Ecofiex } & 165.4 \\ & 148.7 \\ & 184.1 \\ & 171.9 \\ 5 \% & 201.4 \\ & 211.1 \\ & 184.7 \\ & 169.5 \\ 10 \% & 166.6 \\ & 172.7 \\ & 171.8 \\ & 16 \% \\ 15 \% & 154.6 \\ & 145.2 \\ & \end{array}$

ITS results for LAM mixes

Sample

ITS

$\begin{array}{cc} & 92.4 \\ \text { Control } & 80.3 \\ & 92.8 \\ & \\ & 56.5 \\ 10 \% & 88.5 \\ & 79.7\end{array}$



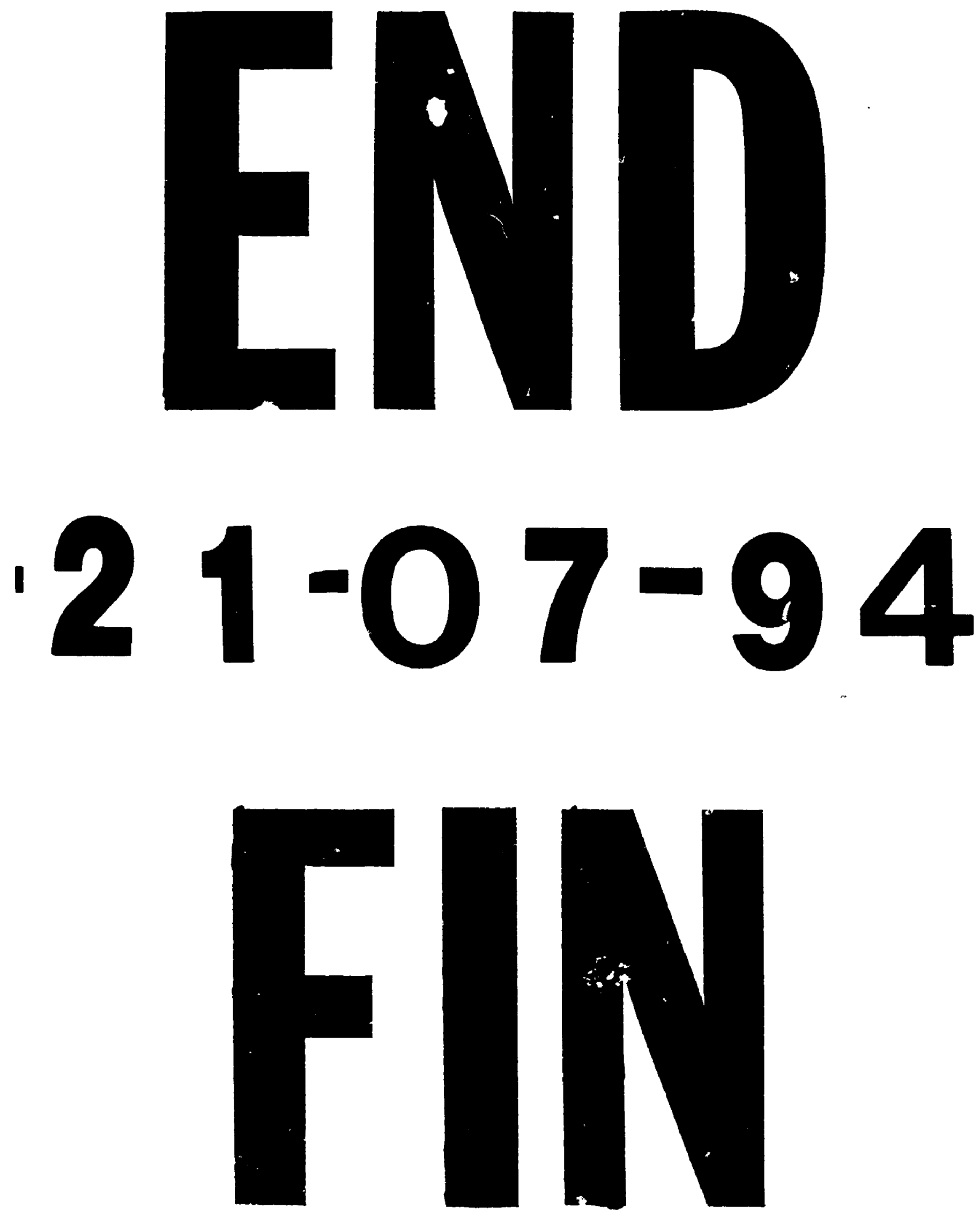